Cahiers du MONDE RUSSE

\section{Cahiers du monde russe}

Russie - Empire russe - Union soviétique et États indépendants

\title{
Ispytanie vlast'ju: iz istorii formirovanija bjurokratii Kazahskoj ASSR, 1920-e gg
}

L'exercice du pouvoir : de la formation de la bureaucratie en République socialiste soviétique autonome kazakhe dans les années 1920 New at governing: A history of the formation of bureaucracy in the Kazakh ASSR in the 1920s

\section{Dina A. Amonžolova}

\section{(2) OpenEdition}

\section{Journals}

Édition électronique

URL : http://journals.openedition.org/monderusse/8220

DOI : $10.4000 /$ monderusse. 8220

ISSN : $1777-5388$

Éditeur

Éditions de l'EHESS

\section{Édition imprimée}

Date de publication : 1 octobre 2015

Pagination : 753-791

ISBN : 978-2-7132-2507-9

ISSN : 1252-6576

Référence électronique

Dina A. Amonžolova, «Ispytanie vlast’ju: iz istorii formirovanija bjurokratii Kazahskoj ASSR, 1920-e gg », Cahiers du monde russe [Онлайн], 56/4 | 2015, Выложить онлайн 01 octobre 2018, Наводить справки в 21 avril 2019. URL : http://journals.openedition.org/monderusse/8220 ; DOI : 10.4000/ monderusse. 8220

Ce document a été généré automatiquement le 21 avril 2019

(c) École des hautes études en sciences sociales 


\section{Ispytanie vlast'ju: iz istorii formirovanija bjurokratii Kazahskoj ASSR, 1920-e gg}

L'exercice du pouvoir : de la formation de la bureaucratie en République socialiste soviétique autonome kazakhe dans les années 1920

New at governing: A history of the formation of bureaucracy in the Kazakh ASSR in the 1920s

Dina A. Amonžolova

1 БОЛЬШЕВИЗАЦИЯ НАЦИОНАЛЬНЫХ КАДРОВ ПРОИСХОДИЛА ОДНОВРЕМЕННО СО СТАНОВЛЕНИЕМ СОВЕТСКОЙ ПОЛИТИЧЕСКОЙ СИСТЕМЫ И БЫЛА ЕЕ НЕПРЕМЕННЫМ УСЛОВИЕМ. УКРЕПЛЯЯ ВЛАСТЬ, БОЛЬШЕВИКИ АКТИВНО И ЦЕЛЕНАПРАВЛЕННО ИСКАЛИ И АПРОБИРОВАЛИ РАЗНЫЕ СРЕДСТВА ${ }^{1}$. ПРЕЖДЕ ВСЕГО ОБРАЩАЛИ ВНИМАНИЕ НА ВЫЯВЛЕНИЕ И ПРИВЛЕЧЕНИЕ ЛОЯЛЬНЫХ ПРЕДСТАВИТЕЛЕЙ КОРЕННОГО НАСЕЛЕНИЯ (ЭТОТ ПРИЕМ ИСПОЛЬЗОВАЛСЯ ВО ВСЕХ МНОГОНАЦИОНАЛЬНЫХ ГОСУДАРСТВАХ, В Т.Ч. В РОССИЙСКОЙ ИМПЕРИИ $)^{2}$, А ТАКЖЕ НА ВКЛЮЧЕНИЕ В ИХ СОСТАВ ДЕЯТЕЛЕЙ, ИСПЫТАННЫХ ПАРТИЙНОЙ ИСТОРИЕЙ И ХОТЯ БЫ МИНИМАЛЬНО ЗНАКОМЫХ С ЭТНОКУЛЬТУРНОЙ СПЕЦИФИКОЙ РЕГИОНА. ОНИ ДОЛЖНЫ БЫЛИ «ПОМОГАТЬ» НАЦИОНАЛАМ ВЕРНО ДЕЙСТВОВАТЬ В РАМКАХ ЗАДАННОЙ ПАРАДИГМЫ СТРОИТЕЛЬСТВА СОЦИАЛИЗМА, ОЛИЦЕТВОРЯЯ КУРС НА САМООПРЕДЕЛЕНИЕ И РАВЕНСТВО НАРОДОВ.

РЕГИОНАЛЬНАЯ НОМЕНКЛАТУРА БЫЛА ВАЖНОЙ ПОЛИТИЧЕСКОЙ СИЛОЙ В ЦЕМЕНТИРОВАНИИ СОВЕТСКОЙ СИСТЕМЫ ${ }^{3}$. СОЦИОКУЛЬТУРНЫЕ ОСОБЕННОСТИ, ОРГАНИЗАЦИОННО-ПОЛИТИЧЕСКИЙ ОПЫТ ВЗАИМООТНОШЕНИЙ ОБЕИХ ГРУПП НАЦИОНАЛОВ С ЦЕНТРОМ И ПОВЕДЕНЧЕСКИЕ МОДЕЛИ КАЗАХСКОГО СОЦИУМА ВЛИЯЛИ НА СОВЕТСКОЕ СТРОИТЕЛЬСТВО, ОБУСЛОВЛИВАЯ СПЕЦИФИКУ ВЛАСТИ. ФОРМИРОВАНИЕ БЮРОКРАТИИ КАССР СОПРОВОЖДАЛОСЬ ПРОТИВОРЕЧИЯМИ МЕЖДУ ПРЕДСТАВИТЕЛЯМИ ЦЕНТРА, Т.Н. «ЕВРОПЕЙЦАМИ», И СОБСТВЕННО НАЦИОНАЛЬНЫМИ КАДРАМИ, А ТАКЖЕ СОПЕРНИЧЕСТВОМ ВНУТРИ КАЗАХСКОЙ ЧАСТИ РУКОВОДСТВА, ЧТО ПОЛУЧИЛО 
ОПРЕДЕЛЕНИЕ «ГРУППИРОВОЧНАЯ БОРЬБА» И РАСПРОСТРАНЯЛОСЬ ИЗ ЦЕНТРА РЕСПУБЛИКИ НА ОБЛАСТНЫЕ И МЕСТНЫЕ ИНСТАНЦИИ ВЛАСТИ. ОНА ИМЕЛА МЕСТО И В ДРУГИХ НАЦИОНАЛЬНО-ГОСУДАРСТВЕННЫХ ОБРАЗОВАНИЯХ ${ }^{4}$, А В КАССР ПРИОБРЕЛА ОСОБО СЛОЖНЫЙ ХАРАКТЕР (В СИЛУ ГОСПОДСТВА КОЧЕВОЙ КУЛЬТУРЫ НА ОГРОМНОЙ ТЕРРИТОРИИ, СЛОЖНОСТИ ВНУТРИЭТНИЧЕСКИХ ОТНОШЕНИЙ И ПОЛИТИЧЕСКОЙ РАЗДРОБЛЕННОСТИ КАЗАХСКОЙ ИНТЕЛЛИГЕНЦИИ, ЕЕ РОЛИ В ПОЛИТИЧЕСКОЙ ЖИЗНИ ВСЕГО ЦЕНТРАЛЬНОАЗИАТСКОГО РЕГИОНА, В Т.Ч. В СВЯЗИ С РАЗМЕЖЕВАНИЕМ), ЗАСТАВИВ ЦК РКП(Б)-ВКП(Б) УДЕЛЯТЬ РЕСПУБЛИКЕ БОЛЬШОЕ ВНИМАНИЕ. В СВЯЗИ С ЭТИМ ВАЖНО РАССМОТРЕТЬ, В ЧЕМ ЗАКЛЮЧАЛИСЬ ОСНОВНЫЕ ПРОБЛЕМЫ СМЕНЫ РЕКРУТИРУЕМЫХ ВО ВЛАСТЬ НАЦИОНАЛОВ, КАК ЭТО ПОВЛИЯЛО НА УПРОЧЕНИЕ ВЕРТИКАЛИ СОВЕТСКОЙ ВЛАСТИ В РЕСПУБЛИКЕ И ЕЕ СООТВЕТСТВИЕ ПРОЕКТУ ЦЕНТРА. ИЗУЧЕНИЕ НЕКОТОРЫХ АСПЕКТОВ УЧАСТИЯ НАЗНАЧЕНЦЕВ В УСТРАНЕНИИ ГРУППИРОВОК ПОЗВОЛИТ УТОЧНИТЬ СВЯЗЬ ОРГАНИЗАЦИОННО-ПОЛИТИЧЕСКИХ И ЭТНИЧЕСКИХ ФАКТОРОВ В ФОРМИРОВАНИИ РУКОВОДСТВА КАССР 5

ЭТИ ВОПРОСЫ НА ПРИМЕРЕ КАЗАХСТАНА ПОКА ИЗУЧЕНЫ НЕДОСТАТОЧНО ${ }^{6}$. НЕКОТОРЫЕ АВТОРЫ КАСАЮТСЯ ИХ В КОНТЕКСТЕ ИСТОРИИ АЛАШ. В.К. ГРИГОРЬЕВ, Н.Р. ДЖАГФАРОВ И В.П. ОСИПОВ БЕЗ ДЕТАЛИЗАЦИИ УКАЗАЛИ НА ФОРМИРОВАНИЕ В СОВЕТСКОМ РУКОВОДСТВЕ КАССР «НАЦИОНАЛ-УКЛОНИСТСКИХ» ГРУППИРОВОК «ПО РОДОПЛЕМЕННЫМ ПРИЗНАКАМ». ЧУТЬ ПОЗЖЕ ДЖАГФАРОВ И ОСИПОВ, ХАРАКТЕРИЗУЯ ФАКТОЛОГИЮ И ОБСТОЯТЕЛЬСТВА ВЗАИМОДЕЙСТВИЯ КАК ВНУТРИ КАЗАХСКОЙ БЮРОКРАТИИ, ТАК И «ЕВРОПЕЙЦЕВ» С НЕЙ, КВАЛИФИЦИРОВАЛИ КОНФЛИКТНЫЕ ДЕЙСТВИЯ «ЕВРОПЕЙЦЕВ» КАК ПРОЯВЛЕНИЕ ШОВИНИЗМА. ОНИ ЖЕ КОНСТАТИРОВАЛИ СОХРАНЯЮЩИЕСЯ ДО СИХ ПОР ОПАСЕНИЯ КАЗАХСТАНСКИХ ИСТОРИКОВ ПО ПОВОДУ ИЗУЧЕНИЯ «СКАНДАЛЬНЫХ ЭПИЗОДОВ ${ }^{8}$. Н.Е. МАСАНОВ В 1990-Е ГОДЫ ОБРАТИЛСЯ К РЕТРОСПЕКТИВЕ КЛАНОВЫХ ПРОТИВОРЕЧИЙ И ВНУТРИЭТНИЧЕСКОГО СОПЕРНИЧЕСТВА В КАЗАХСКОЙ ЭЛИТЕ ХХ ВЕКА ВО ВЗАИМОСВЯЗИ С НОВЕЙШЕЙ ИСТОРИЕЙ КАЗАХСКОЙ БЮРОКРАТИИ.

\section{Новая власть как ресурс влияния для « бывших»}

4 В 1920-Е ГГ. ПОД РУКОВОДСТВОМ И ПО ПРОГРАММЕ ПРАВЯЩЕЙ ПАРТИИ ПРИВЛЕЧЕННЫЕ К УПРАВЛЕНИЮ «БЫВШИЕ» - «СТАРАЯ» ИНТЕЛЛИГЕНЦИЯ, ПРЕДСТАВЛЯВШАЯ МОДЕРНИЗАТОРСКИЙ ПОТЕНЦИАЛ КАЗАХСКОГО ОБЩЕСТВА, И ЧАСТЬ ПРЕЖНЕЙ БЮРОКРАТИИ - СМЕНЯЛИСЬ ВЫДВИЖЕНЦАМИ-НАЦИОНАЛАМИ ИЗ ТРУДОВЫХ СЛОЕВ. В 1922 Г. УДЕЛЬНЫЙ ВЕС КАЗАХОВ В ПАРТОРГАНИЗАЦИЯХ КАССР НЕ ПРЕВЫШАЛ $20 \%$, ПРИЧЕМ СТАЖ ДО 1917 Г. ИМЕЛИ 0,3-0,4 \% ${ }^{10}$. В 1920 Г. И.В. СТАЛИН ПИСАЛ :

ОДНОЙ ИЗ СЕРЬЕЗНЫХ ПРЕГРАД ПО ПУТИ К ОСУЩЕСТВЛЕНИЮ СОВЕТСКОЙ АВТОНОМИИ ЯВЛЯЕТСЯ БОЛЬШОЙ НЕДОСТАТОК ИНТЕЛЛИГЕНТНЫХ СИЛ МЕСТНОГО ПРОИСХОЖДЕНИЯ НА ОКРАИНАХ, [...] БЫЛО БЫ НЕРАЗУМНО, ВРЕДНО ДЛЯ ДЕЛА ОТТАЛКИВАТЬ ОТ СЕБЯ [...] МАЛОЧИСЛЕННЫЕ ГРУППЫ МЕСТНЫХ ИНТЕЛЛИГЕНТОВ. ${ }^{11}$ ПАРТИЙНЫМИ РУКОВОДИТЕЛЯМИ КАЗАХСТАНА ЗА ПЕРВЫЕ 5 ЛЕТ 1920-Х ГГ. ПОБЫВАЛИ 6 ЧЕЛОВЕК (ВЕСНОЙ 1924 Г. И.О. СЕКРЕТАРЯ КИРОБКОМА БЫЛ ТАКЖЕ Г.М. ДУНАЕВ) ${ }^{12}$, СРЕДИ НИХ 1 КАЗАХ М. МУРЗАГАЛИЕВ - ЛИШЬ ПОЛГОДА. С СЕРЕДИНЫ 1925 Г. В ВЫСШЕЙ ИНСТАНЦИИ ПРОИЗОШЛА СТАБИЛИЗАЦИЯ, ЧТО ПОКАЗАТЕЛЬНО С УЧЕТОМ ОБЩЕЙ ДИНАМИКИ ГОСУДАРСТВЕННОГО РАЗВИТИЯ. 
СОСТАВ КИРОБКОМА ПАРТИИ В 1921-1925 ГГ. ВЫРОС С 14 ДО 28 ЧЕЛ., С 1921 ПО ОКТЯБРЬ 1924 Г. ЕГО ВОЗГЛАВЛЯЛ ПРЕЗИДИУМ, ЗАТЕМ БЮРО (ОТ 5 ДО 7 ЧЕЛ.), С СЕНТЯБРЯ 1924 Г. ПОЯВИЛСЯ СЕКРЕТАРИАТ СО СВОИМ СТАТУСОМ, А С 5 АПРЕЛЯ 1922 ПО ОКТЯБРЬ 1924 Г. ПО РЕШЕНИЮ И НАЗНАЧЕНИЮ ЦК РКП(Б) РАБОТАЛО ЕЩЕ И КИРБЮРО ЦК ПАРТИИ, СТОЯВШЕЕ НАД ОБКОМОМ. ЕГО ВОЗГЛАВИЛ СНАЧАЛА В.Г. ЮДОВСКИЙ, НО ВСКОРЕ СМЕНИЛ ОТВЕТСЕКРЕТАРЬ ОБКОМА Г.А. КОРОСТЕЛЕВ, А ТАКЖЕ ВХОДИЛИ ПРЕДСЕДАТЕЛЬ КИРСТО А.И. ВАЙНШТЕЙН, ПРЕДСЕДАТЕЛЬ КИРЦИКА С.М. МЕНДЕШЕВ И ПРЕДСЕДАТЕЛЬ КИРЭКОСО И ЗАМЕСТИТЕЛЬ ГЛАВЫ ПРАВИТЕЛЬСТВА В.И. ВЕЛЬМАН. ПОСТ ВТОРОГО СЕКРЕТАРЯ В ФЕВРАЛЕ 1922 Г. ПОЛУЧИЛ А.М. АСЫЛБЕКОВ, НО ЧЕРЕЗ ГОД НА ЭТУ ДОЛЖНОСТЬ НИКОГО НЕ ИЗБРАЛИ, А ЕЩЕ ЧЕРЕЗ ГОД ЕЕ ВОССТАНОВИЛИ, ИЗБРАВ И.М. КУРАМЫСОВА. В ДЕКАБРЕ 1925 Г. ЕГО СМЕНИЛ У.Д. ИСАЕВ (ДО 1929 Г.). Н.И. ЕЖОВ ЧАСТО ПОЗИЦИОНИРОВАЛСЯ КАК 3 -Й СЕКРЕТАРЬ КРАЙКОМА, ХОТЯ ОФИЦИАЛЬНО ТАКОЙ ДОЛЖНОСТИ НЕ БЫЛО, И В 19251926 ГГ. ОН БЫЛ ЗАМЕСТИТЕЛЕМ ОТВЕТСЕКРЕТАРЯ. ПРИ ЭТОМ ПОЧТИ ВСЕ НАЗНАЧЕНЦЫ МОСКВЫ ДО ТОГО ВООБЩЕ НЕ ИМЕЛИ ОТНОШЕНИЯ К РЕГИОНУ (РЕДКИЕ ИСКЛЮЧЕНИЯ И.А. АКУЛОВ И Г.А. КОРОСТЕЛЕВ, РАБОТАВШИР В ОРЕНБУРГЕ, И ГОЛОЩЕКИН, ИМЕВШИЙ НЕБОЛЬШОЙ И НЕ ВПОЛНЕ УДАЧНЫЙ ОПЫТ ОБЩЕНИЯ С МУСУЛЬМАНАМИ В БАШКИРИИ И ТУРКЕСТАНЕ), И НЕ ЗНАЛИ КАЗАХСКОГО ЯЗЫКА. В СОСТАВЕ ПРЕЗИДИУМА КИРОБКОМА И БЮРО КАЗКРАЙКОМА ПАРТИИ В 1921 Г. КАЗАХОВ БЫЛО 2 ИЗ 7, В 1922 - 5 ИЗ 7, В 1923 - 2 ИЗ 5, В МАЕ 1924 - 4 ИЗ 9, В СЕНТЯБРЕ 1924 - 3 ИЗ 6, В ДЕКАБРЕ 1925 - 10 ИЗ 14 ; НОЯБРЕ 1927 Г. - 11 ИЗ 19. СТРУКТУРА МЕСТНЫХ ОРГАНОВ ПАРТИИ ТАКЖЕ ПЕРЕЖИЛА НЕМАЛО РЕОРГАНИЗАЦИЙ ${ }^{13}$.

Таблица 1. Партийное руководство

\begin{tabular}{|c|c|c|c|c|c|}
\hline $\begin{array}{ll}\text { Фио, } & \text { годы } \\
\text { жизни } & \end{array}$ & НАЦИОНАЛЬНОСТЬ & $\begin{array}{l}\text { С КАКОГО } \\
\text { ГОДА ЧЛЕН } \\
\text { КОМПАРТИИ }\end{array}$ & $\begin{array}{l}\text { ПРОИСХОЖДЕНИЕ, } \\
\text { ОБРАЗОВАНИЕ }\end{array}$ & должность & $\begin{array}{l}\text { годЫ } \\
\text { РАБОТЫ }\end{array}$ \\
\hline $\begin{array}{l}\text { ПЕСТКОВСКИЙ } \\
\text { С.с. } \\
(1882-1943)\end{array}$ & поляк & 1902 & $\begin{array}{l}\text { ДВОРЯНИН, ГИМНАЗИЯ } \\
\text { ЛОДЗИ, УНИВЕРСИТЕТ } \\
\text { ЛОНДОНЕ (1914-1915) }\end{array}$ & \begin{tabular}{|l|} 
ОТВЕТСЕКРЕТАРЬ \\
(ПРЕДСЕДАТЕЛЬ) \\
КИРОБЛБЮРО РКП \\
(Б)
\end{tabular} & $\begin{array}{l}\text { МАЙ - } \\
\text { СЕНТЯБРЬ } \\
1920\end{array}$ \\
\hline $\begin{array}{l}\text { АКУЛОВ } \\
(1888-1939)\end{array}$ & русский & 1907 & $\begin{array}{l}\text { ИЗ МЕЩАН, ПЕТЕРБУРГСКАЯ } \\
\text { ТОРГОВО-ПРОМЫШЛЕННАЯ } \\
\text { ШКОЛА }\end{array}$ & $\begin{array}{l}\text { ОТВЕТСЕКРЕТАРЬ } \\
\text { (ПОЛИТСЕКРЕТАРЬ) } \\
\text { КИРОБЛБЮРО РКП } \\
\text { (Б) }\end{array}$ & $\begin{array}{l}\text { СЕНТЯБРЬ } \\
1920- \\
\text { ЯНВАРЬ } \\
1921\end{array}$ \\
\hline $\begin{array}{l}\text { МУРЗАГАЛИЕВ } \\
\text { М. (1887-1938, } \\
\text { 1941) }\end{array}$ & КАЗАХ & 1919 & $\begin{array}{l}\text { ИЗ СОСТОЯТЕЛЬНОЙ СЕМЬИ, } \\
\text { САРАТОВСКОЕ } \\
\text { СЕЛЬСКОХОЗЯЙСТВЕННОЕ } \\
\text { УЧИЛИЩЕ }\end{array}$ & $\begin{array}{lr}\text { ОТВЕТ. (ПЕРВЫЙ) } \\
\text { СЕКРЕТАРЬ } \\
\text { КИРОБЛБЮРО } \\
\text { КИРОБКОМА } \\
\begin{array}{ll}\text { (Б) } & \text { РКП } \\
\end{array}\end{array}$ & $\begin{array}{l}\text { ЯНВАРЬ - } \\
\text { Июль } \\
1921\end{array}$ \\
\hline $\begin{array}{l}\text { КОСТЕЛОВСКАЯ } \\
\text { М.М. } \\
(1878-1964)\end{array}$ & РУССКАЯ & 1903 & $\begin{array}{l}\text { ИЗ СЕМЬИ } \text { МЕЛКИХ } \\
\text { чИНОВНИКОВ, } \\
\text { ЖЕНСКИЕ КУРСЫ В СПБ }\end{array}$ & $\begin{array}{l}\text { ОТВЕТСЕКРЕТАРЬ } \\
\text { КИРОК РКП(Б) }\end{array}$ & $\begin{array}{l}\text { июль - } \\
\text { АВГУст } \\
1921\end{array}$ \\
\hline
\end{tabular}




\begin{tabular}{|c|c|c|c|c|c|}
\hline $\begin{array}{l}\text { КОРОСТЕЛЕВ } \\
\text { Г.А. } \\
(1885-1932)\end{array}$ & РУсский & 1905 & ИЗ РАБОЧИХ, САМОУЧКА & $\begin{array}{l}\text { ОТВЕТСЕКРЕТАРЬ } \\
\text { КИРОК, СЕКРЕТАРЬ } \\
\text { КИРБЮРО ЦК РКП } \\
\text { (Б) }\end{array}$ & $\begin{array}{l}\text { СЕНТЯБРЬ } \\
1921 \quad- \\
\text { ОКТЯБРЬ } \\
1924\end{array}$ \\
\hline
\end{tabular}

7 ПО СОВЕТСКОЙ ЛИНИИ И В ПРАВИТЕЛЬСТВЕ, КОТОРЫЕ ЗАНИМАЛИ, КАК ИЗВЕСТНО, ПОДЧИНЕННОЕ МЕСТО, ПРЕОБЛАДАЛИ НАЦИОНАЛЫ ${ }^{14}$.

Таблица 2. Председатели ЦИК КАССР

\begin{tabular}{|c|c|c|c|c|}
\hline $\begin{array}{l}\text { Фио, } \quad \text { годы } \\
\text { жизни }\end{array}$ & $\begin{array}{l}\text { НАЦИОНАЛЬ } \\
\text { НОСТЬ }\end{array}$ & $\begin{array}{l}\text { С КАКОГО ГОДА } \\
\text { ЧЛЕН ПАРТИИ }\end{array}$ & ПРОИСХОЖДЕНИЕ, ОБРАЗОВАНИЕ & $\begin{array}{l}\text { годы } \\
\text { РАБОты }\end{array}$ \\
\hline $\begin{array}{l}\text { МЕНДЕШЕВ С.М. } \\
(1882-1937)\end{array}$ & КАЗАХ & 1919 & $\begin{array}{l}\text { ИЗ БЕДНЯКОВ, КАЗАНСКАЯ } \\
\text { УЧИТЕЛЬ } \\
\text { СКАЯ СЕМИНАРИЯ }\end{array}$ & $1920-1925$ \\
\hline $\begin{array}{l}\text { МЫНБАЕВ Ж. } \\
\text { (1892-1929) }\end{array}$ & KA3AX & $?$ & $\begin{array}{l}3 \text { КЛАССА РУССКО-КАЗАХСКОЙ } \\
\text { ШКОЛЫ В ФОРТ-ШЕВЧЕНКО }\end{array}$ & $1925-1927$ \\
\hline $\begin{array}{l}\text { ЕРНАЗАРОВ } \\
\text { (ТЫШКАН } \\
\text { БАЕВ) } \\
(1887-1945)\end{array}$ & КАЗАX & 1919 & $\begin{array}{l}\text { БАТРАК, МАЛОГРА } \\
\text { МОТНЫЙ }\end{array}$ & $1927-1934$ \\
\hline
\end{tabular}

Таблица 3. Председатели СНК КАССР

\begin{tabular}{|l|l|l|l|l|}
\hline ФИО, ГОДЫ ЖИЗНИ & НАЦИОНАЛЬ & $\begin{array}{l}\text { С КАКОГО } \\
\text { ГОДА ЧЛЕН } \\
\text { ПАРТИИ }\end{array}$ & $\begin{array}{l}\text { ПРОИСХОЖДЕНИЕ, } \\
\text { ОБРАЗОВАНИЕ }\end{array}$ & РАБОТЫ \\
\hline $\begin{array}{l}\text { РАДУС-ЗЕНЬКОВИЧ } \\
\text { В.А. (1877-1971) }\end{array}$ & РУССКИЙ & 1898 & $\begin{array}{l}\text { ИЗ СЛУЖАЩИХ, МЕДФАК-Т } \\
\text { МОСК. УНИВЕРСИТЕТА }\end{array}$ & $\begin{array}{l}12.10 . \\
1920-1921\end{array}$ \\
\hline
\end{tabular}




\begin{tabular}{|c|c|c|c|c|c|}
\hline $\begin{array}{l}\text { МУРЗАГАЛИЕВ } \\
(1887-1938,1941)\end{array}$ & & КАЗАХ & 1919 & $\begin{array}{l}\text { ИЗ СОСТОЯТЕЛЬНОЙ СЕМЬИ, } \\
\text { САРАТОВСКОЕ } \\
\text { СЕЛЬСКОХОЗЯЙС-ТВЕННОЕ } \\
\text { УЧИЛИЩЕ }\end{array}$ & \begin{tabular}{|l} 
ОКТЯБРЬ \\
1921 \\
СЕНТЯБРЬ \\
1922
\end{tabular} \\
\hline $\begin{array}{l}\text { СЕЙФУЛЛИН } \\
\text { (1894-1939) }\end{array}$ & C. & КАЗАХ & $\begin{array}{l}\text { ФЕВРАЛЬ } \\
1918\end{array}$ & $\begin{array}{ll}\text { ОМСКАЯ } & \text { УЧИТЕЛЬСКАЯ } \\
\text { СЕМИНАРИЯ } & \end{array}$ & \begin{tabular}{|l} 
СЕНТЯБРЬ \\
1922 \\
ОКТЯБРЬ \\
1924
\end{tabular} \\
\hline $\begin{array}{l}\text { НУРМАКОВ } \\
(1895-1937)\end{array}$ & H.H. & КАЗАХ & 1920 & $\begin{array}{ll}\text { ОМСКАЯ } & \text { УЧИТЕЛЬСКАЯ } \\
\text { СЕМИНАРИЯ } & \end{array}$ & \begin{tabular}{|l} 
ОКТЯБРЬ \\
1924 \\
АПРЕЛЬ 1929
\end{tabular} \\
\hline $\begin{array}{l}\text { ИСАЕВ } \\
(1899-1938)\end{array}$ & У.Д. & КАЗАХ & 1920 & $\begin{array}{l}\text { 2-ХКЛАССНОЕ НАЧАЛЬНОЕ } \\
\text { РУССКО-КАЗАХСКОЕ } \\
\text { УЧИЛИЩЕ }\end{array}$ & $\begin{array}{l}\text { АПРЕЛЬ } 1929 \\
-5 \text { ДЕКАБРЯ } \\
1936\end{array}$ \\
\hline
\end{tabular}

« СТАРАЯ» ИНТЕЛЛИГЕНЦИЯ В АППАРАТЕ УПРАВЛЕНИЯ ПОДТАЛКИВАЛА НАЗНАЧЕНЦЕВ ИЗ МОСКВЫ К УЧЕТУ НАЦИОНАЛЬНОЙ СПЕЦИФИКИ В ХОЗЯЙСТВЕННОЙ ДЕЯТЕЛЬНОСТИ, ПРАВЕ, СОЦИАЛЬНЫХ СВЯЗЯХ И ПР., ДАБЫ ПОВЛИЯТЬ НА СОДЕРЖАНИЕ И ХАРАКТЕР ДЕЯТЕЛЬНОСТИ ОРГАНОВ ВЛАСТИ ${ }^{15}$. В КАЗАХСТАНЕ ЭТУ РОЛЬ ИГРАЛИ БЫВШИЕ УЧАСТНИКИ ДВИЖЕНИЯ АЛАШ. В ОТЛИЧИЕ ОТ «ЕВРОПЕЙЦЕВ» ОНИ ЯВЛЯЛИСЬ ГАРМОНИЧНОЙ И ЭЛИТНОЙ ЧАСТЬЮ ОБЩЕСТВА. МНОГИЕ ИМЕЛИ РАЗНООБРАЗНЫЙ И БЕСЦЕННЫЙ ДЛЯ РЕГИОНА ДОРЕВОЛЮЦИОННЫЙ ОПЫТ: СЛУЖИЛИ В УЧРЕЖДЕНИЯХ ОБРАЗОВАНИЯ И УПРАВЛЕНИЯ, СОЗДАВАЛИ НАЦИОНАЛЬНУЮ ПЕРИОДИКУ И ЗАНИМАЛИСЬ НАУЧНЫМИ ИССЛЕДОВАНИЯМИ, УЧАСТВОВАЛИ В ЛЕГАЛЬНОЙ ОБЩЕСТВЕННОПОЛИТИЧЕСКОЙ ДЕЯТЕЛЬНОСТИ, В Т.Ч. В РАБОТЕ ГОСУДАРСТВЕННОЙ ДУМЫ, ЛИБЕРАЛЬНЫХ И СОЦИАЛИСТИЧЕСКИХ ПАРТИЙ, ЗЕМСКО-ГОРОДСКОГО СОЮЗА, ОРГАНИЗУЕМЫХ ИМИ С 1917 Г. ЗЕМСТВ, КУЛЬТУРНЫХ ОБЪЕДИНЕНИЙ. АЛАШЕВЦЕВ ОТЛИЧАЛИ СВЕТСКОЕ И ДУХОВНОЕ ОБРАЗОВАНИЕ, ХОРОШЕЕ ЗНАНИЕ ЕВРОПЕЙСКОЙ И РУССКОЙ КУЛЬТУРЫ, В Т.Ч. ЯЗЫКОВ, ПЕДАГОГИЧЕСКИЙ, ЖУРНАЛИСТСКИЙ И НАУЧНЫЙ ОПЫТ ; ЭТНОЦЕНТРИЗМ ; ПРЕДПОЧТЕНИЕ ЛЕГИТИМНЫХ ДЕЙСТВИЙ, ПЕРЕГОВОРОВ И СОГЛАСОВАНИЙ ОТКРЫТЫМ КОНФЛИКТАМ ; ВЫНУЖДЕННОЕ ПРИЗНАНИЕ БОЛЬШЕВИЗМА ; АВТОРИТЕТ ЛИЧНОСТИ И РОДА, ОБЕСПЕЧИВШИЙ ИМ ВЛИЯНИЕ НА МАССЫ И МОЛОДЕЖЬ ${ }^{16}$; СТРЕМЛЕНИЕ ИСПОЛЬЗОВАТЬ НОВЫЕ РЕСУРСЫ И РЫЧАГИ ДЛЯ СОХРАНЕНИЯ ВЛИЯНИЯ, В Т.Ч. МАНИПУЛИРОВАНИЕ МЕНЕЕ ОПЫТНЫМИ КАЗАХСКИМИ И «ЕВРОПЕЙСКИМИ» АППАРАТЧИКАМИ. ЭТО БЫЛИ ЕЩЕ ПЕРСПЕКТИВНЫЕ ПО ВОЗРАСТУ И ВПОЛНЕ СЛОЖИВШИЕСЯ ЛИЧНОСТИ, ИМЕВШИЕ ЗА ПЛЕЧАМИ ПРАКТИКУ АДМИНИСТРИРОВАНИЯ ПРИ РАЗНЫХ РЕЖИМАХ, БОГАТЫЙ ТВОРЧЕСКИЙ ЗАДЕЛ, ДРАМАТИЧНЫЙ ОПЫТ ПОЛИТИЧЕСКОЙ БОРЬБЫ, КОМПРОМИССОВ И АЛЬЯНСОВ, ПЕРЕГОВОРОВ И ПРОТИВОСТОЯНИЙ. ОРИЕНТИРУЯСЬ НА ОФИЦИАЛЬНЫЕ ДОКУМЕНТЫ РКП(Б), ОНИ, КАЖЕТСЯ, ПОВЕРИЛИ В ВОЗМОЖНОСТЬ СОТРУДНИЧЕСТВА. НАИБОЛЕЕ ЯРКО ЭТО ВЫРАЗИЛ Ж. АКПАЕВ ${ }^{17} .10$ МАРТА 1920 Г. ОН ВЫСПРЕННО ТЕЛЕГРАФИРОВАЛ В КИРВРК : « ИСКРЕННЕ И СЕРДЕЧНО ПРИВЕТСТВУЮ КИРРЕВКОМ ЗА НЕСЕНИЕ ТЯЖЕЛОЙ И ОТВЕТСТВЕННОЙ МИССИИ ПО СОЗДАНИЮ ФУНДАМЕНТА АВТОНОМИИ КАЗАХСТАНА И ПО ОСУЩЕСТВЛЕНИЮ ЗАВЕТНОЙ МЕЧТЫ И ЧАЯНИЯ КАЗАК-КИРГИЗСКОГО НАРОДА ЗА НАРОДОПРАВСТВО. 
ЗАВЕРШИТЬ СТРОЙНОЕ ЗДАНИЕ КАЗАХСКОЙ АВТОНОМИИ ВОЗМОЖНО ПРИ ТВЕРДОМ ВЫПОЛНЕНИИ ТРЕБОВАНИЯ МОРАЛЬНОЙ ФОРМУЛЫ І. ХРИСТА : «НЕСТЬ ЕЛЛИН, НЕСТЬ ИУДЕЙ», -ФОРМУЛЫ, ЯВЛЯЮЩЕЙСЯ КВИНТЭССЕНЦИЕЙ ЧЕЛОВЕЧЕСКОГО СЕРДЦА, ПРОИЗВЕДЕНИЕМ ЧЕЛОВЕЧЕСКОГО УМА И СОКРОВИЩНИЦЕЮ ОБЩЕЧЕЛОВЕЧЕСКОЙ КУЛЬТУРЫ. ВООДУШЕВЛЕНИЕ СТЕПИ, ВО ИМЯ ОТЧИЗНЫ, ДА ПОСЛУЖИТ ФАКТОРОМ ДЛЯ ОБЪЕДИНЕНИЯ КАЗАХСТАНА.... ${ }^{18}$.

А. БАЙТУРСЫНОВ ПИСАЛ В ЗАЯВЛЕНИИ О ПРИЕМЕ В ПАРТИЮ 4 АПРЕЛЯ 1920 Г.: « ОСВОБОЖДЕННЫЙ КАЗАХСКИЙ НАРОД МОЖЕТ ПОЛУЧИТЬ СЧАСТЬЕ ТОЛЬКО ВМЕСТЕ СО ВСЕЙ УГНЕТЕННОЙ ЧАСТЬЮ ЧЕЛОВЕЧЕСТВА, ТО ЕСТЬ В МИРОВОЙ РЕВОЛЮЦИИ, МИРОВОЙ ФЕДЕРАЦИИ» ${ }^{19}$. В РКП(Б) ВСТУПИЛИ А. АЛИБЕКОВ, А. КЕНЖИН, Н. БАЙДИЛЬДИН, М. САМАТОВ И ДР. ПО ДАННЫМ Х. ГАББАСОВА, В НАЧАЛЕ 1920-ХГГ. АЛАШОРДИНЦЫ ОБСУЖДАЛИ ИДЕЮ КОЛЛЕКТИВНОГО ВСТУПЛЕНИЯ В ПАРТИЮ ДЛЯ « ЗАВОЕВАНИЯ ВЕСА В ПОЛИТИЧЕСКОЙ ЖИЗНИ» И «БЕЗ РАЗЛИЧИЯ, РАЗДЕЛЯЮТ ЛИ ОНИ В ПРИНЦИПЕ ПРОГРАММУ ВКП(Б)». В ИТОГЕ ВОЗОБЛАДАЛ ЗДРАВЫЙ СМЫСЛ: НЕ ЖЕЛАЯ НИКОГО ОБМАНЫВАТЬ, РЕШИЛИ « ПРЕДОСТАВИТЬ КАЖДОМУ ПРАВО ВСТУПЛЕНИЯ, СОГЛАСНО ЕГО УБЕЖДЕНИЙ» ${ }^{20}$.

11 АЛАШОРДИНЦЫ ПО ИНИЦИАТИВЕ И ПОД КОНТРОЛЕМ ВЛАСТИ ЭНЕРГИЧНО ВКЛЮЧИЛИСЬ В СОЗДАНИЕ АВТОНОМИИ. А. ЕРМЕКОВ ВОЗГЛАВИЛ ПРЕДСТАВИТЕЛЬСТВО КРАЯ В МОСКВЕ, Х. ГАББАСОВ БЫЛ УПОЛНОМОЧЕННЫМ КИРВРК ПРИ СИБВРК, Б. САРСЕНЕВ СОТРУДНИКОМ КРАЕВОЙ КО-МИССИИ ПО СОЗЫВУ УЧРЕДИТЕЛЬНОГО СЪЕЗДА, В. ТАНАЧЕВ - ЗАВПОДОТДЕЛОМ ЗАКОНОДАТЕЛЬНЫХ ПРЕДПОЛОЖЕНИЙ И А. КЕНЖИН ЗАВВНЕШКОЛЬНЫМ ОТДЕЛОМ КИРВРК. В СОВЕТСКИХ ОРГАНАХ В НАЧАЛЕ 1920-Х ГГ. РАБОТАЛИ И. ОМАРОВ, К. ТАТТИБАЕВ, И. ТЕРЕГУЛОВ, С. ДОЩАНОВ, А. КОЗБАГАРОВ, С. КАДИРБАЕВ, А. АКПАЕВ. НЕПОСРЕДСТВЕННОЕ УЧАСТИЕ В ПОДГОТОВКЕ УЧРЕДИТЕЛЬНОГО СЪЕЗДА КАССР, СБОРЕ ИСТОРИКО-СТАТИСТИЧЕСКИХ, ЭКОНОМИЧЕСКИХ, ЭТНОГРАФИЧЕСКИХ И КАРТОГРАФИЧЕСКИХ ДАННЫХ И МАТЕРИАЛОВ ДЛЯ ОПРЕДЕЛЕНИЯ ГРАНИЦ АВТОНОМИИ, В ОБСУЖДЕНИЯХ ВО ВЦИКЕ И ЕГО КОМИССИЯХ ПРИНЯЛИ БАЙТУРСЫНОВ, ЕРМЕКОВ, ГАББАСОВ, АЛИБЕКОВ И ДР.

УВЫ, ОЧЕНЬ СКОРО ОПТИМИЗМ ПО ПОВОДУ РЕАЛИЗАЦИИ АВТОНОМИСТСКОГО СОБЛАЗНА У МНОГИХ СМЕНИЛСЯ СОВСЕМ ДРУГИМИ, ТЯЖЕЛЫМИ ЧУВСТВАМИ. УЖЕ 17 МАЯ 1920 Г. БАЙТУРСЫНОВ В ПИСЬМЕ В.И. ЛЕНИНУ ПОДЧЕРКИВАЛ : ВЗАИМНОЕ НЕДОВЕРИЕ МЕЖДУ ПРЕДСТАВИТЕЛЯМИ ЦЕНТРА И НАСЕЛЕНИЕМ, В РУССКО-КАЗАХСКИХ ОТНОШЕНИЯХ НА ВСЕХ УРОВНЯХ МОЖНО ПРЕОДОЛЕТЬ ЛИШЬ С ПОМОЩЬЮ ИНТЕЛЛИГЕНЦИИ, КОТОРАЯ « НИ ЗА КАКИЕ ЛИЧНЫЕ БЛАГА И ВЫГОДЫ» СОЗНАТЕЛЬНО НЕ ПРОДАСТ СВОЕГО НАРОДА, НО ТАК ЖЕ, КАК И ОН, ЯВЛЯЕТСЯ ЖЕРТВОЙ ВЗАИМНЫХ ПОДОЗРЕНИЙ И НАСТОРОЖЕННОСТИ. ОН ОБРАТИЛ ВНИМАНИЕ НА РАСТОРОПНОСТЬ ОЗАБОЧЕННЫХ ЛИЧНЫМ УСПЕХОМ И БЛАГОПОЛУЧИЕМ ДЕЛЬЦОВ :

В НАСТОЯЩЕЕ ВРЕМЯ ВСЯКИЙ ВСТРЕЧНЫЙ НАЗЫВАЕТ СЕБЯ КОММУНИСТОМ. НЕ ПРИГЛЯДЕВШИСЬ К НИМ ПОБЛИЖЕ, ПОДУМАЕШЬ, ЧТО СОВЕРШИЛОСЬ ЧУДО - ВСЕ ПРЕВРАТИЛИСЬ В КОММУНИСТОВ. НО ЧУДЕСА БЫВАЮТ В СКАЗКАХ, ...КОММУНИЗМ У МНОГИХ НЕ ПРОСТИРАЕТСЯ ДАЛЬШЕ ЯРЛЫЧКА.

13 НАСТОЯЩИЕ ИДЕЙНЫЕ КОММУНИСТЫ И СТОЛЬ ЖЕ ИДЕЙНЫЕ НАЦИОНАЛЫ, НЕ ОБРЕМЕНЕННЫЕ ПОГОНЕЙ ЗА ВЛАСТЬЮ И ЛИЧНЫМ БЛАГОПОЛУЧИЕМ, - ИХ СОЮЗ В УПРАВЛЕНИИ ОН СЧИТАЛ ЕДИНСТВЕННЫМ УСЛОВИЕМ ПРАКТИЧЕСКОГО ОСУЩЕСТВЛЕНИЯ АВТОНОМИИ ${ }^{21}$. НО СДЕЛАТЬ ЭТО БЫЛО НЕ ПРОСТО. С. САДВОКАСОВ В 1921 Г. ЗАЯВИЛ, ЧТО КАЗАХСКАЯ ИНТЕЛЛИГЕНЦИЯ «ОЧЕНЬ НЕМНОГОЧИСЛЕННА, ЗАГНАНА И ПРИНИЖЕНА 
ЦАРСКОЙ ВЛАСТЬЮ, И ПРИВЛЕЧЬ ЕЕ К СОВЕТСКОЙ РАБОТЕ НЕСКОЛЬКО РИСКОВАННО. КАЖДОГО КВАЛИФИЦИРОВАННОГО КИРИНТЕЛЛИГЕНТА ПРИХОДИТСЯ ПРИНИМАТЬ НА СОВЕТСЛУЖБУ С БОЛЬШОЙ ОСТОРОЖНОСТЬЮ», А РУССКИЕ РАБОТНИКИ «ДОЛЖНЫ ПРИЛОЖИТЬ МАКСИМУМ УСИЛИЙ» В ИХ ВОСПИТАНИИ. ВПРОЧЕМ, ПРОВЕДЕННАЯ ИМ ПЕРЕТРЯСКА СЕМИПАЛАТИНСКОГО ГУБЕРНСКОГО И УЕЗДНЫХ ИСПОЛКОМОВ ДАЛА ПОВОД К ОБВИНЕНИЮ ЕГО САМОГО В НАЦИОНАЛ-УКЛОНИЗМЕ С СООТВЕТСТВУЮЩИМИ ОРГАНИЗАЦИОННЫМИ И ИНЫМИ ПОСЛЕДСТВИЯМИ ${ }^{22}$.

ДОВОЛЬНО СКОРО ПОДАВЛЯЮЩЕЕ БОЛЬШИНСТВО АЛАШЕВЦЕВ БЫЛО ОТТЕСНЕНО ОТ АКТИВНОЙ ОБЩЕСТВЕННО-ПОЛИТИЧЕСКОЙ ПРАКТИКИ. НА ІІІ СЪЕЗДЕ СОВЕТОВ КАССР (ОКТЯБРЬ 1922 Г.) ИХ ПОПЫТКИ ПРОВЕСТИ СВОИХ ПРЕДСТАВИТЕЛЕЙ В ПРЕЗИДИУМ НЕ УДАЛИСЬ ${ }^{23}$. АЛАШОРДИНЦЫ ВЕРНУЛИСЬ К КУЛЬТУРНО-ПРОСВЕТИТЕЛЬНОЙ И НАУЧНОПЕДАГОГИЧЕСКОЙ РАБОТЕ, ЛИТЕРАТУРНОМУ ТВОРЧЕСТВУ. БАЙТУРСЫНОВ В СВЯЗИ С ИСКЛЮЧЕНИЕМ ЕГО ИЗ ПАРТИИ В НОЯБРЕ 1921 Г. ПРЯМО ПОДТВЕРДИЛ : СОСТАВЛЕНИЕ УЧЕБНИКОВ ДЛЯ НЕГО НЕИЗМЕРИМО ВАЖНЕЕ, НЕЖЕЛИ ПОСЕЩЕНИЕ ПАРТСОБРАНИЙ ${ }^{24}$. СЕКРЕТАРЬ СЕМИПАЛАТИНСКОГО ГУБКОМА ПАРТИИ КОСТЕРИН ДОКЛАДЫВАЛ В ЦК, ЧТО В ОТЛИЧИЕ ОТ НИЗОВОЙ ИНТЕЛЛИГЕНЦИИ, ПОВЕРНУВШЕЙ В СТОРОНУ СОВЕТСКОЙ ВЛАСТИ И ПАРТИИ, В ЕЕ ВЕРХАХ, КОТОРЫЕ И СОСТАВЛЯЛИ ПРЕДСТАВИТЕЛИ АЛАШ, ЧУВСТВУЕТСЯ ОТЧУЖДЕННОСТЬ. НА КРАЕВЕДЧЕСКОМ СЪЕЗДЕ ВО ВРЕМЯ ДОКЛАДА СЕКРЕТАРЯ ПО ТЕМЕ «РЕВОЛЮЦИЯ И ИНТЕЛЛИГЕНЦИЯ» ПРОЗВУЧАЛА РЕПЛИКА : ИНТЕЛЛИГЕНЦИЯ ОТВЕРНУЛАСЬ ОТ РЕВОЛЮЦИИ, ТАК КАК НЕ МОГЛА МИРИТЬСЯ С ЕЕ АБСУРДОМ ${ }^{25}$. ОН УТОЧНЯЛ ПО ПОВОДУ БЫВШИХ АЛАШОРДИНЦЕВ :

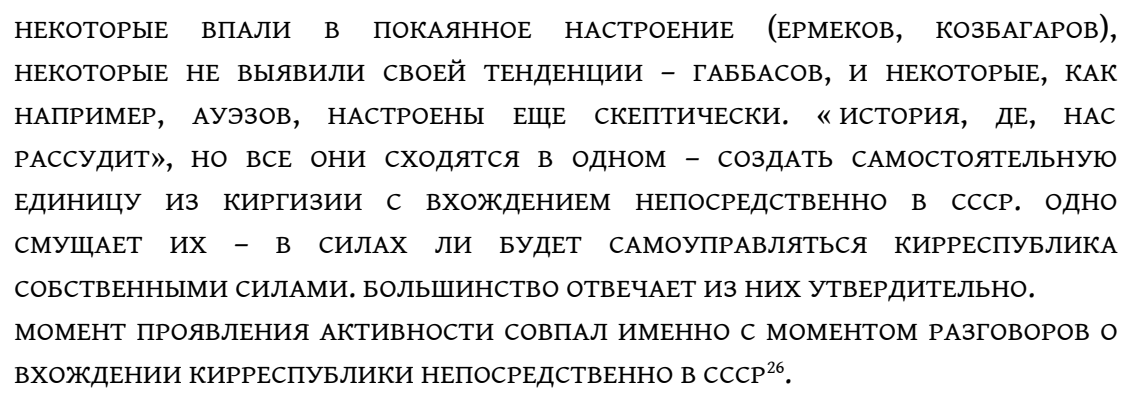

В КАЗАХСТАНЕ СОВЕТСКАЯ ВЛАСТЬ В АЛАШОРДИНЦАХ НАШЛА, ПУСТЬ ВРЕМЕННО, КАК, ВПРОЧЕМ, И В ДРУГИХ НАЦИОНАЛЬНЫХ РЕГИОНАХ, ЕДИНСТВЕННО ВОЗМОЖНЫХ И ПРИЕМЛЕМЫХ ПАРТНЕРОВ ДЛЯ ОРГАНИЗАЦИИ НОВОГО ПОРЯДКА. ПОПЫТКИ КОМПРОМИССА, ПОИСК РЫЧАГОВ ДЛЯ ПРЕОБРАЗОВАНИЙ В ЭТНОКУЛЬТУРНЫХ РЕГИОНАХ ВЕЛИСЬ С ОБЕИХ СТОРОН, ОБНАРУЖИВАЯ ПОРОЙ ПОЛЯРНЫЕ ПРЕДСТАВЛЕНИЯ О ПУТЯХ И СРЕДСТВАХ ДОСТИЖЕНИЯ ПРОГРЕССА И САМОЙ ЕГО СУЩНОСТИ. ПОСЛАНЦЫ ЦЕНТРА ВО МНОГОМ ОКАЗАЛИСЬ ЗАЛОЖНИКАМИ ИДЕОЛОГИИ, КОТОРОЙ ПРЕДАННО СЛУЖИЛИ, И КОТОРАЯ ЛИШЬ В ОБЩЕМ ВИДЕ ОТВЕЧАЛА НА КОНКРЕТНЫЕ ВОПРОСЫ ЖИЗНИ. ПРЕДСТАВИТЕЛИ МОДЕРНИЗАТОРСКОГО СЛОЯ КАЗАХСКОГО ОБЩЕСТВА НАДЕЯЛИСЬ ИСПОЛЬЗОВАТЬ В СОВЕТСКОЙ ПРАКТИКЕ НАВЫКИ ПОЛИТИЧЕСКОЙ ДЕМОКРАТИИ, УЧИТЫВАЯ И РОЛЬ ТРАДИЦИОННЫХ СОЦИАЛЬНЫХ СВЯЗЕЙ. В «ЛОВУШКУ» НАЦИОНАЛЬНОЙ ГОСУДАРСТВЕННОСТИ ПОПАЛИ И БОЛЬШЕВИКИ, И НАЦИОНАЛЫ. ПРАВДА, ОДНИ СТРЕМИЛИСЬ ИСПОЛЬЗОВАТЬ ЕЕ ДЛЯ УТВЕРЖДЕНИЯ КЛАССОВОЙ СПРАВЕДЛИВОСТИ, А ДРУГИЕ УПОВАЛИ НА НЕЕ КАК НА УНИВЕРСАЛЬНОЕ ЛЕКАРСТВО В ЛЕЧЕНИИ ВСЕХ БОЛЯЧЕК ЭТНОСОЦИАЛЬНОГО ОРГАНИЗМА. НИ ТО, НИ ДРУГОЕ НЕ МОГЛО БЫТЬ ОСУЩЕСТВЛЕНО ИСКЛЮЧИТЕЛЬНО АДМИНИСТРАТИВНЫМИ И ПОЛИТИЧЕСКИМИ ПРИЕМАМИ, КОИМ ТОГДА ОТДАВАЛОСЬ ПРЕДПОЧТЕНИЕ. 
ОТСТРАНЯЕМЫЕ ОТ СТРУКТУР ВЛАСТИ, АЛАШЕВЦЫ ПРОДОЛЖАЛИ ВЛИЯТЬ НА КАЗАХОВУПРАВЛЕНЦЕВ БЛАГОДАРЯ АВТОРИТЕТУ, ПРОЧНЫМ ЛИЧНЫМ И ЭТНОСОЦИАЛЬНЫМ ВЗАИМОЗАВИСИМОСТЯМ, ТРАДИЦИОННЫМ И НАИБОЛЕЕ СИЛЬНЫМ ДЛЯ КАЗАХСКОЙ КУЛЬТУРЫ СРЕДСТВОМ - ОБРАЗНЫМ ЭЗОПОВЫМ ЯЗЫКОМ, ПОЭТИЧЕСКОЙ МУДРОСТЬЮ. КАК И ДО РЕВОЛЮЦИИ, ИХ СТАТЬИ МОГЛИ СОДЕРЖАТЬ АЛЛЕГОРИИ И ИНТЕРПРЕТАЦИИ ТЕКУЩИХ СОБЫТИЙ, НЕ В ПРЯМОМ СМЫСЛЕ, А В ВИДЕ НАРОДНЫХ ПОГОВОРОК, ИНОСКАЗАТЕЛЬНЫХ И ПРОЧЕЕ, ГЛУБОКИЙ, ИСТИННЫЙ СМЫСЛ КОТОРЫХ УЛОВИТЬ МОГУТ ТОЛЬКО «СВОИ» ЛЮДИ, А ПОСЛЕДНИЕ УЖЕ ДОЛЖНЫ БУДУТ ТОЛКОВАТЬ ИХ МАССАМ НАСЕЛЕНИЯ. ТАК РУССКОЯЗЫЧНЫЕ ЧИНОВНИКИ ОТСТРАНЯЛИСЬ ОТ СОЦИАЛЬНОПСИХОЛОГИЧЕСКИХ И КУЛЬТУРНЫХ ИНСТРУМЕНТОВ ВЛИЯНИЯ, ИГРАВШИХ « ГРОМАДНУЮ РОЛЬ ВО ВСЕЙ ОБЩЕСТВЕННОЙ ЖИЗНИ» КАЗАХОВ ${ }^{27}$. НАНЕЙШВИЛИ ПОДТВЕРЖДАЛ : НАЦИОНАЛЫ ВО ВЛАСТИ НАХОДЯТСЯ

В СЛИШКОМ БЛИЗКИХ, БОЛЬШЕ, ЧЕМ МОЖНО, ОТНОШЕНИЯХ С «БЕСПАРТИЙНОЙ» КАДЕТСКОЙ (АЛАШОРДИНСКОЙ) ИНТЕЛЛИГЕНЦИЕЙ, ...ТЕРЯЕТСЯ ГРАНЬ МЕЖДУ КИРГИЗОМ-КОММУНИСТОМ И КИРГИЗОМ - БЕСПАРТИЙНЫМ ИНТЕЛЛИГЕНТОМ. ВМЕСТЕ С ПОСЛЕДНИМИ ОБСУЖДАЮТСЯ САМЫЕ, МОЖНО СКАЗАТЬ, ПАРТИЙНЫЕ ВОПРОСЫ В УЗКОМ СМЫСЛЕ ЭТОГО СЛОВА. БЕСПАРТИЙНАЯ ИНТЕЛЛИГЕНЦИЯ ВЛИЯЕТ НА КИРГИЗ-КОММУНИСТОВ, А НЕ НАОБОРОТ. ${ }^{28}$

НЕ ИМЕЯ РЫЧАГОВ ПРЯМОГО ВЛИЯНИЯ, КУЛУАРНО ОНА СТАЛА АКТИВНЕЕ ОПИРАТЬСЯ НА НЕФОРМАЛЬНЫЕ ИЕРАРХИЧЕСКИЕ СЕТИ, ОСНОВАННЫЕ НА ПЕРСОНАЛЬНЫХ, В Т.Ч. РОДСТВЕННЫХ ОТНОШЕНИЯХ, ГДЕ СОХРАНЯЛИ СВОЮ РОЛЬ ЧУВСТВА УВАЖЕНИЯ И СОЛИДАРНОСТИ. СОБСТВЕННО, ИНАЧЕ И НЕ МОГЛО БЫТЬ: УСТОЙЧИВАЯ ВНУТРИЭТНИЧЕСКАЯ ИЕРАРХИЯ СЛУЖИЛА ЕСТЕСТВЕННЫМ ОРГАНИЗАЦИОННЫМ МЕХАНИЗМОМ, КОТОРЫЙ В ОТНОШЕНИЯХ С НОВЫМИ ИНСТИТУТАМИ ВЛАСТИ ОКАЗАЛСЯ ЦЕННЫМ ТЕНЕВЫМ РЕСУРСОМ ${ }^{29}$.

\section{Коллизии казахизации}

МОДИФИКАЦИЯ И « ПЕРЕКОДИРОВАНИЕ» ТРАДИЦИОННОЙ ПОЛИТИЧЕСКОЙ КУЛЬТУРЫ И СОЦИАЛЬНЫХ ДОМИНАНТ ЭТНИЧЕСКИХ ОБЩНОСТЕЙ И ИХ ЭЛИТ ПРОИСХОДИЛИ В УСЛОВИЯХ ДИНАМИЧНОГО МЕЖКУЛЬТУРНОГО ВЗАИМОДЕЙСТВИЯ И СТАНОВЛЕНИЯ НОВОЙ ГОСУДАРСТВЕННОСТИ. СЛОЖНЫЕ ПРОЦЕССЫ СМЕНЫ ПОКОЛЕНИЙ КАЗАХСКИХ УПРАВЛЕНЦЕВ, ВОПЛОЩАВШИЕ ПЕРЕСЕЧЕНИЕ ТРАДИЦИОННЫХ, РЕФОРМАТОРСКИХ ДОСОВЕТСКИХ И РЕВОЛЮЦИОННЫХ МОДЕЛЕЙ ПОЛИТИЧЕСКОГО ДЕЙСТВИЯ, ПРЕДОПРЕДЕЛИЛИ СООТНОШЕНИЕ ОБЩЕГО И СПЕЦИФИЧЕСКОГО, СФОРМИРОВАЛИ ИНЕРЦИЮ ИХ ПРЕДПОЧТИТЕЛЬНЫХ ОРГАНИЗАЦИОННО-ПОЛИТИЧЕСКИХ ПРИЕМОВ. ПОСКОЛЬКУ ЕСТЕСТВЕННОЙ СРЕДОЙ РЕАЛИЗАЦИИ БОЛЬШЕВИСТСКОГО ПРОЕКТА ЯВИЛИСЬ ПАРТИЙНЫЕ ОРГАНЫ, СТАНОВЯЩАЯСЯ СОВЕТСКАЯ СИСТЕМА АПРИОРИ ОКАЗАЛАСЬ ИХ ЗАЛОЖНИЦЕЙ. ОТСУТСТВИЕ СРЕДИ КАЗАХОВ СТРОГОЙ КЛАССОВОЙ ДИФФЕРЕНЦИАЦИИ, НА КОТОРУЮ ОНА БЫЛА РАССЧИТАНА, И ЕСТЕСТВЕННАЯ ОТСТРАНЕННОСТЬ МАСС ОТ ФОРМИРУЮЩИХСЯ ПОЛИТИЧЕСКИХ ИНСТИТУЦИЙ, ЗНАКОМЫХ ГЛАВНЫМ ОБРАЗОМ ГОРОЖАНАМ ПО КРАТКОСРОЧНОМУ ЭКСТРЕМАЛЬНОМУ ОПЫТУ 1917-1920 ГГ., ПРЕДОПРЕДЕЛИЛИ ИСКУССТВЕННОСТЬ НАСАЖДАЕМЫХ СОВЕТОВ И ТРУДНОСТИ ПОСЛАНЦЕВ ЦЕНТРА В РЕАЛИЗАЦИИ РЕВОЛЮЦИОННОГО ЗАМЫСЛА, ВКЛЮЧАВШЕГО ФОРМИРОВАНИЕ НАЦИОНАЛЬНОЙ НОМЕНКЛАТУРЫ. НА МЕСТАХ ОТСУТСТВИЕ КОММУНИСТОВ-КАЗАХОВ ОБОРАЧИВАЛОСЬ ТЕМ, ЧТО В СИЛУ БОЛЕЕ ВЫСОКОГО 
СОЦИАЛЬНОГО СТАТУСА СРЕДИ УПРАВЛЕНЦЕВ ПОНАЧАЛУ ЗАКРЕПЛЯЛИСЬ НЕ ТОЛЬКО МАЛОЧИСЛЕННЫЕ ИНТЕЛЛИГЕНТЫ, НО И ВЫХОДЦЫ ИЗ ИМУЩИХ КРУГОВ, ИМЕВШИЕ ОПЫТ « ПАРТИЙНОЙ» БОРЬБЫ ВО ВРЕМЯ ВОЛОСТНЫХ ВЫБОРОВ. УСТОЯВШИЕСЯ СПЕЦИАЛЬНЫЕ ФОРМЫ РЕГУЛИРОВАНИЯ СОЦИАЛЬНЫХ ПРИТЯЗАНИЙ, КОМПРОМИССА ГРУППОВЫХ ИНТЕРЕСОВ, ПОЗИЦИОНИРОВАНИЯ И СТАТУСА В СИСТЕМЕ ВЛАСТНЫХ ОТНОШЕНИЙ НА ОСНОВЕ ВЗАИМОДЕЙСТВИЯ КОЧЕВЫХ ОБЩИН, ОТСУТСТВИЕ ПРЕДСТАВЛЕНИЙ И ОПЫТА В ПРОЦЕДУРАХ СОЗДАНИЯ СОВЕТОВ ПРИВОДИЛИ К ВСТРАИВАНИЮ ТРАДИЦИОННЫХ НОРМ ОРГАНИЗАЦИИ УПРАВЛЕНИЯ В НОВЫЙ ФОРМАТ ${ }^{30}$.

АДАПТИРОВАННЫЕ К ДОСОВЕТСКОЙ БЮРОКРАТИЧЕСКОЙ МАШИНЕ, ОНИ ОКАЗАЛИСЬ ЖИВУЧИМИ И ВПОЛНЕ ПРИГОДНЫМИ В СОВЕТИЗИРУЮЩИХСЯ АППАРАТАХ. ЗАМЕЧАТЕЛЬНЫЙ АНАЛИЗ КАЗАХСКОЙ ПОЛИТИКО-ПРАВОВОЙ КУЛЬТУРЫ, КОТОРАЯ ВСТРАИВАЛАСЬ В СОВЕТСКИЙ ПОРЯДОК, ДАЛ Т.И.СЕДЕЛЬНИКОВ, ИСКЛЮЧЕННЫЙ ИЗ СОСТАВА КИРВРК ЗА «КАЗАХСКИЙ НАЦИОНАЛИЗМ». ЕГО НАБЛЮДЕНИЯ КАСАЮТСЯ И ОТНОШЕНИЯ РЯДОВЫХ КАЗАХОВ К « ЕВРОПЕЙЦАМ» ВО ВЛАСТИ :

ТАМ СИДЕЛИ ЧУЖИЕ ЛЮДИ, СУДИВШИЕ ПО НИКОМУ НЕ ВЕДОМЫМ И НЕ ПОНЯТНЫМ «КНИЖКАМ». КАК К НИМ ПОДОЙТИ, ЧТОБЫ «ЗАДОБРИТЬ», АЛЛАХ ВЕДАЕТ ! ОТСЮДА ПОТРЕБНОСТЬ В «ХОДАТАЯХ» И «АДВОКАТАХ», КОТОРЫЕ ПИСАЛИ «ПРОШЕНИЯ», «ЖАЛОБЫ», «КАССАЦИИ» И «АПЕЛЛЯЦИИ», ОБИРАЯ ОДНОВРЕМЕННО ПРАВОГО И ВИНОВАТОГО. ${ }^{31}$

ЧЛЕН КЦИК, ЗАМЕСТИТЕЛЬ ГЛАВЫ СЕМИПАЛАТИНСКОГО ГИКА БОЛЬШАКОВ ОТМЕЧАЛ, ЧТО НАСЕЛЕНИЕ, ОСОБЕННО КАЗАХСКОЕ,

ПРОДОЛЖАЕТ ЖИТЬ И МЫСЛИТЬ ПО ПРИМЕРУ СВОИХ ДЕДОВ И ОТЦОВ. ОНО ЗНАЕТ СОВЕТСКУЮ ВЛАСТЬ ПО НАЗВАНИЮ, А СУДИТ О НЕЙ ПО ТЕМ ПОСТУПКАМ И ПОВЕДЕНИЮ ВСЕХ НАЧАЛЬСТВУЮЩИХ ЛИЦ... ОТ РАБОТЫ НЕКОТОРЫХ НАШИХ «РАБОТНИКОВ» ЧАСТО ВЕЕТ УЖАСАМИ СРЕДНЕВЕКОВЬЯ, РАЗНУЗДАННОСТЬЮ, ПОДЧАС ПРЕВОСХОДЯЩИХ РАЗНУЗДАННОСТЬ КОЛЧАКОВСКИХ ВРЕМЕН, БАНДИТИЗМОМ, ЧТО ПОДРЫВАЕТ ВСЯКУЮ ВЕРУ У ТРУДЯЩИХСЯ МАСС В СВОЮ РАБОЧЕ-КРЕСТЬЯНСКУЮ ВЛАСТЬ.

ОТВЕТСЕКРЕТАРЬ СЫР-ДАРЬИНСКОГО ГУБКОМА ПАРТИИ Г.Д. КАУЧУКОВСКИЙ ДОКЛАДЫВАЛ В ЦК, ЧТО

В НИЗОВОМ СОВЕТСКОМ АППАРАТЕ ЦАРИТ ПОЛНЫЙ ОТРЫВ ОТ МАСС : ПЬЯНСТВО, ВЗЯТОЧНИЧЕСТВО, РОДОВАЯ БОРЬБА, ПРОИЗВОЛ И ПРОЧЕЕ. СОВЕТСКАЯ ВЛАСТЬ, ТАКОЙ, КАК ОНА ДОЛЖНА БЫТЬ В АУЛЕ И КИШЛАКЕ, ОТСУТСТВУЕТ СОВЕРШЕННО. [... ] ОЧЕНЬ ЧАСТО ДЕХКАНЕ ГОВОРЯТ ПРЯМО, ЧТО СОВЕТСКИЙ АППАРАТ ПЛОХ ТЕМ, ЧТО ОБХОДИТСЯ ИМ ДОРОЖЕ, ЧЕМ ЦАРСКИЙ... ${ }^{32}$

ВСЯ ПРАКТИКА СТАНОВЛЕНИЯ СОВЕТСКОЙ ГОСУДАРСТВЕННОСТИ И НАЦИОНАЛЬНОЙ БЮРОКРАТИИ В КАССР ПОДТВЕРЖДАЕТ - ЭТНОСОЦИАЛЬНЫЙ ОРГАНИЗМ ОСВАИВАЛ ПРЕДЛАГАЕМЫЙ КАРКАС, ОПУТЫВАЯ ЕГО МНОЖЕСТВОМ ХИТРОСПЛЕТЕНИЙ, МАЛО ЗАМЕТНЫХ И НЕ ОСЯЗАЕМЫХ ИМЕЮЩИМСЯ У МОСКОВСКИХ « ОПЕРАТОРОВ» ИНСТРУМЕНТАРИЕМ. ОНИ ВОЗНИКАЛИ И КАК ЕСТЕСТВЕННЫЙ СПОСОБ АДАПТАЦИИ К НОВОЙ СРЕДЕ ОБИТАНИЯ, И КАК СОЗНАТЕЛЬНОЕ ВСТРАИВАНИЕ НАЛИЧНЫХ МОДЕЛЕЙ ПОЛИТИЧЕСКОГО ПОВЕДЕНИЯ ИХ НОСИТЕЛЯМИ - НАЦИОНАЛАМИ, ПРИГЛАШЕННЫМИ САМИМИ «АГЕНТАМИ КРЕМЛЯ». ТАК, В 1924 Г. В НЕКОТОРЫХ ПАРТЯЧЕЙКАХ АКТЮБИНСКОЙ ГУБЕРНИИ ОТКАЗЫВАЛИСЬ ПРИНИМАТЬ В ПАРТИЮ ПРЕДСТАВИТЕЛЕЙ ДРУГИХ РОДОВ. МОСКВА РЕКОМЕНДОВАЛА ОБЪЕДИНЯТЬ В ВЫБОРНЫХ СОВЕТСКИХ ОРГАНАХ БЕДНЫХ ПРЕДСТАВИТЕЛЕЙ РАЗНЫХ РОДОВ, ПОДДЕРЖИВАТЬ СЛАБЫЕ РОДОВЫЕ ГРУППЫ И ПРОВОДИТЬ «СОВЕЩАНИЯ ПРЕДСТАВИТЕЛЕЙ ВРАЖДУЮЩИХ ГРУПП» ДЛЯ ЛИКВИДАЦИИ «БАРЫМТАЧЕСТВА» ${ }^{33}$. ПРИ НАЛИЧИИ ИМУЩИХ И ОБЕДНЕВШИХ РОДОВ 
КЛАССОВЫЙ ПОДХОД ОБРЕКАЛ ВЛАСТЬ НА КОНСЕРВАЦИЮ РОДОВОЙ СЕТИ, А ПРОТИВОПОСТАВЛЕНИЕ « НИЗОВ ВЕРХАМ» ВНУТРИ РОДА НЕРЕДКО ВЫВОДИЛО В СОСТАВ МЕСТНОЙ БЮРОКРАТИИ ПОДСТАВНЫХ ЛИЦ, ЧТО ТАКЖЕ ДЕЛАЛО ЦЕНТР НЕВОЛЬНЫМ СТАБИЛИЗАТОРОМ ТРАДИЦИОННОЙ ИЕРАРХИИ.

ВО ВСЕЙ КИРГИЗИИ, - ПИСАЛ В 1920 Г. С.С. ПЕСТКОВСКИЙ, - НАЙДЕТСЯ СЕЙЧАС ЕДВА 2-3 ДЕСЯТКА НАДЕЖНЫХ И СОЗНАТЕЛЬНЫХ КОММУНИСТОВ-КИРГИЗ. КОММУНИСТОВ ВООБЩЕ МНОГО, НО БЕДА В ТОМ, ЧТО БЫВШИЕ КИРГИЗСКИЕ ЦАРСКИЕ ЧИНОВНИКИ СОТНЯМИ В НЕСКОЛЬКО НЕДЕЛЬ ОКРАСИЛИСЬ В КОММУНИСТИЧЕСКИЙ ЦВЕТ И СТАНОВЯТСЯ ВО ГЛАВЕ ВОЛОСТНЫХ И АУЛЬНЫХ СОВДЕПОВ. ВО МНОГИХ МЕСТАХ ... ТОТ ЖЕ БЫВШИЙ ВОЛОСТНОЙ У УПРАВИТЕЛЬ» ИЛИ АУЛЬНЫЙ СТАРОСТА ПЕРЕИМЕНОВЫВАЛСЯ В ПРЕДСЕДАТЕЛЯ СОВДЕПА И ПРАВИТ ПО-ПРЕЖНЕМУ.

ПРИ ЭТОМ НОВАЯ ВЛАСТЬ СТОЛЬ ЖЕ УСПЕШНО, КАК И ПРЕЖНЯЯ, ОБЕСПЕЧИВАЛА СЕБЯ,

И ДАЖЕ БЕДНЯК, СЛУЧАЙНО СТАВШИЙ « ВЛАСТЬЮ» НОРОВИТ КАК-НИБУДЬ ЗАРАБОТАТЬ СО СВОЕГО ЖЕ БРАТА-БЕДНЯКА.

КАК КИРГИЗЫ ПРИВЫКЛИ СМОТРЕТЬ НА ВЛАСТЬ, КАК ДЕЛАЛИ ВСЕ БЫВШИЕ У ВЛАСТИ, ТАК, ПО ИХ МНЕНИЮ, ОНИ И ДОЛЖНЫ ДЕЛАТЬ. ${ }^{34}$

КОНТРОЛИРОВАТЬ СИТУАЦИЮ НА ДЕЛЕ БЫЛО КРАЙНЕ СЛОЖНО ИЗ-ЗА ОТСУТСТВИЯ ТРАНСПОРТНЫХ СЕТЕЙ И «НИЧТОЖНОГО» ЧИСЛА НАДЕЖНЫХ ЛЮДЕЙ. ВЫХОД АВТОР ВИДЕЛ ОДИН :

НУЖНО БРАТЬ МОЛОДЫХ КИРГИЗ, НЕ СЛУЖИВШИХ ЕЩЕ ПРИ СТАРОМ РЕЖИМЕ, ЕЩЕ НЕ ИСПОРЧЕННЫХ, ОБУЧАТЬ ИХ НА ОБЩЕОБРАЗОВАТЕЛЬНЫХ И АДМИНИСТРАТИВНЫХ КУРСАХ В СПЕШНОМ ПОРЯДКЕ И БРОСАТЬ ЗАТЕМ В СТЕПЬ ДЛЯ РАБОТЫ.

В 1922 Г. В КУТВ НА КУРСАХ ЕСТЕСТВОЗНАНИЯ ОБУЧАЛИСЬ 2 КАЗАХА ИЗ 59 СЛУШАТЕЛЕЙ, ИНСТРУКТОРСКУЮ ШКОЛУ ОКОНЧИЛИ 2 КАЗАХА (ВСЕГО 82 ЧЕЛ.). СРЕДИ ЛЕКТОРОВ БЫЛО 13 КАЗАХОВ. ИЗ 672 СТУДЕНТОВ КУТВ КАЗАХОВ БЫЛО 23. 44 \% КУРСАНТОВ НУЖДАЛИСЬ В ХОРОШЕМ ОТДЫХЕ, У ОСТАЛЬНЫХ НАБЛЮДАЛИСЬ ПРИЗНАКИ ИСТОЩЕНИЯ И ПЕРЕУТОМЛЕНИЯ ${ }^{35}$. ПЕСТКОВСКИЙ НЕ ТОЛЬКО ВПОЛНЕ ОБЪЕКТИВНО ОЦЕНИЛ СИТУАЦИЮ, НО И ИЗЛОЖИЛ БАЗОВЫЕ ЭЛЕМЕНТЫ ПРОГРАММЫ ВЛАСТИ ПО ФОРМИРОВАНИЮ НОВЫХ ЭТНОИДЕНТИФИКАЦИОННЫХ ХАРАКТЕРИСТИК. ОНИ ДОЛЖНЫ БЫЛИ ОБЕСПЕЧИВАТЬ ЛОМКУ ПРЕЖНЕЙ ИЕРАРХИИ СОЦИАЛЬНЫХ ОТНОШЕНИЙ И ВСТРАИВАНИЕ ОБРЕТАВШЕГО ОДНОВРЕМЕННО ИНЫЕ ОБЩЕСТВЕННЫЕ ЦЕННОСТИ ГРАЖДАНИНА В СОВЕТСКИЕ ИНСТИТУЦИИ. В ОБУЧЕНИИ ПАРТИЙНО-СОВЕТСКОЙ БЮРОКРАТИИ ОСНОВНОЕ ВНИМАНИЕ УДЕЛЯЛОСЬ ИДЕОЛОГИЧЕСКОЙ ПОДГОТОВКЕ. ЭТНОСОЦИАЛЬНАЯ СПЕЦИФИКА ТРАКТОВАЛАСЬ КАК НЕОТЪЕМЛЕМАЯ ЧАСТЬ УЧЕНИЯ О КЛАССОВОЙ БОРЬБЕ.

ДЛЯ УВЕЛИЧЕНИЯ ЧИСЛА ЗНАЮЩИХ ЯЗЫК ШИРОКО ИСПОЛЬЗОВАЛИСЬ ПРАКТИКАНТСТВО И ОРГАНИЗАЦИЯ КУРСОВ ПРИ КЦИК И ВЕДОМСТВАХ ДЛЯ НАЦИОНАЛОВ, ГРУПП «ЕВРОПЕЙЦЕВ» ДЛЯ ИЗУЧЕНИЯ КАЗАХСКОГО ЯЗЫКА, ЧТО К 1925 Г. РЕШИТЕЛЬНО СИТУАЦИЮ НЕ ИЗМЕНИЛО. В КРАЕВЫХ УЧРЕЖДЕНИЯХ ЗНАЮЩИХ КАЗАХСКИЙ ЯЗЫК БЫЛО лишь $5 \%$.

ВЫДВИЖЕНИЯ, НЕСОМНЕННО, БОЯТСЯ, - ЖАЛОВАЛСЯ ГОЛОЩЕКИН В 1926 Г. - И ИЗ СИЛЫ ДВИГАЮЩЕЙ ОНИ ПОСТЕПЕННО ПРЕВРАЩАЮТСЯ В СИЛУ ЗАДЕРЖИВАЮЩУЮ. РУССКИЙ ЯЗЫК СПОСОБСТВУЕТ ОТЧАСТИ СОПРОТИВЛЕНИЮ ПРОТИВ КОРЕНИЗАЦИИ ДАЖЕ СРЕДИ ТЕХНИЧЕСКОГО АППАРАТА... И КАЖДЫЙ КОММУНИСТ КАК ТОЛЬКО ОН НЕМНОГО НАУЧИЛСЯ ГРАМОТЕ, НЕ ИДЕТ НА ПРОСТУЮ ТЕХНИЧЕСКУЮ РАБОТУ, А ТОЛЬКО ОБЯЗАТЕЛЬНО ЗАВЕДУЮЩИМ ОТДЕЛОМ. 
В МАЕ 1926 Г. ПО ЕГО ИНИЦИАТИВЕ ОТВЕТСТВЕННОСТЬ ЗА КОРЕНИЗАЦИЮ БЫЛА ВОЗЛОЖЕНА НА НК РКИ, САМА ОНА ТЕПЕРЬ ПРЕСЛЕДОВАЛА ЦЕЛЬ НЕ ПРОСТО МЕХАНИЧЕСКОГО «ПРОЦЕНТНОГО ЗАМЕЩЕНИЯ ДОЛЖНОСТЕЙ», А СТАНОВИЛАСЬ ФУНКЦИОНАЛЬНОЙ. КОРЕНИЗАЦИИ ЗА ПЕРИОД ОТ ПОЛУГОДА ДО 2 ЛЕТ ПОДЛЕЖАЛИ КАДРЫ ПО 42 ДОЛЖНОСТЯМ СРЕДНЕТЕХНИЧЕСКОГО ПЕРСОНАЛА ${ }^{36}$ НОМЕНКЛАТУРЫ АДМИНИСТРАТИВНЫХ И ХОЗЯЙСТВЕННЫХ УЧРЕЖДЕНИЙ. ЦЕЛЕНАПРАВЛЕННАЯ РАБОТА ПОСТЕПЕННО ПРИНОСИЛА СВОИ ПЛОДЫ.

Таблица 4. Национальный состав высших органов власти КАССР в 1927 г. ${ }^{3738}$

\begin{tabular}{|l|l|l|l|l|}
\hline НАЦИОНАЛЬНОСТЬ & ПРЕЗИДИУМ ЦИК КАССР & ПЛЕНУМ ЦИК КАССР & СНК КАССР & ХОЗОРГАНЫ \\
\hline КАЗАХИ & 12 & 97 & 11 & 8 \\
\hline РУССКИЕ & 2 & & & \\
\hline ПРОЧИЕ & 2 (КАРАКАЛПАК И УЗБЕК) & $53^{38}$ & 5 & 8 \\
\hline
\end{tabular}

Таблица 5. Национальный состав местных органов власти ${ }^{39}$

\begin{tabular}{|c|c|c|c|c|c|c|c|c|c|}
\hline НАЦ-ТЬ & $\begin{array}{l}\text { ПРЕД. } \\
\text { ГИК }\end{array}$ & ЗАВ.ГЗУ & $\begin{array}{l}\text { ЗАВ. } \\
\text { ОНО }\end{array}$ & $\begin{array}{l}\text { ПРЕД. } \\
\text { ГУБСУДА }\end{array}$ & $\begin{array}{l}\text { ЗАВ.ГУБ. } \\
\text { ВНУТР. } \\
\text { ДЕЛ }\end{array}$ & $\begin{array}{l}\text { ПРОКУ } \\
\text { РОРОВ }\end{array}$ & $\begin{array}{l}\text { ПРЕД. } \\
\text { УИК }\end{array}$ & $\begin{array}{l}\text { НАР. } \\
\text { СУДЕЙ }\end{array}$ & $\begin{array}{l}\text { НАР. } \\
\text { СЛЕДОВА- } \\
\text { ТЕЛЕЙ }\end{array}$ \\
\hline КАЗАХИ & 8 & 8 & 9 & 8 & 4 из 9 & 6 & 20 & 113 & 79 \\
\hline ПРОЧИЕ & $\begin{array}{l}1 \text { (КАРА- } \\
\text { КАЛПАК) }\end{array}$ & $\begin{array}{l}1 \text { (КАРА- } \\
\text { КАЛПАК) }\end{array}$ & & $\begin{array}{l}1 \text { (КАРА- } \\
\text { КАЛПАК) }\end{array}$ & & 2 & 13 & 83 & 90 \\
\hline В Т.Ч. & & & & & & & $\begin{array}{l}7 \\
\text { EBPEEB }\end{array}$ & $\begin{array}{l}3 \text { УЗБЕКА, } \\
2 \text { ТАРАН- } \\
\text { ЧИНЦА, } \\
6 \text { КАРА- } \\
\text { КАЛПАКОВ }\end{array}$ & $\begin{array}{l}1 \text { ТАРАН- } \\
\text { ЧИНЕЦ, } \\
28 \text { КАРА- } \\
\text { КАЛПАКОВ }\end{array}$ \\
\hline
\end{tabular}

ОДНАКО СПЕШНАЯ КАЗАХИЗАЦИЯ НЕ МОГЛА УЛУЧШИТЬ КАЧЕСТВО УПРАВЛЕНЧЕСКОГО ПЕРСОНАЛА. МИНИМАЛЬНАЯ ОБЩАЯ И ПОЛИТИЧЕСКАЯ КУЛЬТУРА, ИСКУССТВЕННОСТЬ НАВЯЗЫВАЕМЫХ СТАНДАРТОВ ГРАЖДАНСТВЕННОСТИ ПОРОЖДАЛИ ЦИНИЗМ БЕЛЬСЕНДЫ ${ }^{40}$, ИЖДИВЕНЧЕСКОЕ ОТНОШЕНИЕ К ВЛАСТИ И ПРЕДСТАВЛЯВШИМ ЕЕ СТРУКТУРАМ, РАЗЛИЧНЫЕ СПОСОБЫ СОЦИАЛЬНОЙ МИМИКРИИ И ЛАТЕНТНОЕ ДОМИНИРОВАНИЕ ИНДИВИДУАЛЬНЫХ ИНТЕРЕСОВ НАД ОБЩЕСТВЕННЫМИ. ЭТО ОПРЕДЕЛЯЛО НИЗКОЕ КАЧЕСТВО УПРАВЛЕНЧЕСКОЙ КУЛЬТУРЫ И САМОЙ НОМЕНКЛАТУРЫ В ОТЛИЧИЕ ОТ « СТАРОЙ» ИНТЕЛЛИГЕНЦИИ. « РЕКРУТЫ» ИЗ НАРОДА ИМЕЛИ КАЧЕСТВЕННО ИНЫЕ ЧЕРТЫ В ОТЛИЧИЕ ОТ АЛАШЕВЦЕВ И ПРЕДСТАВИТЕЛЕЙ ЦЕНТРА - НЕДОСТАТОЧНОЕ ОБРАЗОВАНИЕ, МИНИМАЛЬНЫЙ ОПЫТ ПУБЛИЧНОЙ ОБЩЕСТВЕННОЙ ПРАКТИКИ, ЗНАНИЙ, УМЕНИЙ И НАВЫКОВ РЕШЕНИЯ СОЦИАЛЬНО-ЭКОНОМИЧЕСКИХ, КУЛЬТУРНЫХ И ПР. ВОПРОСОВ ; 
ПОВЕРХНОСТНОЕ ОСВОЕНИЕ БОЛЬШЕВИЗМА, ПРИНЦИПОВ ФУНКЦИОНИРОВАНИЯ НОВОЙ ВЛАСТИ.

« ПОКРУТИВШИСЬ» И ОСОЗНАВ НЕПОКОЛЕБИМУЮ РЕШИМОСТЬ БОЛЬШЕВИКОВ РЕАЛИЗОВАТЬ СВОЙ РЕВОЛЮЦИОННЫЙ ЗАМЫСЕЛ, МНОГИЕ ПРЕДПОЧЛИ ВСЕ-ТАКИ ПРИСПОСОБИТЬСЯ И ДАЖЕ ВПИСАТЬСЯ В НОВУЮ СИСТЕМУ, ИСПОЛЬЗУЯ ПОДВЕРНУВШИЕСЯ ШАНСЫ (КАТАСТРОФИЧЕСКИЙ ДЕФИЦИТ ОБРАЗОВАННЫХ ЛЮДЕЙ, ХАОТИЗАЦИЯ СОЦИАЛЬНОЙ ЖИЗНИ, ПОЯВЛЕНИЕ НОВЫХ ВОЗМОЖНОСТЕЙ В РАЗНЫХ СФЕРАХ И Т.Д.) КАК ЛИФТ ДЛЯ СОЦИАЛЬНОГО ВОЗВЫШЕНИЯ, РОСТА БЛАГОСОСТОЯНИЯ И ПРЕСТИЖНОГО ПОТРЕБЛЕНИЯ. ПОЛУЧИВ ПОСТ

КИРГИЗСКОГО НАРКОМА, - ПИСАЛ КОРОСТЕЛЕВ - ТАКОВОЙ ОТПРАВЛЯЛСЯ В СТЕПЬ И

ТАМ СИДЕЛ 5 - 6 МЕСЯЦЕВ, НЕ ЗАГЛЯДЫВАЯ В СВОЙ НАРКОМАТ.

ЕМУ ВТОРИЛ ЖИХАНОВ :

КИРГИЗЫ ВСЕ ИНТЕЛЛИГЕНТЫ, РАБОЧИХ ПОЧТИ НЕТ, РАБОТАТЬ СРЕДИ МАСС НЕ УМЕЮТ. В СИЛУ ЭТОГО СОЗДАЕТСЯ НАГЛЯДНЫЙ КАРЬЕРИЗМ И ШКУРНИЧЕСТВО, А ИМЕННО ПОЕЗДКИ НА СОБРАНИЯ НА ЛОШАДЯХ, ХОТЯ ЭТО ОЧЕНЬ НЕДАЛЕКО, И ВООБЩЕ НИ ШАГУ [...] НИКОГДА НЕ ВЫСТУПАЮТ НИ ПО КАКОМУ ВОПРОСУ. ${ }^{41}$

ДИСЦИПЛИНА ОБЫЧНОГО ПРАВА И РОДА ОБРАЩАЛАСЬ К ТЕМ ВЫДВИЖЕНЦАМНАЦИОНАЛАМ, КОТОРЫЕ СУМЕЛИ ВПИСАТЬСЯ В НОВЫЕ ПРАВИЛА ИГРЫ (БЕЗОГОВОРОЧНОЕ ПРИЗНАНИЕ КЛАССОВОЙ БОРЬБЫ КАК СТЕРЖНЯ ИСТОРИЧЕСКОГО ПРОГРЕССА, ДЕКЛАРАТИВНАЯ ПРИВЕРЖЕННОСТЬ ОФИЦИАЛЬНОЙ ИДЕОЛОГИИ, ПОДЧИНЕНИЕ ПАРТИЙНОЙ ИЕРАРХИИ, ИСПОЛНИТЕЛЬСКАЯ ДИСЦИПЛИНА, ПУБЛИЧНЫЙ ОТКАЗ ОТ ТРАДИЦИОННЫХ СОЦИАЛЬНО-КУЛЬТУРНЫХ И ДУХОВНЫХ ПРАКТИК) И ОБРЕСТИ НЕКИЙ АДМИНИСТРАТИВНЫЙ И НЕФОРМАЛЬНЫЙ РЕСУРС В ПАРТИЙНО-СОВЕТСКООБЩЕСТВЕННЫХ СЕТЯХ. ДЕЛЕГИРОВАНИЕ ПОЛНОМОЧИЙ ПО ЗАЩИТЕ ИЛИ ПРЕДСТАВЛЕНИЮ ИНТЕРЕСОВ МЕЖ ТЕМ ПРОИСХОДИЛО ПО ОБЫЧНОЙ СХЕМЕ, ХОТЯ ВНЕШНЕ ОНА ИМЕЛА ИНЫЕ ФОРМЫ.

КАЖДЫЙ ОТВЕТРАБОТНИК НА БОЛЬШИНСТВЕ УРОВНЕЙ СИСТЕМЫ УПРАВЛЕНИЯ В СИЛУ ОСТРОГО ДЕФИЦИТА КАДРОВ СОВМЕЩАЛ, КАК ПРАВИЛО, НЕСКОЛЬКО ДОЛЖНОСТЕЙ. НАРЯДУ С КОЛОССАЛЬНОЙ ФИЗИЧЕСКОЙ И УМСТВЕННОЙ НАГРУЗКОЙ, ХРОНИЧЕСКОЙ УСТАЛОСТЬЮ, ПСИХОЛОГИЧЕСКОЕ ДАВЛЕНИЕ НЕ МОГЛО НЕ СКАЗЫВАТЬСЯ НА ИХ ПОВЕДЕНИИ И НАСТРОЕНИЯХ. ЗА 1924 ГОД ЧИСЛО СЛУЖАЩИХ В ГОСАППАРАТЕ БЫЛО СОКРАЩЕНО НА 21 \% И СОСТАВЛЯЛО 31 341, ЗАРПЛАТА ПО ГОСБЮДЖЕТУ ПОДНЯЛАСЬ С 18 ДО 22 РУБ., ПО МЕСТНОМУ БЮДЖЕТУ - С 13 ДО 22 РУБ. ${ }^{42}$ ПОВЫШЕНИЕ КВАЛИФИКАЦИИ ИЛИ МОБИЛИЗАЦИЯ БОЛЕЕ ИЛИ МЕНЕЕ ПОДГОТОВЛЕННЫХ КАДРОВ НЕ ОЗНАЧАЛИ УСТОЙЧИВОЕ ЗАКРЕПЛЕНИЕ НА МЕСТАХ. ТАК, ДО КАМПАНИИ ПО МОБИЛИЗАЦИИ СЕКРЕТАРИ РАЙКОМОВ ПАРТИИ ПОЛУЧАЛИ 160 РУБ. В МЕСЯЦ, А ПОСЛЕ НЕЕ - 75, И МНОГИЕ СТРЕМИЛИСЬ ВЕРНУТЬСЯ В ГОРОДА К ПРЕЖНЕЙ РАБОТЕ И УРОВНЮ ЖИЗНИ. НАПРАВЛЕННЫЕ ПО РАЗНАРЯДКЕ ИЗ ЦЕНТРА 150 ЧЕЛ., НЕСМОТРЯ НА ДИРЕКТИВЫ, РАСПРЕДЕЛЯЛИСЬ НЕ ТОЛЬКО НА ПАРТРАБОТУ: 41,3\% ОКАЗАЛИСЬ НА СОВЕТСКОАДМИНИСТРАТИВНОЙ, КООПЕРАТИВНОЙ И ПР., ВПЛОТЬ ДО БИРЖ ТРУДА И ИНСПЕКТОРОВ КОМХОЗОВ. РЕШАЮЩУЮ РОЛЬ ИГРАЛИ ПЛОХИЕ МАТЕРИАЛЬНО-БЫТОВЫЕ УСЛОВИЯ, СТРЕМЛЕНИЕ ВЛАСТЕЙ ОБЕСПЕЧИТЬ КАДРАМИ САМЫЕ СЛАБЫЕ ОБЛАСТИ УПРАВЛЕНИЯ ${ }^{43}$. В ИТОГЕ ПОЛУЧИЛИ РАСПРОСТРАНЕНИЕ Т.Н. « БОЛЕЗНЕННЫЕ ЯВЛЕНИЯ». ПРИВЕДЕМ ДАННЫЕ СЫР-ДАРЬИНСКОЙ КОНТРОЛЬНОЙ КОМИССИИ ГУБКОМА ПАРТИИ. 
Таблица 6. Привлеченные к ответственности коммунисты Сыр-Дарьинской губернии за майоктябрь 1926 г. $^{44}$

\begin{tabular}{|l|l|l|l|l|}
\hline & КАЗАХОВ & ЕВРОПЕЙЦЕВ & УЗБЕКОВ & ПРОчИХ \\
\hline ЗА ПЬЯНСТВО & 8 & 34 & 1 & 1 \\
\hline НАРУШЕНИЕ ПАРТ ДИСЦИПЛИНЫ & 15 & 28 & 2 & 1 \\
\hline ПРЕСТУПЛЕНИЕ ПО ДОЛЖНОСТИ & 10 & 12 & 3 & - \\
\hline ХАЛАТНОСТЬ & 5 & 4 & - & - \\
\hline РАСТРАТА & 2 & 3 & 1 & - \\
\hline чУЖДЫЙ ЭЛЕМЕНТ & 2 & 3 & 1 & - \\
\hline ГРУППИРОВКИ & 5 & - & - & - \\
\hline РЕЛИГИОЗНЫЕ ОБРЯДЫ & - & 5 & - & - \\
\hline ПО СУДУ & 10 & 1 & $11(1,3 \%)$ & $2(0,6 \%)$ \\
\hline РАЗНОЕ & $39(1,7 \%)$ & $96(4,1 \%)$ & - \\
\hline ИТОГО & 1 & 5 & - & - \\
\hline
\end{tabular}

\section{Попытки « освежения руководства» : тактика « европейцев»}

ИТАК, СУБЭТНИЧЕСКИЕ СЕТИ НЕ МОГЛИ БЫТЬ ИСКОРЕНЕНЫ ПРОСТЫМ УЧРЕЖДЕНИЕМ НОВЫХ ОРГАНОВ ВЛАСТИ, БОЛЕЕ ТОГО - САМ ПРОЦЕСС ИХ СОЗДАНИЯ СОПРОВОЖДАЛСЯ ИСПОЛЬЗОВАНИЕМ ТРАДИЦИОННЫХ ИНСТРУМЕНТОВ УПРАВЛЕНИЯ. НАЦИОНАЛЫ ПРИБЕГАЛИ К НИМ ДЛЯ УПРОЧЕНИЯ ВЛАСТНЫХ ПОЗИЦИЙ. СТАВШИЕ ПЕРМАНЕНТНЫМИ КОНФЛИКТЫ В РУКОВОДСТВЕ КАССР РАСПРОСТРАНЯЛИСЬ ПО ЭТИМ СЕТЯМ, ЧТО ЗАСТАВЛЯЛО ЦЕНТР И ЕГО НАЗНАЧЕНЦЕВ НЕ ТОЛЬКО БОРОТЬСЯ С ПРОЯВЛЕНИЯМИ « ОТСТАЛОСТИ», НО И ПРИСПОСАБЛИВАТЬСЯ К РЕАЛЬНОСТИ. ОНИ ОКАЗАЛИСЬ ВТЯНУТЫ В ГРУППИРОВОЧНУЮ БОРЬБУ КАЗАХОВ, КОТОРЫХ ВРЯД ЛИ ВОСПРИНИМАЛИ КАК КОНКУРЕНТОВ, ПОСКОЛЬКУ ИЗНАЧАЛЬНО ИМЕЛИ ВЛАСТЬ И СЧИТАЛИСЬ ПРОФЕССИОНАЛАМИ. ОДНИ ИЗ «ЕВРОПЕЙЦЕВ» ДЕЙСТВОВАЛИ КАК «СТАРШИЕ ТОВАРИЩИ», ПЫТАЯСЬ КОНСОЛИДИРОВАТЬ НАЦИОНАЛОВ ПУТЕМ ИСКЛЮЧЕНИЯ СУБЪЕКТИВНЫХ МОТИВОВ (РАДУС-ЗЕНЬКОВИЧ, ПЕСТКОВСКИЙ, НАНЕЙШВИЛИ). ДРУГИЕ (КОРОСТЕЛЕВ, ЕЖОВ, ГОЛОЩЕКИН) СКЛОНЯЛИСЬ К МАНИПУЛИРОВАНИЮ КОНКУРИРУЮЩИМИ ГРУППАМИ, ОПРАВДЫВАЯСЬ ИДЕОЛОГИЧЕСКИМИ ДИРЕКТИВАМИ, С ПОСЛЕДУЮЩИМ УСТРАНЕНИЕМ НЕПОКОРНЫХ. ПОВОДАМИ СЛУЖИЛИ «ГРЕХИ» СОТРУДНИЧЕСТВА С АНТИБОЛЬШЕВИСТСКИМИ СИЛАМИ ИЛИ « НЕСВОЕВРЕМЕННОЕ» ПРИЗНАНИЕ СОВЕТСКОЙ ВЛАСТИ, СЫГРАЛИ РОЛЬ ПОДОЗРИТЕЛЬНОСТЬ ЕВРОПЕЙЦЕВ» И 
МЕСТНЫХ РАБОТНИКОВ ДРУГ К ДРУГУ В УКЛОНЕНИЯХ К ШОВИНИЗМУ (« КОЛОНИЗАТОРСТВО») ИЛИ НАЦИОНАЛИЗМУ, ЛИЧНЫЕ АМБИЦИИ, БЕСКОНЕЧНЫЕ ПЕРЕГРУППИРОВКИ ОДНИХ И ТЕХ ЖЕ ЛИЦ, ИНТРИГИ И ОБИДЫ. ПРИ ЭТОМ ОППОЗИЦИЯ «ЕВРОПЕЙЦЕВ-КОЛОНИЗАТОРОВ» И КАЗАХОВ-НАЦИОНАЛИСТОВ БЫЛА ПРИНЯТА ПРАКТИЧЕСКИ ВСЕМИ ИЗНАЧАЛЬНО КАК ИСТОРИЧЕСКАЯ ДАННОСТЬ, КОТОРУЮ СЛЕДОВАЛО ПРЕОДОЛЕТЬ. ДОПОЛНИТЕЛЬНУЮ НАПРЯЖЕННОСТЬ ВНОСИЛ БДИТЕЛЬНЫЙ ВНУТРИПАРТИЙНЫЙ КОНТРОЛЬ ЗА ЧИСТОТОЙ РЯДОВ СВОИХ АДЕПТОВ. В 1919 И 1920 ГГ. В СВЯЗИ С ВВЕДЕНИЕМ ЕДИНОГО ОБРАЗЦА ПАРТБИЛЕТА ПРОШЛА ПЕРЕРЕГИСТРАЦИЯ КОММУНИСТОВ. С АВГУСТА 1921 ПО ФЕВРАЛЬ 1922 Г. ШЛА ЧИСТКА РЯДОВ ПАРТИИ, И К СЕНТЯБРЮ ЦКК ИСКЛЮЧИЛА ИЗ РКП(Б) МУРЗАГАЛИЕВА КАК БЫВШЕГО ЧИНОВНИКА И ЧЛЕНА ОБЛУПРАВЫ АЛАШ-ОРДЫ, А ОБЛАСТНАЯ КК - АРГАНЧЕЕВА ЗА «СВЯЗЬ С НЕКОТОРЫМИ ЧЛЕНАМИ АЛАШ-ОРДЫ» ${ }^{45}$. ВЕСНОЙ НАЧАЛАСЬ ВСЕРОССИЙСКАЯ ПАРТПЕРЕПИСЬ С ОБМЕНОМ ДОКУМЕНТОВ, В 19221924 ГГ. КОНТРОЛЬНЫЕ КОМИССИИ ПАРТКОМОВ КАССР ВЫНЕСЛИ РЕШЕНИЯ ОБ ОЧИЩЕНИИ ОТ 1512 ЧЕЛ., «НЕ ОПРАВДАВШИХ ДОВЕРИЯ». В 1925 Г. СОСТОЯЛАСЬ ПРОВЕРКА НЕПРОИЗВОДСТВЕННЫХ ПАРТЯЧЕЕК, В 1925-1926 - ВЫБОРОЧНАЯ ПРОВЕРКА АУЛЬНОСЕЛЬСКИХ, В 1927 - НОВОЕ ИСПЫТАНИЕ ВСЕСОЮЗНОЙ ПАРТПЕРЕПИСЬЮ, А ЛЕТОМ 1929 Г. ПО РЕШЕНИЮ ХVI КОНФЕРЕНЦИИ ВКП(Б) НАЧАЛАСЬ ГЕНЕРАЛЬНАЯ ЧИСТКА. ВСЕ ЭТИ АКЦИИ В Т.Ч. ПРОВОЦИРОВАЛИ КОНФЛИКТЫ, СТРЕМЛЕНИЕ ИСПОЛЬЗОВАТЬ СПУЩЕННЫЕ СВЕРХУ МЕХАНИЗМЫ В БОРЬБЕ АМБИЦИЙ И ДЛЯ УДОВЛЕТВОРЕНИЯ КАРЬЕРНЫХ ЦЕЛЕЙ ПУТЕМ УСТРАНЕНИЯ СОПЕРНИКОВ. ДОСТАТОЧНО АКТИВНО ИСПОЛЬЗОВАЛИСЬ ЧАСТЫЕ РОТАЦИИ РАБОТНИКОВ ИЗ РЕГИОНА В РЕГИОН ПОД ВСЕВОЗМОЖНЫМИ БЛАГОВИДНЫМИ ПРЕДЛОГАМИ (НЕ МЕНЕЕ ЧАСТЫЕ АДМИНИСТРАТИВНО-ТЕРРИТОРИАЛЬНЫЕ ПЕРЕКРОЙКИ ТОЖЕ ДАВАЛИ ПОВОД ДЛЯ ЭТОГО), ЧТО ПОЗВОЛЯЛО ОТСТРАНИТЬ ОТ КЛЮЧЕВЫХ ПОСТОВ НЕУГОДНЫХ И ВЫДВИНУТЬ СТОРОННИКОВ. ОПРЕДЕЛЕННУЮ РОЛЬ В ЭТИХ ПЕРЕТРЯСКАХ ИГРАЛИ РОДСТВЕННЫЕ И КЛАНОВЫЕ СВЯЗИ ${ }^{46}$.

НАРЯДУ С МНОЖЕСТВОМ ДЕЙСТВИТЕЛЬНО СЛОЖНЫХ И ОСТРЫХ ЗАДАЧ, КОТОРЫЕ ПРИХОДИЛОСЬ РЕШАТЬ ПРИЗВАННЫМ В РЯДЫ УПРАВЛЕНЦЕВ ВСЕХ УРОВНЕЙ, МАЛО ПРЕДСКАЗУЕМАЯ СИТУАЦИЯ ТРЕБОВАЛА ОГРОМНЫХ УСИЛИЙ ДЛЯ ТЩАТЕЛЬНОГО АНАЛИЗА БЫСТРО МЕНЯЮЩЕЙСЯ КОНЪЮНКТУРЫ, УМЕНИЯ ГИБКО И ОПЕРАТИВНО ПЕРЕСТРАИВАТЬСЯ НА ХОДУ, В Т.Ч. В ОТНОШЕНИЯХ С КОЛЛЕГАМИ, ТАКЖЕ РИСКОВАВШИМИ ЛЕГКО ПОТЕРЯТЬ ДОЛЖНОСТЬ И ЧИН ИЛИ, НАОБОРОТ, РЕЗКО ПОДНЯТЬСЯ ПО ИЕРАРХИЧЕСКОЙ ЛЕСТНИЦЕ. ДАЖЕ ДЛЯ НЕ ЗАПЯТНАВШИХ СЕБЯ СОТРУДНИЧЕСТВОМ С « КЛАССОВЫМИ ВРАГАМИ» ВСЕ ЭТО БЫЛО СИЛЬНЫМ ИСПЫТАНИЕМ ВЫДЕРЖКИ, УМА И АДАПТИВНОСТИ. АЛАШОРДИНЦЫ НАХОДИЛИСЬ ЕЩЕ И ПОД ГНЕТОМ УЖЕ НЕИСПРАВИМОГО КРАМОЛЬНОГО ПРОШЛОГО. ВСЕМ ТРЕБОВАЛОСЬ ПОСТОЯННО ДОКАЗЫВАТЬ СВОЮ ЛОЯЛЬНОСТЬ ВЛАСТИ, ЧТО ЗАСТАВЛЯЛО НЕКОТОРЫХ ВООБЩЕ ОТКАЗЫВАТЬСЯ ОТ СОВЕТСКОЙ РАБОТЫ И ДАЖЕ ВЫХОДИТЬ ИЗ ПАРТИИ. НА РЯДОВОМ ПАРТИЙНО-СОВЕТСКОМ СОСТАВЕ ОТЗЫВАЛАСЬ И ОСТРАЯ ВНУТРИПАРТИЙНАЯ БОРЬБА С РАЗЛИЧНЫМИ « ОППОЗИЦИЯМИ» В ЦЕНТРЕ.

СРЕДИ ОСНОВНЫХ ЧЕРТ НАЗНАЧЕНЦЕВ МОСКВЫ ВЫДЕЛИМ ДОРЕВОЛЮЦИОННЫЙ ПАРТИЙНЫЙ СТАЖ И ОБРАЗОВАНИЕ, ПАРТИЙНУЮ ДИСЦИПЛИНИРОВАННОСТЬ И ПРЕДПОЧТЕНИЕ РЕВОЛЮЦИОННОЙ ЦЕЛЕСООБРАЗНОСТИ - ПРАВУ; ОРГАНИЗАТОРСКИЕ НАВЫКИ, ОПЫТ ПОЛИТИЧЕСКОЙ И ОБЩЕСТВЕННОЙ РАБОТЫ, ПРЕЖДЕ ВСЕГО НЕЛЕГАЛЬНОЙ И ВОЕННО-ПОЛИТИЧЕСКОЙ ; КОМАНДНО-БЮРОКРАТИЧЕСКИЙ СТИЛЬ ПРИ ОФИЦИАЛЬНОЙ 
ДЕКЛАРАЦИИ КОЛЛЕГИАЛЬНОСТИ, ПРИВЕРЖЕННОСТЬ ВЕРТИКАЛЬНОЙ ИЕРАРХИИ ОТНОШЕНИЙ. ОНИ БЫЛИ ГЛАВНЫМ ИНСТРУМЕНТОМ ПРЕОБРАЗОВАНИЙ И ОПОРОЙ ДЛЯ ВЛАСТИ. ИМЕЯ ДАВНИЕ И ЧАСТО НЕФОРМАЛЬНЫЕ СВЯЗИ С РУКОВОДСТВОМ И МНОГИМИ РАБОТНИКАМИ ЦЕНТРА, «ЕВРОПЕЙЦЫ» ПРИНИМАЛИ НЕПОСРЕДСТВЕННОЕ УЧАСТИЕ В СОЗДАНИИ НОВОЙ ПОЛИТИЧЕСКОЙ СИСТЕМЫ, НО ЗНАНИЕ МЕХАНИЗМОВ ДЕЯТЕЛЬНОСТИ ОРГАНОВ ВЛАСТИ И УПРАВЛЕНИЯ ИМЕЛИ МИНИМАЛЬНОЕ. ПО ЛИЧНОМУ ОПЫТУ И ЛИШЬ В КАЧЕСТВЕ ОБЪЕКТОВ КОНТРОЛЯ ИМ БЫЛА ЗНАКОМА ГЛАВНЫМ ОБРАЗОМ РАБОТА ДЕПАРТАМЕНТА ПОЛИЦИИ МВД РОССИЙСКОЙ ИМПЕРИИ. ОЧЕВИДНО, ПАМЯТЬ ОБ ЭТОМ КАРАТЕЛЬНОМ АППАРАТЕ ПОВЛИЯЛА НА ХАРАКТЕР ОРГАНИЗАЦИОННОЙ И АДМИНИСТРАТИВНОЙ ПРАКТИКИ БЫВШИХ НЕЛЕГАЛОВ. ИСКУССТВУ МЕНЕДЖМЕНТА, ТЕМ ПАЧЕ КРОСС-КУЛЬТУРНОГО, СОВЕТСКИХ УПРАВЛЕНЦЕВ НИКТО НЕ УЧИЛ, И ПОЛАГАЛИСЬ ОНИ ПОЧТИ ИСКЛЮЧИТЕЛЬНО НА УБЕЖДЕННОСТЬ В ИСТОРИЧЕСКОЙ ПРАВОТЕ МАРКСИЗМА И БОЛЬШЕВИЗМА, КЛАССОВЫЙ ПОДХОД К ОЦЕНКЕ ОБЩЕСТВЕННЫХ ЯВЛЕНИЙ И КАДРОВ, ИНТЕРНАЦИОНАЛИЗМ, А ТАКЖЕ НЕКИЙ БАГАЖ МЕЖЭТНИЧЕСКИХ КОММУНИКАЦИЙ, КОТОРЫЙ, СУДЯ ПО ИХ БИОГРАФИЯМ, БЫЛ НЕБОГАТ.

НАПРАВЛЕНИЕ НА ОКРАИНЫ МНОГИЕ ВОСПРИНИМАЛИ БЕЗ ЭНТУЗИАЗМА, ДАЛЕКО НЕ ВСЕГДА СПРАВЛЯЯСЬ С ЗАДАНИЕМ ЦЕНТРА ${ }^{47}$. НЕЗНАНИЕ ХОЗЯЙСТВЕННОЙ И СОЦИАЛЬНОЙ СПЕЦИФИКИ, КУЛЬТУРЫ КАЗАХСКОГО ОБЩЕСТВА ПОРОЖДАЛИ ПОДОЗРИТЕЛЬНОСТЬ И НЕДОВЕРИЕ К НАЦИОНАЛАМ, СОЧЕТАВШИЕСЯ С МАНИПУЛИРОВАНИЕМ КОРЫСТНЫМИ ИНТЕРЕСАМИ ИХ ПРЕДСТАВИТЕЛЕЙ И РИСКОМ СТАТЬ МАРИОНЕТКОЙ В ИХ РУКАХ, СТРЕМЛЕНИЕМ ВЫДЕЛИТЬ И ПОДДЕРЖАТЬ ТУ ЧАСТЬ НАЦИОНАЛОВ, К КОТОРЫМ ИСПЫТЫВАЛИ ДОВЕРИЕ ${ }^{48}$. УЖЕ В 1919 Г. С. ПЕСТКОВСКИЙ ОБНАРУЖИЛ ЭТИ ОПАСНОСТИ И ПИСАЛ В ЦК И ЛЕНИНУ О ПОЛИТИЧЕСКОМ КАРЬЕРИЗМЕ И ЖУЛЬНИЧЕСТВЕ ТРЕХ ГРУПП КАЗАХОВ В КИРВРК (БАЙТУРСЫНОВ-ТУНГАНЧИН, ДЖАНГИЛЬДИН-КАРАТАЕВ, МЕНДЕШЕВ) : « ИНОГДА СЛУЧАЕТСЯ, ЧТО Я ДОЛЖЕН ЗАЩИЩАТЬ НАЦИОНАЛЬНЫЕ ПРАВА КИРГИЗ ПРОТИВ НИХ [...]». К ТОМУ ЖЕ « С БОЛЬШИМ ТРУДОМ УДАЕТСЯ МНЕ ПРОВОДИТЬ ИНОГДА ТАКИЕ КОМПРОМИССНЫЕ РЕШЕНИЯ, КОТОРЫЕ, ПО КРАЙНЕЙ МЕРЕ, НЕ ВРЕДНЫ» ${ }^{49}$. ЗАКРЫТЫЕ ПИСЬМА В МОСКВУ ХОРОШО ОТРАЖАЮТ, КАК НАЗНАЧЕНЦЫ ПОНИМАЛИ РОЛЬ СВОИХ КОЛЛЕГ, РАССТАНОВКУ СИЛ ВНУТРИ КАЗАХСКОЙ ЧАСТИ РУКОВОДСТВА КАССР И ИХ СОРАТНИКОВ В ГУБЕРНИЯХ, ПОЛИТИЧЕСКУЮ КУЛЬТУРУ И НАСТРОЕНИЯ САМИХ АВТОРОВ, СЛУЖИВШИХ ДЛЯ ЦЕНТРА ГЛАВНЫМИ ЭКСПЕРТАМИ ПО СИТУАЦИИ НА МЕСТАХ ${ }^{50}$. ТАК, КОРОСТЕЛЕВ В ПИСЬМЕ СТАЛИНУ НАЗЫВАЛ «РАЗВРАЩАЮЩЕЙ» ЛИНИЮ РАДУСЗЕНЬКОВИЧА, «СУМЕВШЕГО ОБЪЕДИНИТЬ ВСЕХ КИРГИЗ», ЧТО ПРИВЕЛО К УСИЛЕНИЮ ВЛИЯНИЯ ЛИДЕРА АЛАШ «СТАРИКА БУКЕЙХАНОВА» НА МАЛООПЫТНУЮ И МАЛОУСТОЙЧИВУЮ МОЛОДЕЖЬ, И БОРЬБА С «РАЗЛАГАЮЩИМ ЯВЛЕНИЕМ» ВЫГЛЯДЕЛА БЫ ТЕПЕРЬ 《ЯВНЫМ КОЛОНИЗАТОРСТВОМ». ПРИ УТВЕРЖДЕНИИ ПРЕДСТАВИТЕЛЕЙ ЦЕНТРА ОТКРЫТЫХ ВОЗРАЖЕНИЙ НАЦИОНАЛОВ НЕ БЫЛО, НО «ПРЯМАЯ БОЯЗНЬ ЛИЦ ПОТЕРЯТЬ ВЫСОКИЕ ПОСТЫ И ВИДЕТЬ ВЕЗДЕ И ВСЮДУ СЕБЕ КОНКУРЕНТОВ» РОЖДАЛА ОБРАЩЕНИЯ В ЦК ОБ ОТЗЫВЕ « ЕВРОПЕЙЦЕВ». НЕ ЖЕЛАЯ « СКУЛИТЬ», КОРОСТЕЛЕВ ВСЕ ЖЕ ПРОСИЛ « ТОВАРИЩА ИОСИФА» ОТОЗВАТЬ В МОСКВУ БУКЕЙХАНОВА, «КАК ЧЕЛОВЕКА БЕЗУСЛОВНО ВРЕДНОГО», А ЗАОДНО ОТПРАВИТЬ ТУДА ЖЕ УЧИТЬСЯ И САДВОКАСОВА, СТРАДАВШЕГО «МЕЛКОБУРЖУАЗНОЙ ПСИХОЛОГИЕЙ». ОН ПРЕДЛАГАЛ ПРОТИВОПОСТАВЛЯТЬ ГРУППЫ НАЦИОНАЛОВ, ДАБЫ ЗАСТАВИТЬ ИХ «ПОДТЯНУТЬСЯ», ТЕМ БОЛЕЕ ЧТО ПРИВЛЕЧЬ БЕДНОТУ КАК КЛАССОВО ВЫДЕРЖАННЫЙ ЭЛЕМЕНТ НЕ ПОЛУЧАЛОСь ${ }^{51}$. 


$$
\begin{array}{lllllr}
\text { СРЕДИ РУКОВОДИТЕЛЕЙ } & \text { КАССР } & 2 \text { МАРТА } & \text { 1922 Г. ОПИСАЛ } & \text { СТАЛИНУ } & \text { НАИБОЛЕЕ } \\
\text { ПОСЛЕДОВАТЕЛЬНЫЙ } & \text { СТОРОННИК ЛИНИИ } & \text { ЦЕНТРА } & \text { МЕНДЕШЕВ. } & \text { ПРИЕЗД } \\
\text { УПОЛНОМОЧЕННОГО ЦК В.Г. ЮДОВСКОГО } & & &
\end{array}
$$

СОВПАЛ С КРАЙНЕ НЕБЛАГОПРИЯТНЫМ МОМЕНТОМ, КОГДА НАЦИОНАЛИСТИЧЕСКИШОВИНИСТИЧЕСКИЕ ГРУППЫ КИРГИЗ, В ТОМ ЧИСЛЕ МНОГИЕ ПАРТИЙНЫЕ, ВРОДЕ АУЭЗОВЫХ, НАХИМЖАНОВ, БАЙДИЛЬДИНЫХ, [...] ОПРЕДЕЛЕННО СТАЛИ ПОДНИМАТЬ ГОЛОВЫ И ПРЕДЪЯВЛЯТЬ ДЛЯ СВОЕЙ РАБОТЫ ТАКИЕ УСЛОВИЯ, КОТОРЫЕ ПОВЕЛИ БЫ К ПОЛНОМУ РАСКАССИРОВАНИЮ ДЕЙСТВИТЕЛЬНО ПОДЛИННЫХ ПРЕДСТАВИТЕЛЕЙ ТРУДЯЩИХСЯ КИРГИЗ. ОНИ ВЫДВИНУЛИ КОМИССИЮ ИЗ КИРГИЗ, КОТОРАЯ БУДЕТ РАСПРЕДЕЛЯТЬ КИРРАБОТНИКОВ, ДУМАЯ ТАКИМ ПУТЕМ СОЗДАТЬ ОБОСОБЛЕННУЮ ГРУППУ ПОД СВОИМ ВЛИЯНИЕМ И ПОВЕСТИ К ДАЛЬНЕЙШЕМУ ОТРЫВУ КИРГИЗ ОТ ПАРТИИ. Я ВСТАЛ ПРОТИВ ТАКОЙ ГРУППИРОВКИ. Т. ЮДОВСКИЙ ПРИСОЕДИНИЛСЯ К ЭТОЙ ГРУППЕ, КОТОРАЯ [...] ПОВЕЛА РЕШИТЕЛЬНОЕ НАСТУПЛЕНИЕ НА КОММУНИСТОВ-КИРГИЗ, [...] НАЗЫВАЯ ИХ СПЛОШЬ КОЛОНИЗАТОРАМИ. [...] ПОД ВЛИЯНИЕМ НАШИХ НАЦИОНАЛКОММУНИСТОВ ОН СТРЕМИТСЯ ПОСТАВИТЬ КИРГИЗСКОЕ НАСЕЛЕНИЕ ПРОТИВ РУССКОГО НАСЕЛЕНИЯ, [...] ТОВ. МУРЗАГАЛИЕВ, КОТОРОГО Я ОЧЕНЬ ЛЮБИЛ ЗА ЕГО ЭНЕРГИЧНОСТЬ, ОКАЗАЛСЯ ОЧЕНЬ БОЛЬШИМ ИНТРИГАНОМ. [...] ОН ПРИСТАЛ ТОЖЕ К НАЦИОНАЛИСТАМ И ПЛЯШЕТ СЕЙЧАС ПОД ИХ ДУДКУ. ${ }^{53}$

КУЛЬТУРА КОЧЕВОЙ ОБЩИНЫ ЗА ПРЕДЕЛАМИ ПРЕЖНЕГО ПРОСТРАНСТВА РЕАЛИЗАЦИИ УСИЛИВАЛА КОНСОЛИДИРУЮЩУЮ ЛОЯЛЬНОСТЬ И РОЖДАЛА НОВЫЕ КОНФИГУРАЦИИ В ОТНОШЕНИЯХ С «ВНЕШНИМ» АКТОРОМ В ЛИЦЕ НАЗНАЧЕНЦЕВ. ИМ ЖЕ ОНА КАЗАЛАСЬ ПОСЛЕДНИМ РУДИМЕНТОМ ПРОШЛОГО, ПОДЛЕЖАЩИМ ИСКОРЕНЕНИЮ, НАЦИОНАЛЬНОЙ ФОРМОЙ ВНУТРИПАРТИЙНОЙ ОППОЗИЦИИ КУРСУ ЦК.

А. ЖИХАНОВ ПОДЧЕРКИВАЛ - В СОСТАВЕ ОБКОМА ПАРТИИ ЕДИНОДУШИЯ НЕТ, И ДАЛ ВЕСЬМА НЕЛИЦЕПРИЯТНЫЕ ХАРАКТЕРИСТИКИ ВСЕМ : КОРОСТЕЛЕВ « ЧЕЛОВЕК ХОРОШИЙ, НО ДЛЯ ОБКОМА СЛАБОВАТ», АСЫЛБЕКОВ, « КАК И ВСЕ КИРГИЗЫ, ЛЕНИВЫЙ, СКРЫТНЫЙ», НО « КАЖЕТСЯ, ЧТО ЛУЧШЕ МНОГИХ ДРУГИХ». ЮДОВСКИЙ « ВЕДЕТ СЕБЯ КРУТО, НАЧАЛ ГРУППИРОВАТЬ БОЛЕЕ НАЦИОНАЛИСТИЧЕСКИ НАСТРОЕННЫХ КИРГИЗ», МУРЗАГАЛИЕВ «ПРЕДСОВНАРКОМА - ЛЕНИВ, ПЬЕТ И ТУПОЙ, ПО МОЕМУ МНЕНИЮ. Т. АУЭЗОВ СЕКРЕТАРЬ КЦИКА, Т. БАЙДИЛЬДИН, Т. САДВОКАСОВ - РЕБЯТА МОЛОДЫЕ, РАЗВИТЫЕ, НО НАХОДЯТСЯ ПОД ВЛИЯНИЕМ СТАРИКА БУКЕЙХАНОВА, ЯРОГО “АЛАШ-ОРДЫНА”, И ЕЩЕ НЕ УСТОЯВШИЕСЯ ПОЛИТИЧЕСКИ И К СЕРЬЕЗНОЙ ПОВСЕДНЕВНОЙ РАБОТЕ, ПО-МОЕМУ, МАЛО ПОДГОТОВЛЕНЫ». ЛИШЬ МЕНДЕШЕВ ОТМЕЧЕН КАК «ОДИН ИЗ ЛУЧШИХ РАБОТНИКОВ. МНОГО РАБОТАЕТ, ТОЛКОВО РАЗБИРАЕТСЯ ВО ВСЕХ ВОПРОСАХ, НЕ ПОПАДАЕТ ПОД ВЛИЯНИЕ ДРУГИХ И ВООБЩЕ ЦЕННЫЙ РАБОТНИК ${ }^{54}$. В ИТОГЕ ИЗ ЭТОЙ РАЗНОГОЛОСИЦЫ ОЦЕНОК ЯСНО БЫЛО, ПО КРАЙНЕЙ МЕРЕ, ТО, ЧТО СОЛИДАРНО ДЕЙСТВУЮЩЕГО СОСТАВА РУКОВОДИТЕЛЕЙ В МОЛОДОЙ РЕСПУБЛИКЕ НЕТ, КАЖДЫЙ ПОНИМАЕТ СЛОЖНОСТЬ ПОЛОЖЕНИЯ, НО ПЫТАЕТСЯ ПРЕДСТАВИТЬ В ЛУЧШЕМ СВЕТЕ САМОГО СЕБЯ. ПОЛОЖИТЕЛЬНО ОХАРАКТЕРИЗОВАННЫЕ РЫСКУЛОВЫМ ${ }^{55}$ АУЭЗОВ И САДВОКАСОВ НЕ БЕЗ ОСНОВАНИЙ МОГЛИ ПОДОЗРЕВАТЬСЯ В СОЧУВСТВИИ ИДЕЯМ АЛАШ ${ }^{56}$, МУРЗАГАЛИЕВ И БАЙДИЛЬДИН ВЫГЛЯДЕЛИ МЕЧУЩИМИСЯ МЕЖДУ РАЗНЫМИ СИЛАМИ ПРИТЯЖЕНИЯ, А МЕНДЕШЕВ И КОРОСТЕЛЕВ - НЕ СПОСОБНЫМИ ОБУЗДАТЬ АМБИЦИИ ТОВАРИЩЕЙ И ПРЕДОТВРАТИТЬ ОБОСТРЕНИЕ ОТНОШЕНИЙ. ЦЕНТРУ, НАЦЕЛЕННОМУ НА УЛУЧШЕНИЕ УПРАВЛЯЕМОСТИ РЕГИОНА, ПРИШЛОСЬ ВМЕШАТЬСЯ В СИТУАЦИЮ. 5 АПРЕЛЯ СЕКРЕТАРИАТ ЦК РКП(Б) НА ОСНОВЕ ПОСТУПИВШЕГО 
МОЛОТОВУ ПИСЬМА ОТВЕТРАБОТНИКОВ КАССР (МУРЗАГАЛИЕВ, АУЭЗОВ, АЛМАНОВ, АРГАНЧЕЕВ, КЕНЖИН И ДР.) РАССМОТРЕЛ «КИРГИЗСКИЕ ДЕЛА», РЕШИВ СОЗДАТЬ В РЕСПУБЛИКЕ БЮРО ЦК С ПРАВОМ ПРИОСТАНОВКИ РЕШЕНИЙ КИРОБКОМА. В НЕГО ВОШЛИ ЮДОВСКИЙ, ВАЙНШТЕЙН И МЕНДЕШЕВ, КОТОРЫЙ В ЦЕНТРЕ ВОСПРИНИМАЛСЯ НАИБОЛЕЕ НАДЕЖНЫМ СРЕДИ НАЦИОНАЛОВ ${ }^{57}$. 12 МАЯ ПО ДОКЛАДУ И.В. СТАЛИНА СЕКРЕТАРИАТ ПРИНЯЛ К СВЕДЕНИЮ ПИСЬМО МЕНДЕШЕВА, 23 МАЯ УТВЕРДИЛ ЦИРКУЛЯР, КОНСТАТИРОВАВ ИЗВРАЩЕНИЕ ОСНОВ НАЦИОНАЛЬНОЙ ПОЛИТИКИ И НЕПОНИМАНИЕ ПАРТОРГАНИЗАЦИЯМИ КАССР ЕЕ СВЯЗИ С НЭП. ВЗАИМНАЯ БОРЬБА Т.Н. « КОЛОНИЗАТОРОВ И НЕ МЕНЕЕ СИЛЬНОЙ ГРУППЫ НАЦИОНАЛИСТИЧЕСКИ НАСТРОЕННЫХ ЭЛЕМЕНТОВ», ГОВОРИЛОСЬ ДАЛЕЕ,

СПЛОШЬ И РЯДОМ ПРЕВРАЩАЕТСЯ В СКЛОКУ, МЕЛКИЕ ДРЯЗГИ И УВЛЕЧЕНИЯ БЕСПЛОДНЫМИ СПОРАМИ, МИТИНГОВЫМИ РАЗГОВОРАМИ, КОТОРЫЕ ОТВЛЕКАЮТ [... ] КАК ОТ НЕПОСРЕДСТВЕННОЙ РАБОТЫ ПО УКРЕПЛЕНИЮ ПАРТИЙНЫХ ОРГАНИЗАЦИЙ, ТАК И ОТ РУКОВОДСТВА АДМИНИСТРАТИВНО-ХОЗЯЙСТВЕННОЙ РАБОТОЙ.

ПАРТОРГАНИЗАЦИИ, ГДЕ ОТМЕЧАЛИСЬ ПАССИВНОСТЬ И УПАДОЧНОЕ НАСТРОЕНИЕ (А В СОВЕТСКОЙ РАБОТЕ ЗАСТОЙ), ОБЯЗЫВАЛИСЬ « ОТКАЗАТЬСЯ ОТ МЕЛОЧНЫХ СПОРОВ И СКЛОКИ И СОСРЕДОТОЧИТЬ СИЛЫ НА ДЕЛОВОЙ ПРАКТИЧЕСКОЙ РАБОТЕ ${ }^{58}$. В НОЯБРЕ ОРГБЮРО ЦК РКП(Б) ПО РЕЗУЛЬТАТАМ ОБСЛЕДОВАНИЯ ПАРТОРГАНИЗАЦИЙ ПРИЗНАЛО НЕОБХОДИМЫМ СОХРАНИТЬ КИРБЮРО КАК ПРЕДСТАВИТЕЛЬСТВО ЦК И ОТМЕТИЛО СЛАБОСТЬ РАБОТЫ КИРБОКОМА. ДЛЯ ПОПРАВКИ ДЕЛ В РАСПОРЯЖЕНИЕ КИРБЮРО УЧРАСПРЕД ЦК КОМАНДИРОВАЛ 5 НОВЫХ ГУБЕРНСКИХ РАБОТНИКОВ ${ }^{59}$.

41 В СЕНТЯБРЕ МЕЖДУ ЛЕНИНЫМ И СТАЛИНЫМ ВОЗНИКЛИ ПРИНЦИПИАЛЬНЫЕ РАЗНОГЛАСИЯ В ВОПРОСЕ О ФОРМЕ ОТНОШЕНИЙ ЦЕНТРА $С$ НЕЗАВИСИМЫМИ РЕСПУБЛИКАМИ, КОГДА СТАЛИН ПРЕДЛОЖИЛ РАЗЪЯСНИТЬ МОЛОДОМУ ПОКОЛЕНИЮ КОММУНИСТОВ НА ОКРАИНАХ, ЧТО ЗАЯВЛЕНИЯ О НЕЗАВИСИМОСТИ - ЛИШЬ ИГРА ${ }^{60}$. ПОЖАЛУЙ, В ЭТОМ КОНТЕКСТЕ ИДЕЯ РЫСКУЛОВА О РОСПУСКЕ КАССР ЛИШЬ ПОДКРЕПЛЯЛА УБЕЖДЕННОСТЬ СТАЛИНА В СВОЕЙ ПРАВОТЕ. ТЕМ ВРЕМЕНЕМ КРЕПНУЩАЯ БОРЬБА ПРОТИВ Т.Н. ПРОЯВЛЕНИЙ ВЕЛИКОДЕРЖАВНОГО ШОВИНИЗМА И МЕСТНОГО НАЦИОНАЛИЗМА ПРИОБРЕТАЛА БОЛЕЗНЕННЫЙ И ЗАТЯЖНОЙ ХАРАКТЕР, ТРАНСФОРМИРОВАЛАСЬ В ПРОВОЦИРОВАНИЕ ГРУППОВЫХ КОНФЛИКТОВ ВНУТРИ ЭТНОЭЛИТ, КОТОРЫЕ УМЕЛО ИСПОЛЬЗОВАЛИСЬ В ИНТЕРЕСАХ УКРЕПЛЕНИЯ ВЛАСТИ НОМЕНКЛАТУРЫ. САМИ НАЦИОНАЛЫ, СТАВ ЕЕ ЧАСТЬЮ, ВНОСИЛИ В НИХ СУЩЕСТВЕННЫЙ ЭТНОКУЛЬТУРНЫЙ кОЛОРИТ.

42 « ЕВРОПЕЙЦЫ» С РАЗНЫМ УСПЕХОМ СТРЕМИЛИСЬ ПОВЛИЯТЬ НА БОРЬБУ ГРУППИРОВОК РЕГУЛЯРНЫЕ АНАЛИТИЧЕСКИЕ ВЫКЛАДКИ ПРЕДСТАВИТЕЛЕЙ ГПУ В КАССР О НАЦИОНАЛЬНЫХ ГРУППИРОВКАХ ${ }^{61}$ И ВЫВОДЫ ПАРТИЙНЫХ РУКОВОДИТЕЛЕЙ В ЦЕЛОМ СОГЛАСУЮТСЯ, НО ЖЕСТКАЯ ПРИВЯЗКА КОНКУРИРУЮЩИХ АЛЬЯНСОВ НАЦИОНАЛОВ К ТЕРРИТОРИЯМ И КЛАНАМ ОГРАНИЧИВАЛА ПОНИМАНИЕ НЮАНСОВ СУБКУЛЬТУРНОГО И ЛИЧНОСТНОГО СВОЙСТВА (МЕЖДУ МЕНДЕШЕВЫМ И СЕЙФУЛЛИНЫМ, В ЧАСТНОСТИ). ДУНАЕВ В МАЕ 1924 Г. ОТМЕЧАЛ: ПОД ВИДОМ БОРЬБЫ С ГРУППИРОВКАМИ МНОГИЕ НАЦИОНАЛЫ СВОДЯТ ТЕ ЖЕ ГРУППОВЫЕ СЧЕТЫ С НЕКОТОРЫМИ ОТВЕТСТВЕННЫМИ КРАЕВЫМИ РАБОТНИКАМИ, А ДРУГАЯ ЧАСТЬ ВОССТАВАВШИХ ПРОТИВ ГРУППИРОВОК В ЗНАЧИТЕЛЬНОЙ МЕРЕ НАХОДИЛАСЬ ПОД ВЛИЯНИЕМ ОТДЕЛЬНЫХ АВТОРИТЕТНЫХ РУССКИХ ТОВАРИЩЕЙ С МЕСТ». ОДНАКО, « КАЖДАЯ ГРУППИРОВКА ИМЕЕТ СВОЮ БОЛЕЕ ИЛИ МЕНЕЕ ОПРЕДЕЛЕННУЮ ИДЕОЛОГИЮ, КОТОРАЯ В КОНЕЧНОМ СЧЕТЕ ОТОБРАЖАЕТ 
ЭКОНОМИКУ, КУЛЬТУРНОЕ СОСТОЯНИЕ И ПОЛИТИЧЕСКОЕ ПРОШЛОЕ ВОСТОЧНОЙ И ЗАПАДНОЙ КИРГИЗИИ». ОН ПОДЧЕРКИВАЛ « БЕССОЗНАТЕЛЬНЫЙ» ХАРАКТЕР ОППОЗИЦИИ ВОСТОЧНЫХ ДЕЯТЕЛЕЙ «ЕВРОПЕЙСКОМУ» СОСТАВУ ОБКОМА, БАЗИРУЮЩЕЙСЯ НА ИХ ЭКОНОМИЧЕСКИХ И РОДОВЫХ ИНТЕРЕСАХ, ОПРЕДЕЛЯЮЩИХ НАЦИОНАЛИЗМ И ПОПЫТКИ ИЗМЕНИТЬ ОБЛАСТНОЕ ДЕЛЕНИЕ КАССР. НЕСМОТРЯ НА НЕКУЮ ХОЗЯЙСТВЕННУЮ ПОЛЬЗУ, ДУНАЕВ ОПАСАЛСЯ : ЭТО БУДЕТ РАВНОСИЛЬНО « ЗАКРЕПЛЕНИЮ РОДОВОГО, ВЕРНЕЕ БОЛЕЕ ШИРОКО ТЕРРИТОРИАЛЬНОГО ГРУППОВОГО АНТАГОНИЗМА», ВПЛОТЬ ДО СОЗДАНИЯ ТРЕХ АВТОНОМНЫХ КИРГИЗСКИХ РЕСПУБЛИК». ОЦЕНИВАЯ НЮАНСЫ ВНУТРИЭЛИТНЫХ ОТНОШЕНИЙ И ПОЛИТИЧЕСКИЙ ВЕС ОСНОВНЫХ СИЛ, ОН ВСЕ ЖЕ НЕ РЕШАЛСЯ ОСЛАБИТЬ ОДНУ ИЛИ РАЗГРОМИТЬ ДРУГУЮ, Т.К. НАДЕЖНЫЕ КАДРЫ ЕЩЕ СЛЕДОВАЛО НАЙТИ НА БОЛЕЕ НИЗКОМ И « МЕНЕЕ ОТВЕТСТВЕННОМ» УРОВНЕ, ОБУЧИТЬ, « ОЗДОРОВИТЬ», « ОРАБОЧИТЬ», НЕ ОСТАВЛЯЯ НАДЕЖДЫ И НА « ОСВЕЖЕНИЕ» РУКОВОДСТВА ИЗ ОБЕИХ ГРУППИРОВОК ${ }^{62}$.

К ТОМУ ЖЕ ОТМЕЧАЛОСЬ «СТРЕМЛЕНИЕ МОЛОДЕЖИ К ЗАХВАТУ ОТВЕТСТВЕННЫХ КРАЕВЫХ ПОСТОВ И ВЫТЕСНЕНИЮ СТАРЫХ», А РУССКИХ - «БЕЖАТЬ ИЗ КИРГИЗИИ». НА ВРЕМЯ ДУНАЕВУ УДАЛОСЬ ОБЪЕДИНИТЬ МЕНДЕШЕВА, СЕЙФУЛЛИНА, НУРМАКОВА И АЙТИЕВА. САДВОКАСОВ, «ХОТЯ И ПОЛИТИКАНСТВУЮЩИЙ ЗА ЧУЖОЙ СПИНОЙ», ЗНАЧИТЕЛЬНО ОЗДОРОВИЛСЯ. «АБСОЛЮТНО НЕ СПОСОБНЫХ К ПРАКТИЧЕСКОЙ РАБОТЕ, ЭКСПАНСИВНЫХ И НЕУСТОЙЧИВЫХ» АСЫЛБЕКОВА И ДЖАНГИЛЬДИНА ДУНАЕВ ПРОСИЛ НЕЙТРАЛИЗОВАТЬ: ПЕРВОГО НАПРАВИТЬ УЧИТЬСЯ В МОСКВУ, ДЖАНГИЛЬДИНА ЖЕ, СПРОВОЦИРОВАННОГО «ТОВАРИЩАМИ» ДОБИВАТЬСЯ ПОСТА ГЛАВЫ ЦИКА, - ПОСЛЕ СООТВЕТСТВУЮЩИХ ВНУШЕНИЙ В ЦК ВНОВЬ УТВЕРДИТЬ НАРКОМСОБЕСА ${ }^{63}$.

В.И. НАНЕЙШВИЛИ В НОЯБРЕ 1924 Г. ПРИЗВАЛ НЕ АБСОЛЮТИЗИРОВАТЬ РОЛЬ « РОДОВОЙ ВРАЖДЫ» И ОГУЛЬНО НЕ ОБВИНЯТЬ ВСЮ « ВОСТОЧНУЮ» ГРУППИРОВКУ. ОН ПОДМЕТИЛ В НЕЙ РАЗНЫЕ МОТИВЫ ДЛЯ КОНСОЛИДАЦИИ И СТРЕМЛЕНИЕ ЛИДЕРА ВТОРОЙ ГРУППЫ МЕНДЕШЕВА «ОПИРАТЬСЯ НА РУССКИХ ТОВАРИЩЕЙ», ЧТО ЛИШЬ СОЗДАЕТ « ВПЕЧАТЛЕНИЕ, ЧТО ОН БОЛЕЕ ВЫДЕРЖАННЫЙ КОММУНИСТ. ЕМУ ПРИХОДИЛОСЬ КОКЕТНИЧАТЬ С ОРЕНБУРГСКОЙ ОРГАНИЗАЦИЕЙ, А РАБОТНИКИ ОБКОМА БЫЛИ ВЫХОДЦЫ ОРЕНБУРГСКОЙ ОРГАНИЗАЦИИ», ИЗ-ЗА СЛАБОСТИ СТОРОННИКОВ-НАЦИОНАЛОВ «ЛЮДЕЙ НЕНАДЕЖНЫХ, С ТЕМНЫМ ПРОШЛЫМ». НАНЕЙШВИЛИ НЕ ВИДЕЛ ПРИНЦИПИАЛЬНЫХ РАЗЛИЧИЙ МЕЖДУ « ВОСТОЧНИКАМИ» И ЗАПАДНИКАМИ», Т.К. ЛИШЬ ТАКТИЧЕСКИ ПЕРВЫЕ СМЫКАЛИСЬ С АЛАШОРДИНСКОЙ БЕСПАРТИЙНОЙ ИНТЕЛЛИГЕНЦИЕЙ, А ВТОРЫЕ БЕЗОТЧЕТНО ВРАЖДЕБНЫ К НЕЙ. ОН КОНСТАТИРОВАЛ ОБЪЕКТИВНО : НАЦИОНАЛЬНЫЙ УКЛОН ПРОЯВЛЯЮТ ВСЕ, В Т.Ч. КАЖУЩИЙСЯ НАДЕЖНЫМ МЕНДЕШЕВ.

[...] СОБРАНИЕ СВОЕЙ ГРУППЫ ОН УСТРАИВАЕТ СТРОГО СЕКРЕТНО ОТ РУССКИХ ТОВАРИЩЕЙ, ДАЖЕ САМЫХ БЛИЗКИХ К НЕМУ, БЕЗУСЛОВНО ПОДДЕРЖИВАЮЩИХ ВСЕ ЕГО ПРЕДЛОЖЕНИЯ [...] ОН НЕ МЕНЬШИЙ, А БОЛЬШИЙ, НАИБОЛЕЕ ЗАКОРЕНЕЛЫЙ ФРАКЦИОНЕР ИЗ ВСЕХ КИРГИЗ [...]; КОНЕЧНО, ВСЕ ОНИ ФРАКЦИОНЕРЫ, НО НА ОСТАЛЬНЫХ ЛЕГЧЕ ВОЗДЕЙСТВОВАТЬ.

НАНЕЙШВИЛИ СЧИТАЛ, ЧТО СТРЕМИТСЯ ИЗЖИТЬ РАБСКУЮ ПАТРИАРХАЛЬНО-РОДОВУЮ ПСИХОЛОГИЮ» И ДОБИВАЕТСЯ ВЫЯСНЕНИЯ ИСТИННОГО ПОЛОЖЕНИЯ ДЕЛ, ХОТЯ ОБИДА НА ПОВЕДЕНИЕ МЕНДЕШЕВА ВЫДАВАЛА НЕЖЕЛАНИЕ ИЛИ НЕСПОСОБНОСТЬ ПОНЯТЬ ЗАВИСИМОСТЬ УСПЕХОВ ЛЮБОГО НАЦИОНАЛА-УПРАВЛЕНЦА ОТ ЭФФЕКТИВНОСТИ ИСПОЛЬЗОВАНИЯ НЕФОРМАЛЬНЫХ РЕСУРСОВ, ВАЖНУЮ РОЛЬ СТЕРЕОТИПОВ ВЗАИМОДЕЙСТВИЯ ЛЮДЕЙ И КРИТЕРИЕВ «НОРМАЛЬНОГО» ПОВЕДЕНИЯ. ПОСЛЕ СНЯТИЯ 
ВЕСНОЙ 1925 Г. МЕНДЕШЕВА С ДОЛЖНОСТИ ГЛАВЫ ЦИКА ОН ДОБИЛСЯ ОСТАВЛЕНИЯ ЕГО В БЮРО КРАЙКОМА ПАРТИИ, СЧИТАЯ, ЧТО ЭТО СОХРАНИТ БАЛАНС СИЛ МЕЖДУ ГРУППИРОВКАМИ, И ИСПОЛЬЗУЯ ДЛЯ ДЕЛА, ТЕМ БОЛЕЕ, ЧТО «СРЕДИ КИРГИЗ ЧРЕЗВЫЧАЙНО МАЛО ДЕЛЬНЫХ И УМНЫХ РАБОТНИКОВ ${ }^{64}$.

С. ХОДЖАНОВ ${ }^{65}$, СРАЗУ ПОСЛЕ РЕШЕНИЯ ОБ ОБРАЗОВАНИИ УЗБЕКСКОЙ ССР СТАВШИЙ СЕКРЕТАРЕМ КАЗКРАЙКОМА, АКТИВНО ОТСТАИВАЛ ОБЪЕДИНЕНИЕ НАСЕЛЕННЫХ КАЗАХАМИ РАЙОНОВ В СОСТАВЕ КАССР И ПЕРЕНОС СТОЛИЦЫ НА ЮГ РЕСПУБЛИКИ ${ }^{6}$. ОН НЕ ОСТАЛСЯ В СТОРОНЕ ОТ ВНУТРЕННИХ КОНФЛИКТОВ В ЕЕ РУКОВОДСТВЕ И В КОНЦЕ 1924 Г. В ПИСЬМЕ К СТАЛИНУ ОБЪЯСНЯЛ ГРУППИРОВОЧНУЮ БОРЬБУ ОБЪЕКТИВНОЙ ОБСТАНОВКОЙ. ОНА ПРЕВРАЩАЕТ НАЦИОНАЛА В ТИПИЧНОГО БЕЗДУШНОГО КАРЬЕРИСТА, КОТОРЫЙ СЧИТАЕТ СЕБЯ « ЦЕНТРОМ ВСЕГО», СТОЯЩИМ « ВЫШЕ КРИТИКИ, И, ЧТОБЫ ЕМУ НЕ МЕШАЛИ «ТВОРИТЬ», БУДЕТ ДОНОСИТЬ, УГОЖДАТЬ, ЖАЛОВАТЬСЯ И Т.Д. ВЫШЕСТОЯЩИМ ОРГАНАМ И ЛИЦАМ». ПОЯВЛЯЮТСЯ

ВЕРХУШКИ БЕЗ НИЗОВ, РАЗГОВОРНЫЕ РЕВОЛЮЦИОНЕРЫ, В ДЕНЬ ТРИ РАЗА УСТРАИВАЮЩИЕ ПОХОРОНЫ ДАВНО ПОХОРОНЕННОЙ АЛАШ-ОРДЫ, РАССУЖДАЮЩИЕ ТО ТАК, ТО ИНАЧЕ ПО ЛИЧНОМУ СМОТРЕНИЮ И НЕ СВЯЗАННЫЕ НИ В КАКОЙ МЕРЕ ФАКТИЧЕСКИМИ УСЛОВИЯМИ. ${ }^{67}$

ОБ УСИЛЕНИИ Т.Н. ГРУППОВЩИНЫ В ПАРТОРГАНЫ КАССР И ВОСТОЧНЫЙ ОТДЕЛ ГПУ РЕГУЛЯРНО ДОКЛАДЫВАЛИ СОТРУДНИКИ ГПУ И ПП ОГПУ, А ТАКЖЕ САМИ « ФИГУРАНТЫ» ${ }^{6}$ . ЕЩЕ В СЕНТЯБРЕ 1922 Г. ГПУ ОБВИНИЛО РЫСКУЛОВА В СВЯЗИ С ГРУППОЙ БАЙТУРСЫНОВА УЖЕ КАК АЛАШОРДИНЦА, НАРЯДУ С ХОДЖАНОВЫМ, ДОСМУХАМЕДОВЫМ И ДИВЕЕВЫМ. ИХ ПОДОЗРЕВАЛИ НЕ ТОЛЬКО В ЕСТЕСТВЕННОЙ БОРЬБЕ ПРОТИВ « КОЛОНИЗАТОРСТВА», НО НЕРЕДКО В УМЫШЛЕННОЙ ЕЕ ПРОВОКАЦИИ. ОПАСНОСТЬЮ СЧИТАЛОСЬ ТАКЖЕ СТРЕМЛЕНИЕ ЧАСТИ НАЦИОНАЛОВ К ОБЪЕДИНЕНИЮ БАШКИРИИ, КАЗАХСТАНА, ТУРКЕСТАНА И ДРУГИХ ТЕРРИТОРИЙ СРЕДНЕЙ АЗИИ ПО АНАЛОГИИ С РЫСКУЛОВСКИМ ПРОЕКТОМ 1920 Г. В « СРЕДНЕ-АЗИАТСКУЮ ВОСТОЧНУЮ МУСУЛЬМАНСКУЮ ФЕДЕРАЦИЮ АВТОНОМНЫХ ВОСТОЧНЫХ РЕСПУБЛИК», СОЗДАНИЮ КОМПАРТИИ С ЦЕНТРОМ В ТАШКЕНТЕ И РЕСПУБЛИКАНСКИМИ ОБКОМАМИ ${ }^{69}$.

1 ДЕКАБРЯ 1924 Г. ПОЯВИЛОСЬ ОЧЕРЕДНОЕ ПИСЬМО ЦК РКП(Б) ПАРТОРГАНИЗАЦИЯМ КАССР, ГДЕ ЗАЯВЛЯЛОСЬ О ДОПОЛНИТЕЛЬНОМ РОСТЕ ТРУДНОСТЕЙ В СВЯЗИ С РЕОРГАНИЗАЦИЕЙ ТЕРРИТОРИИ: ОНА ВЫРОСЛА ЕЩЕ БОЛЬШЕ, А НИЗКАЯ ПЛОТНОСТЬ НАСЕЛЕНИЯ, ОТСУТСТВИЕ ИНФРАСТРУКТУРЫ, КРАЙНЯЯ ОТСТАЛОСТЬ ХОЗЯЙСТВЕННОЙ И КУЛЬТУРНОЙ БАЗЫ СОХРАНЯЛИСЬ. РАЗНОГЛАСИЯ, УКЛОНЫ И ПРОТИВОРЕЧИЯ В КРУГУ НАЦИОНАЛОВ, КАК И МЕЖДУ НИМИ, С ОДНОЙ СТОРОНЫ, И «РАБОТНИКАМИЕВРОПЕЙЦАМИ», С ДРУГОЙ, ВЫЗЫВАЛИ РЕЗОННЫЕ ОПАСЕНИЯ. ОДНАКО РЕЦЕПТЫ ЦК ПРОПИСАЛ СТАНДАРТНЫЕ : « ОБЪЕДИНИТЬСЯ, УСИЛИТЬ, ПРИНЯТЬ МЕРЫ, ПРОРАБОТАТЬ» ${ }^{70}$ И Т.П., А НЕ ТОЧНЫЕ ПРОПИСИ ПРОЦЕДУР, ДОЗ, ИНСТРУМЕНТОВ И РЕЖИМА ЛЕЧЕНИЯ, И ПОТОМУ НЕ ВОЗЫМЕЛИ ДОЛЖНОГО ЭФФЕКТА.

МЕЖДОУСОБИЦЫ И БОРЬБА ЧЕСТОЛЮБИЙ БЫЛИ НА РУКУ ИЗОЩРЕННЫМ В АППАРАТНЫХ ХИТРОСПЛЕТЕНИЯХ И ИНТРИГАХ СОТРУДНИКАМ ГПУ И « ВСТАВАВШИМ НАД СХВАТКОЙ» ПОСЛАНЦАМ ЦЕНТРА. СОТРУДНИК ГПУ Ф. ИВАНОВ ПИСАЛ ГОЛОЩЕКИНУ И САДВОКАСОВУ (1926 г.) :

[...] ПЕРВООЧЕРЕДНОЙ ОПЕРАЦИОННОЙ РАБОТОЙ ЯВЛЯЕТСЯ СОБИРАНИЕ ЛОЖНЫХ МАТЕРИАЛОВ НА КАЗАХСКИХ ОТВЕТРАБОТНИКОВ. МЫ [...] НАРОЧНО СОЗДАЕМ ГРУППИРОВКИ ИЗ КАЗАХСКИХ ВЛИЯТЕЛЬНЫХ РОДОНАЧАЛЬНИКОВ И РУССКИХ КУЛАКОВ, ЧТОБЫ НАТРАВИТЬ ПОСЛЕДНИХ НА КАЗАХСКИХ ОТВЕТРАБОТНИКОВ И 
ТЕМ САМЫМ ПРИОБРЕТАЕМ НУЖНЫЕ НАМ МАТЕРИАЛЫ, [...] И ДЛЯ ТОГО, ЧТОБЫ ПОБЕЖДАТЬ И ПАРАЛИЗОВАТЬ КАЗАХСКИХ РАБОТНИКОВ ИСКУССТВЕННО НАТРАВЛИВАЕМ ОДНИХ РАБОТНИКОВ НА ДРУГИХ $[. ..] .^{71}$ НЕЛОЯЛЬНОСТИ НАЦИОНАЛОВ, ТОЖЕ ПРИЗНАВАЛИ: ПОСЛЕДНИЕ В СВОЕЙ СРЕДЕ ПРИМЕНЯЮТ «СОВЕРШЕННО ДРУГИЕ МЕТОДЫ, ЧЕМ ПАРТИИ ЭСЕРОВ, МЕНЬШЕВИКОВ И Т.П.». УПРАВЛЕНИЯ РАЗВИВАЛОСЬ НА ОСНОВЕ ИЕРАРХИЧЕСКИХ И КРОВНОРОДСТВЕННЫХ КРИТЕРИЕВ, ПРАВИЛ МЕЖПОКОЛЕНЧЕСКИХ И ЭТНОСОЦИАЛЬНЫХ ОТНОШЕНИЙ. В ТРАДИЦИИ ОКРУЖАЮЩИЙ МИР ИНТЕРПРЕТИРОВАЛСЯ ЧЕРЕЗ СТОЛКНОВЕНИЕ ИНТЕРЕСОВ РАЗНЫХ РОДОВ, А ПРИНАДЛЕЖНОСТЬ К НИМ ДАВАЛА НАДЕЖНУЮ СОЦИАЛЬНУЮ ЗАЩИТУ, ПРИЗНАННЫЙ В КОЛЛЕКТИВЕ СОЦИАЛЬНЫЙ ПРЕСТИЖ ИМЕЛ БОЛЬШУЮ ЦЕННОСТЬ И ВОЗВЫШАЛСЯ ЧЕРЕЗ ДЕМОНСТРАЦИЮ СВОЕГО ВЛИЯНИЯ. В ТО ЖЕ ВРЕМЯ ПРОСТОЙ ФАКТ КРОВНОГО РОДСТВА НЕ ОЗНАЧАЛ ГАРАНТИИ БЕЗУСЛОВНОЙ ПОДДЕРЖКИ, А АВТОРИТЕТ ЛИЧНОСТИ ЗАВИСЕЛ НЕ ТОЛЬКО ОТ РОДОВОЙ ПРИНАДЛЕЖНОСТИ, НО И ОТ ДОЛЖНОСТИ В АДМИНИСТРАТИВНОЙ ИЕРАРХИИ.

52 В СВОЮ ОЧЕРЕДЬ, КОНКУРИРУЮЩИЕ ГРУППЫ НАЦИОНАЛОВ ИСПОЛЬЗОВАЛИ НАЦЕЛЕННОСТЬ ОРГАНОВ ГПУ НА РАЗОБЛАЧЕНИЕ СКРЫТЫХ ВРАГОВ, ЧТОБЫ В ПЕРЕВЫБОРНЫХ КАМПАНИЯХ И ЧИСТКАХ ОБЕСПЕЧИТЬ ВСЕВОЗМОЖНЫЕ ПОСТЫ СВОИМ ЕДИНОМЫШЛЕННИКАМ ${ }^{72}$. БОРЬБА АМБИЦИЙ, ЦИНИЧНЫЙ РАСЧЕТ, ЗАВИСТЬ И ЖЕЛАНИЕ ВЛАСТИ ИЛИ МЩЕНИЯ, ТЩЕСЛАВИЕ И ЧЕСТОЛЮБИЕ, НАРЯДУ СО СТОЛЬ ЖЕ СИЛЬНЫМИ НАМЕРЕНИЯМИ РЕАЛИЗОВАТЬ СЕБЯ В ОБЩЕСТВЕННО ЗНАЧИМОЙ И ПРЕСТИЖНОЙ ДЕЯТЕЛЬНОСТИ, ИНТЕЛЛИГЕНТСКОЙ ИДЕЕЙ СЛУЖЕНИЯ НАРОДУ СПЛЕТАЛИСЬ В КЛУБОК ПЕРЕЖИВАНИЙ И ПОСТУПКОВ. НЕУСТОЙЧИВОСТЬ ПОЗИЦИЙ ВО ВЛАСТИ (ЧИСТКИ, РОТАЦИИ, ГРУППИРОВКИ) И УСИЛЕНИЕ КАРЬЕРНЫХ ИНТЕРЕСОВ НАД ПОЛИТИЧЕСКИМИ И «РОДОВЫМИ» СТИМУЛИРОВАЛИ ИСПОЛЬЗОВАНИЕ УКРЕПИВШИХСЯ В ТРАДИЦИИ МЕТОДОВ : КЕЛЕЙНЫЕ ДЕЙСТВИЯ, КОРЫСТНЫЕ КОАЛИЦИИ, СГОВОРЫ, КЛЯУЗЫ, ИСПОЛЬЗОВАНИЕ ПАРТИЙНОЙ КЛАССИФИКАЦИИ ОППОЗИЦИИ И УКЛОНОВ, КЛАССОВОЙ ТЕРМИНОЛОГИИ ВО ВНУТРИЭТНИЧЕСКОМ СОПЕРНИЧЕСТВЕ. ТАК, НА IV ВСЕКИРГИЗСКОМ СЪЕЗДЕ СОВЕТОВ (ЯНВАРЬ 1924 Г.) ЗАРЕКОМЕНДОВАВШИЕ СЕБЯ НАЦИОНАЛИСТАМИ ПОДДЕРЖИВАЛИ ВПОЛНЕ БЛАГОНАДЕЖНЫХ КОММУНИСТОВ (САДВОКАСОВ ДЖАНГИЛЬДИНА), ДАБЫ СМЕСТИТЬ ОПЫТНЫХ И УМНЫХ КОНКУРЕНТОВ ПРЕДКИРЦИКА МЕНДЕШЕВА И ПРЕДСНК СЕЙФУЛЛИНА И, ЗАКРЕПИВ НА ОДНОЙ ИЗ РЕШАЮЩИХ ДОЛЖНОСТЕЙ АМБИЦИОЗНОГО, НО УПРАВЛЯЕМОГО, «ДОВЕРЧИВОГО И СЛАБОГО ХАРАКТЕРОМ» ДЖАНГИЛЬДИНА, «ЗА ЕГО СПИНОЙ КОМАНДОВАТЬ КАК УГОДНО, В СИЛУ ЕГО ОГРАНИЧЕННОСТИ» ${ }^{73}$.

НЕЛЬЗЯ СОГЛАСИТЬСЯ, ЧТО « УКЛОНЫ» И « ГРУППИРОВКИ» БЫЛИ НАВЯЗАНЫ СВЕРХУ НО ОНИ, БЕЗУСЛОВНО, ИСПОЛЬЗОВАЛИСЬ « ТРЕТЬЕЙ СТОРОНОЙ», В КАЧЕСТВЕ КОТОРОЙ НЕ ОБЯЗАТЕЛЬНО ВЫСТУПАЛИ ЦЕНТР И ЕГО ЭМИССАРЫ. В АПРЕЛЕ 1925 Г. С. СЕЙФУЛЛИН ОБРАТИЛСЯ К СТАЛИНУ С ОБШИРНОЙ ЗАПИСКОЙ О ВНУТРИЭТНИЧЕСКИХ КОЛЛИЗИЯХ БОРЬБЫ ЗА ВЛАСТЬ. КАК И ДРУГИЕ, ОН АКЦЕНТИРОВАЛ ВНИМАНИЕ НА ИДЕЙНОКЛАССОВОМ ПРОТИВОСТОЯНИИ МЕЖДУ УЧАСТНИКАМИ И СТОРОННИКАМИ АЛАШ И БОРЦАМИ ЗА СОВЕТСКУЮ ВЛАСТЬ С 1917 Г., К КОИМ ПРИНАДЛЕЖАЛ. В ОТЛИЧИЕ ОТ ПОСЛЕДНИХ, ВСТУПИВШИЕ В ПАРТИЮ С 1920 Г. ОКАЗАЛИСЬ КАК БЫ ЛЕГАЛИЗОВАННЫМИ 
ПРОВОДНИКАМИ ИДЕЙ АЛАШ, БЫСТРО ВНЕДРЯВШИМИ « СВОИХ ЛЮДЕЙ» И НА ВЫСОКИЕ ПОСТЫ, И НА РУКОВОДЯЩИЕ ДОЛЖНОСТИ В ГУБЕРНИЯХ.

ПРИТОМ ТЯЖЕЛОВЕСНОСТЬ ХАРАКТЕРА ПРЕДСНК НУРМАКОВА И МАЛОГРАМОТНОСТЬ ПРЕДКЦИКА Т. МЫНБАЕВА ПРЕКРАСНО ПОЗВОЛЯЮТ [...] ЗА ИХ СПИНАМИ РАБОТАТЬ ЛЮДЯМ ПРАВОГО УКЛОНА, - УТВЕРЖДАЛ ОН, ПРИВОДЯ КОНКРЕТНЫЕ ПРИМЕРЫ. - ВОТ, В КОНЕЧНОМ СЧЕТЕ, [...] ПРАВЫЕ ЭЛЕМЕНТЫ ГОСПОДСТВУЮТ, А АЛАШ-ОРДА РУКОПЛЕЩЕТ.

ОСОБЕННО ЯРКО ЭТО ПОКАЗАЛА ПОПЫТКА ВЫСТАВИТЬ ЗЕЛЕНОЕ ЗНАМЯ АЛАШ НА V СЪЕЗДЕ СОВЕТОВ КАССР, ПОД НЕПОСРЕДСТВЕННЫМ ВПЕЧАТЛЕНИЕМ КОТОРОГО БЫЛО НАПИСАНО ОБРАЩЕНИЕ ${ }^{75}$. О ТОМ, ЧТО

ИСКРЕННИЕ КИРГИЗСКИЕ КОММУНИСТЫ, В СВОЕМ ПРОШЛОМ НИ В ЧЕМ НЕ ОПОРОЧЕННЫЕ, А РАБОТАЮЩИЕ В СОВУЧРЕЖДЕНИЯХ И ПАРТИЙНЫХ ОРГАНИЗАЦИЯХ С САМОГО НАЧАЛА РЕВОЛЮЦИИ, [...] ПОДПАДАЮТ ПОД ДЕСПОТИЗМ НАЦИОНАЛИСТОВ АЛАШ-ОРДИНЦЕВ [...] И ПО БЛИЗОРУКОСТИ И ОДНОСТОРОННОСТИ КРАЙКОМА РКП(Б) ВЫБРАСЫВАЮТСЯ ЗА БОРТ, КАК НЕНУЖНЫЕ НЫНЕ ЭЛЕМЕНТЫ,

ЖИВОПИСАЛ СТАЛИНУ И ОБИЖЕННЫЙ НА ПРОВАЛ СВОЕЙ КАНДИДАТУРЫ НА СЪЕЗДЕ ДЖАНГИЛЬДИН.

НЕВОЛЬНО ОН СВИДЕТЕЛЬСТВОВАЛ, ЧТО НАЗНАЧЕНЦЫ, ДЕЙСТВУЯ В РАМКАХ КЛАССОВОЙ ПАРАДИГМЫ, ПРОВОЦИРОВАЛИ ИНТЕНСИФИКАЦИЮ ТРАДИЦИОННЫХ МЕХАНИЗМОВ СОЦИАЛЬНОЙ ИНТЕГРАЦИИ И ПОЗИЦИОНИРОВАНИЯ В СИСТЕМЕ ВЛАСТНО-СТАТУСНЫХ ОТНОШЕНИЙ. ПО ЕГО МНЕНИЮ, НАНЕЙШВИЛИ И ЕЖОВ ПРОЯВИЛИ

ОДНОСТОРОННИЙ И ЗАБЛУЖДЕННЫЙ УКЛОН [И] ОКАЗАЛИСЬ БОЛЕЕ НАЦИОНАЛИСТАМИ, [ПОСКОЛЬКУ,] НЕ ЗНАЯ НИ ОБЫЧАЯ, НИ ПРАВА, НИ СНОРОВКИ И НИ ПСИХОЛОГИИ КИРГИЗСКОГО НАРОДА, [...] НЕ ЗНАЮТ НИКАКОГО ПОЛИТИЧЕСКОГО ПОДХОДА И СЛИШКОМ ВЕРЯТ СЛОВАМ АЛАШ-ОРДИНЦЕВ, [...] СОВЕРШЕННО НЕ СООТВЕТСТВУЮТ СВОИМ НАЗНАЧЕНИЯМ.

ДЖАНГИЛЬДИН ДАЛ РЕЗКИЕ ХАРАКТЕРИСТИКИ СВОИМ КОНКУРЕНТАМ - С. ХОДЖАНОВУ (« ОТЪЯВЛЕННЫЙ СКЛОЧНИК, [...] СОЗДАЛ ТЕСНУЮ СВЯЗЬ СО СВОИМИ БЫВШИМИ ЕДИНОМЫШЛЕННИКАМИ АЛАШОРДИНЦАМИ И [...] ОТКРЫЛ ФРОНТ ИСКЛЮЧИТЕЛЬНО ПРОТИВ ПРИНЦИПИАЛЬНЫХ РАБОТНИКОВ КИРГИЗ»), САДВОКАСОВУ И НУРМАКОВУ КАК МЕЛКОБУРЖУАЗНЫМ ЭЛЕМЕНТАМ, И ОТМЕЖЕВАЛСЯ ОТ ВСЕХ, КАК « ПРОИСХОДЯЩИЙ ИЗ НИЗОВ И РАБОТАЮЩИЙ НЕ ЗА СТРАХ, А ЗА СОВЕСТЬ С САМОГО НАЧАЛА РЕВОЛЮЦИИ В АВАНГАРДЕ КИРГИЗСКОГО ПРОЛЕТАРИАТА». ПЕРВЫЙ КАЗАХ-БОЛЬШЕВИК НАСТАИВАЛ « ПОКА НЕ ПОЗДНО» ОТОЗВАТЬ НАНЕЙШВИЛИ, ЕЖОВА И ХОДЖАНОВА «В ИНТЕРЕСАХ ПРИВИВКИ НЕГНИЛЫХ СЕМЯН СОЦИАЛИЗМА СРЕДИ КИРГИЗСКОЙ МАССЫ», ОТВЕТСЕКРЕТАРЕМ КРАЙКОМА ПАРТИИ ПРИСЛАТЬ НА ГОД-ДВА ИСТИННОГО МАРКСИСТА ИЗ ЦЕНТРА, « СОВЕРШЕННО ИЗОЛИРОВАТЬ» ДВУХ ПОСЛЕДНИХ И РАСПУСТИТЬ СТАРЫЙ КОМИТЕТ. ОН ТАКЖЕ БЫЛ ГОТОВ ПРЕДОСТАВИТЬ СПИСОК ПОЛИТИЧЕСКИ ВЫДЕРЖАННЫХ И ПОЛЬЗУЮЩИХСЯ ДОВЕРИЕМ НАЦИОНАЛЬНОГО ПРОЛЕТАРИАТА КАНДИДАТОВ. СИМПТОМАТИЧНО ЗАМЕЧАНИЕ ДЖАНГИЛЬДИНА О ПАТРИОТИЗМЕ АЙМАКА (ОТДЕЛЕНИЯ)» В 5 ЭТАЖЕЙ - ОТДЕЛЕНИЯ, РОДОВОЙ, ПЛЕМЕННОЙ (КОЛЕН), ЖУЗОВЫЙ (« ОРДЫНСКИЙ») И «НАЦИОНАЛЬНЫЙ КИРГИЗСКИЙ», ПОРОЖДАЮЩИХ СТРАШНУЮ ВРАЖДУ СРЕДИ МЕЛКОБУРЖУАЗНЫХ КИРГИЗСКИХ ЭЛЕМЕНТОВ». В ЭТИХ ПАТРИОТИЗМАХ НАНЕЙШВИЛИ И ЕЖОВ «АБСОЛЮТНО НЕ ИМЕЮТ ПОНЯТИЯ», ЗАТО ХОДЖАНОВ, САДВОКАСОВ И НУРМАКОВ « ЭКСПЛУАТИРУЮТ ИХ И СОЗДАЮТ БУЧУ» ${ }^{76}$. 


\section{Административное урегулирование " национального переплета»}

57 МНОГОЧИСЛЕННЫЕ ЖАЛОБЫ И ХОДАТАЙСТВА НАЦИОНАЛОВ ${ }^{77}$ И ДОНЕСЕНИЯ НАЗНАЧЕНЦЕВ, КАЖЕТСЯ, ПРЕВЗОЙДЯ ПОТЕНЦИАЛ ТЕРПЕНИЯ, НЕ МОГЛИ НЕ ВЫЗЫВАТЬ РАЗДРАЖЕНИЯ И ОЗАБОЧЕННОСТИ В МОСКВЕ. ОКАЗАЛОСЬ, ЧТО РЕШЕНИЯ 1922 ГОДА ПО ПОВОДУ «СКЛОК» В РУКОВОДСТВЕ КАССР НЕ ПОМОГЛИ. ЦКК РКП(Б) В НАЧАЛЕ 1925 Г. ТРИЖДЫ ЗАНИМАЛАСЬ «АНТИПАРТИЙНЫМИ ГРУППИРОВКАМИ» В КАССР ${ }^{78}$. 29 МАЯ 1925 Г. СТАЛИН ОБРАТИЛСЯ К ЧЛЕНАМ БЮРО КИРКРАЙКОМА С ПИСЬМОМ ПО ПОВОДУ ГАЗЕТЫ «АК ЖОЛ», В КОТОРОЙ «К УЖАСУ СВОЕМУ» ОБНАРУЖИЛ ДУХОВНУЮ СВЯЗЬ С ЗАГРАНИЧНЫМИ ПУБЛИКАЦИЯМИ М. ЧОКАЕВА. ВРЯД ЛИ ЭТО БЫЛО ОТКРЫТИЕМ ДЛЯ СТАЛИНА - ГОДОМ РАНЕЕ ПОДРОБНЫЙ ДОКЛАД О НАЦИОНАЛЬНОЙ ПЕЧАТИ ПРЕДОСТАВИЛ ВОЖДЮ РЫСКУЛОВ. ДА И ДРУГОЙ ИНФОРМАЦИИ БЫЛО ДОСТАТОЧНО. ТЕПЕРЬ БОРЬБА НА ПОЛИТИЧЕСКОМ И ИДЕОЛОГИЧЕСКОМ ФРОНТЕ», КОТОРАЯ ПРИОБРЕЛА РЕШАЮЩЕЕ ЗНАЧЕНИЕ ДЛЯ САМОГО СТАЛИНА, И НА ОКРАИНАХ ДОЛЖНА БЫЛА НАХОДИТЬСЯ ИСКЛЮЧИТЕЛЬНО В ПАРТИЙНОМ ВЕДОМСТВЕ. К ТОМУ ЖЕ ПЕРЕТАСОВКИ КАДРОВ, А ЕЩЕ БОЛЕЕ - НАЦИОНАЛЬНО-ГОСУДАРСТВЕННОЕ РАЗМЕЖЕВАНИЕ В СРЕДНЕЙ АЗИИ ВНОВЬ НАПОМНИЛИ О ЧУВСТВИТЕЛЬНОСТИ СОЦИАЛЬНОЙ ПСИХОЛОГИИ И ИДЕЙНОНРАВСТВЕННЫХ ТЕРЗАНИЯХ ИНТЕЛЛИГЕНЦИИ ${ }^{79}$.

СЕКРЕТАРЬ КРАЙКОМА Н.И. ЕЖОВ В ПИСЬМЕ В.М. МОЛОТОВУ 24 АВГУСТА 1925 Г. ДОВОЛЬНО ПОДРОБНО ИЗЛАГАЛ СВОИ ОЦЕНКИ СИТУАЦИИ ПОСЛЕ ОТСТАВКИ НАНЕЙШВИЛИ И НАКАНУНЕ ПРИЕЗДА НОВОГО ПОСЛАНЦА МОСКВЫ - Ф.И. ГОЛОЩЕКИНА. БЕЗУСЛОВНО ОДОБРЯЯ РЕШЕНИЯ ЦЕНТРА ПО ПОВОДУ НАЗНАЧЕНИЯ НОВОГО ФАКТИЧЕСКОГО ГЛАВЫ РЕСПУБЛИКИ, НЕДОБРУЮ ПАМЯТЬ О КОТОРОМ ДО СИХ ПОР ХРАНЯТ КАЗАХСТАНЦЫ, ОН НЕ РАЗ, КАК БЫ ПОПУТНО, НО ВСЕГДА КОМПЛИМЕНТАРНО, УПОМИНАЛ СТАЛИНА И ЕГО КУРС. ОСНОВНОЕ ВНИМАНИЕ УДЕЛЕНО БОРЬБЕ В КАЗАХСКОЙ ЧАСТИ БЮРОКРАТИИ, ПРИЧЕМ ОТСУТСТВИЕ ЕДИНСТВА В ОЦЕНКЕ ПРОИСХОДЯЩЕГО СРЕДИ « ЕВРОПЕЙЦЕВ» СВЯЗАНО С « НЕПРАВИЛЬНОСТЬЮ» КАЗАХСКИХ УКЛОНОВ :

БЫЛО БЫ ПОЛБЕДЫ, ЕСЛИ БЫ ХОТЯ ЭТИ ГРУППИРОВКИ ДЕЛИЛИСЬ ПО ТЕМ УКЛОНАМ, О КОТОРЫХ ТАК ЯРКО [...] ГОВОРИЛ ТОВ.СТАЛИН, ТОГДА БЫЛО БЫ ГОРАЗДО ЛЕГЧЕ ВЕСТИ ОПРЕДЕЛЕННУЮ ПОЛИТИКУ МЕЖДУ ЭТИМИ ГРУППИРОВКАМИ. МОЖНО БЫЛО БЫ В КОНЦЕ КОНЦОВ С НАТЯЖКОЙ ОСТАНОВИТЬСЯ НА ОДНОЙ ГРУППЕ, НАИБОЛЕЕ ПРАВИЛЬНО ВЕДУЩЕЙ СВОЮ ПОЛИТИКУ, И НА НЕЕ ОПИРАТЬСЯ, СОЗДАВАЯ ЕЙ И АВТОРИТЕТ И ВСЕ ТО, ЧТО В ЭТИХ СЛУЧАЯХ НУЖНО. РАСТВОРЯЯ В НЕЙ ДРУГИЕ ГРУППИРОВКИ. НО [...] МЫ ЭТОГО СДЕЛАТЬ НЕ МОЖЕМ, Т.Е. МЫ НЕ МОЖЕМ ОПЕРЕТЬСЯ НА ОДНУ КАКУЮ-ЛИБО ГРУППУ, ВСТАВ КАК ГОВОРЯТ, « ОБОИМИ НОГАМИ НА НЕЕ».

ПО-МОЕМУ, МЫ ДОЛЖНЫ ИСКАТЬ ОПОРУ ВО ВСЕХ ЭТИХ ГРУППИРОВКАХ (ОПИРАЯСЬ НА ЗДОРОВЫЙ ЭЛЕМЕНТ ИХ), ОДНОВРЕМЕННО И В ОДИНАКОВОЙ МЕРЕ ВЕДЯ БОРЬБУ С НЕЗДОРОВЫМИ УКЛОНАМИ В КАЖДОЙ ИЗ НИХ, НАПРАВЛЯЯ ТЕМ САМЫМ ИХ ДЕЯТЕЛЬНОСТЬ В ПАРТИЙНОЕ РУСЛО.

БОЛЬШОЙ РАЗНИЦЫ ВО ВЗГЛЯДАХ НАЦИОНАЛОВ ЕЖОВ НЕ УСМАТРИВАЛ ( ВСЕ ЛУЧШЕ»), А ПОТОМУ ПРИЗЫВАЛ « ДАВИТЬ» И ОТСТРАНЯТЬ ИХ ОТ РУКОВОДСТВА С ОДНОВРЕМЕННЫМ РАСКОЛОМ ГРУПП ПУТЕМ ПРОТИВОПОСТАВЛЕНИЯ, ПРЕДОСТЕРЕГАЯ И ОТ ПЕРЕВОДА В МОСКВУ, ГДЕ ОНИ СМОГУТ ОРГАНИЗОВАТЬ «КАЗАХСТАН №2 И ТОРМОЗИТЬ МЕРОПРИЯТИЯ» ПАРТИИ. СНИМАЯ СТОРОННИКОВ ОДНОЙ, ВЫДВИГАЯ НА ИХ МЕСТО 
ПРЕДСТАВИТЕЛЕЙ ДРУГОЙ, ДЕЛАТЬ ГРУППИРОВОЧНУЮ БОРЬБУ Т.О. ПЕРМАНЕНТНОЙ, А ИНТЕЛЛИГЕНЦИЮ - УПРАВЛЯЕМОЙ ${ }^{80}$.

ЕЖОВУ В 1927 Г. УДАЛОСЬ ДОБИТЬСЯ ПЕРЕВОДА В МОСКВУ. ВООБЩЕ, ДЛЯ НЕКОТОРЫХ ПОСЛАНЦЕВ ЦЕНТРА БЕСКРАЙНИЕ КАЗАХСКИЕ ПРОСТОРЫ МОГЛИ ПОНАЧАЛУ ПОКАЗАТЬСЯ УДОБНЫМ КРАТКОСРОЧНЫМ ТРАМПЛИНОМ ДЛЯ КАРЬЕРНОГО ВЗЛЕТА НА ВЫСОКИЕ ДОЛЖНОСТИ В СТОЛИЦЕ. ОДНАКО НЕИЗБЕЖНОЕ ПОГРУЖЕНИЕ В ПОДВИЖНЫЙ И МОЗАИЧНЫЙ ЭТНОПОЛИТИЧЕСКИЙ И СОЦИОКУЛЬТУРНЫЙ ЛАНДШАФТ, ДОПОЛНИТЕЛЬНО ЗАПУТАННЫЙ СЛОЖНЫМ РИСУНКОМ ХИТРОСПЛЕТЕНИЙ, ОШИБОК ИЛИ НЕКОМПЕТЕНТНОСТИ РАБОТНИКОВ И ОБЪЕКТИВНЫМИ ТРУДНОСТЯМИ, ЯЗЫКОВОЙ БАРЬЕР, КАК И ПРОБЛЕМЫ АДАПТАЦИИ К НЕПРИВЫЧНЫМ ПРИРОДНО-КЛИМАТИЧЕСКИМ, БЫТОВЫМ И ГАСТРОНОМИЧЕСКИМ УСЛОВИЯМ, СТАВИЛИ ПОРОЙ ДАЖЕ ИСКРЕННЕ СТРЕМИВШИХСЯ НАЛАДИТЬ ДЕЛО И ПОМОЧЬ НАЦИОНАЛАМ «ЕВРОПЕЙЦЕВ» В ОЧЕНЬ ТЯЖЕЛОЕ ПОЛОЖЕНИЕ ${ }^{81}$. МЕТОДЫ НАТРАВЛИВАНИЯ ДРУГ НА ДРУГА ИСКУСНО ПОДОГРЕВАЕМЫХ ГРУПП АЛАШОРДИНЦЕВ И ИХ ПРОТИВНИКОВ, « ПРАВЫХ» И Л ЛЕВЫХ», И БЕЗ ТОГО ЗАРЯЖЕННЫХ» НА СОПЕРНИЧЕСТВО, СОХРАНИЛИСЬ КАК ОДИН ИЗ ВАЖНЫХ ИНСТРУМЕНТОВ УПРАВЛЕНИЯ, ЧТО НА ДЕЛЕ ПРОТИВОРЕЧИЛО ИНТЕРЕСАМ ВЫТЕСНЕНИЯ ТРАДИЦИОННЫХ СЕТЕЙ И СТАБИЛИЗАЦИИ ВЛАСТНЫХ СТРУКТУР, В ЧЕМ КРОВНО БЫЛ ЗАИНТЕРЕСОВАН ЦЕНТР.

ВЫКЛАДКИ СОТРУДНИКОВ ГПУ И « ЕВРОПЕЙЦЕВ» В СОВЕТСКО-ПАРТИЙНОМ РУКОВОДСТВЕ СОСРЕДОТОЧЕНЫ НА ВЫДЕЛЕНИИ ТРЕХ ГРУПП, ПЕРВАЯ И ВТОРАЯ ИЗ КОТОРЫХ ОКАЗЫВАЮТСЯ НА ДЕЛЕ ВЫРАЗИТЕЛЯМИ ОБЩЕЙ ЛИНИИ: ОБЪЕДИНЕННЫЕ В ПЕРВУЮ АЛАШОРДИНЦЫ (КРОМЕ ЗАНЯВШИХ ЯВНО ПАССИВНУЮ ПОЗИЦИЮ), НЕ ИМЕЯ ДОСТУПА К УПРАВЛЕНИЮ, ПО СУТИ НАПРАВЛЯЛИ МОЛОДЫХ НАЦИОНАЛОВ ИЗ ВТОРОЙ (САДВОКАСОВ И ДР.), ВЫРАЖАВШИХ ЧЕРЕЗ ПЕЧАТЬ И РАЗНЫЕ ОБЩЕСТВЕННЫЕ ФОРУМЫ КРИТИЧЕСКИЕ ОЦЕНКИ « КОЛОНИЗАТОРСКОЙ» ПРАКТИКИ РУССКОЯЗЫЧНОЙ ЧАСТИ АДМИНИСТРАЦИИ И НЕОБХОДИМОСТЬ ЭТНОПОЛИТИЧЕСКОЙ КОНСОЛИДАЦИИ. ОПИСАННЫЕ ПРЕДСТАВИТЕЛЯМИ ЦЕНТРА СОБЫТИЯ ГРУППИРОВОЧНОЙ БОРЬБЫ ПОЗВОЛЯЮТ ВЫДЕЛИТЬ НЕКОТОРЫЕ ОСНОВНЫЕ МЕТОДЫ, ПРИМЕНЯВШИЕСЯ ЕЕ УЧАСТНИКАМИ. В ПРОТИВОСТОЯНИИ С ТРЕТЬЕЙ ГРУППОЙ, В КОТОРУЮ «КОЛОНИЗАТОРЫ» ОБЪЕДИНЯЛИ НАИБОЛЕЕ ПРЕДАННЫХ ВЛАСТИ КАЗАХСКИХ УПРАВЛЕНЦЕВ ВО ГЛАВЕ С МЕНДЕШЕВЫМ, ЧЛЕНЫ ВТОРОЙ БЫСТРО НАУЧИЛИСЬ ИСПОЛЬЗОВАТЬ МЕТОДЫ БОЛЬШЕВИКОВ. ЭТО ОБВИНЕНИЕ В НАЦИОНАЛИЗМЕ; ПРОВЕДЕНИЕ СВОИХ СТОРОННИКОВ С МЕСТ ДО ГУБЕРНСКОГО И РЕСПУБЛИКАНСКОГО УРОВНЯ ДЛЯ ОБЕСПЕЧЕНИЯ БОЛЬШИНСТВА НА ПАРТИЙНЫХ И СОВЕТСКИХ ВЫБОРАХ; ОТКОМАНДИРОВАНИЕ НА ВРЕМЯ ВЫБОРНОЙ КАМПАНИИ ПРОТИВНИКОВ ИЗ РУССКОЯЗЫЧНЫХ РАБОТНИКОВ ; ОБВИНЕНИЕ КОНКУРЕНТОВ В СКЛОКАХ ДЛЯ ОРГАНИЗАЦИИ ЧИСТКИ И ИСКЛЮЧЕНИЯ ИХ ИЗ ПАРТИИ ; ПРИВЛЕЧЕНИЕ СОПЕРНИКОВ К СУДЕБНОЙ ОТВЕТСТВЕННОСТИ ПО ОБВИНЕНИЯМ В РАЗЛИЧНЫХ НАРУШЕНИЯХ И ПР. КАЖДАЯ ГРУППА СТРЕМИЛАСЬ ТАКЖЕ ПРОВЕСТИ СВОИХ ЕДИНОМЫШЛЕННИКОВ В СУДЕБНЫЕ И ИСПОЛНИТЕЛЬНО-АДМИНИСТРАТИВНЫЕ ОРГАНЫ. ПРИ ЭТОМ ВСЕ ТРИ ГРУППЫ НАЦИОНАЛОВ ОБЪЕДИНЯЛА ОБЩАЯ ОБИДА НА ЦЕНТР ЗА СОХРАНЕНИЕ АВТОНОМНОГО СТАТУСА КАЗАХСТАНА В СОСТАВЕ ОБРАЗОВАННОГО СССР ${ }^{82}$. МЕЖ ТЕМ ПОНИМАНИЕ СОЗРЕВШЕГО УЖЕ СРЕДИ САМИХ НАЦИОНАЛОВ СТРЕМЛЕНИЯ « СТАБИЛИЗИРОВАТЬ КАДРЫ» 22 ОКТЯБРЯ 1925 Г. - ПОСЛЕ СНЯТИЯ ХОДЖАНОВА С ПОСТА 2-ГО СЕКРЕТАРЯ И ОТЗЫВА В МОСКВУ ${ }^{83}$ ОБНАРУЖИЛ СЕКРЕТАРЬ КРАЙКОМА У.К. ДЖАНДОСОВ. ПРИЗНАВАЯ ТАКТИЧЕСКИЕ ОШИБКИ ХОДЖАНОВА, ОН ВМЕСТЕ С ТЕМ НЕ 
ОГРАНИЧИЛ ОЦЕНКУ ДЕЛ ИТОГАМИ БОРЬБЫ ГРУППИРОВОК, Т.К. ГЛАВНОЕ ХОЗЯЙСТВЕННОЕ И КУЛЬТУРНОЕ ВОЗРОЖДЕНИЕ НАРОДА, ВСЕМЕРНОЕ ИСПОЛЬЗОВАНИЕ ПРЕИМУЩЕСТВ СОВЕТСКОГО СТРОЯ ДЛЯ НАЦИОНАЛЬНОГО ПРОГРЕССА, КАК БЫ ВТОРЯ ПРЕЖНИМ ВЫВОДАМ АЛАШОРДИНЦЕВ. ДЖАНДОСОВ ПРЕДЛАГАЛ ПРОВОДИТЬ НЕ ОСУЖДЕНИЕ САМОЙ ПОСТАНОВКИ НАЦИОНАЛЬНОГО ВОПРОСА, ЯРКО ПРЕДСТАВЛЕННОЙ ХОДЖАНОВЫМ, А НЕОСЛАБНО ИЗЖИВАТЬ КОЛОНИАЛЬНОЕ ПРОШЛОЕ, В Т.Ч. ОРГАНИЗАЦИЕЙ МАСС ЧЕРЕЗ СОВЕТЫ, ХОЗЯЙСТВЕННО-ОРГАНИЗАЦИОННОЙ ПОМОЩЬЮ АУЛУ. НУЖНО СВЯЗЫВАТЬ АВТОНОМИЮ КАК СУБЪЕКТ С ФЕДЕРАЦИЕЙ В ЦЕЛОМ «НА ОСНОВЕ ЭКОНОМИЧЕСКИХ МЕРОПРИЯТИЙ СВЕРХУ И АДМИНИСТРАТИВНО-КУЛЬТУРНЫХ МЕРОПРИЯТИЙ СНИЗУ, Т.Е. КАК РАЗ ПРЯМО ПРОТИВОПОЛОЖНО ТОМУ, ЧТО БЫЛО ДО СИХ ПОР». ЭТИ ЗАДАЧИ, ПРОСВЕЩЕНИЕ И СПЕЦИАЛИЗАЦИЯ КАДРОВ НИКАК НЕ ВЯЗАЛИСЬ « С НАШИМИ ПРИВЫЧКАМИ ПРОШЛОГО : ПЕРЕБРОСКИ, ЛИЧНЫЕ СВЯЗИ, ГРУППОВАЯ СКЛОКА И Т.Д. [...] МЫ ДОЛЖНЫ (ПУСТЬ ДАЖЕ ПОСТЕПЕННО) ПЕРЕХОДИТЬ К НОВЫМ МЕТОДАМ ПОДГОТОВКИ ВЫДВИЖЕНИЯ И РАСПРЕДЕЛЕНИЯ СИЛ». ИМЕННО ЭТО ОН СЧИТАЛ КАМНЕМ ПРЕТКНОВЕНИЯ «ДЛЯ ВСЕХ НАШИХ ВИДНЕЙШИХ РАБОТНИКОВ» И ПРЕДЛАГАЛ САМОКРИТИЧНО ИЗМЕНИТЬ ОТНОШЕНИЕ К СЛОЖИВШЕЙСЯ ПРАКТИКЕ :

ПРОСТОЙ СГОВОР ТУТ ДЕЛУ НЕ ПОМОЖЕТ. НЕОБХОДИМА И РАБОТА НАД САМИМ СОБОЙ, И РОСТ ПОЛИТИЧЕСКОГО УРОВНЯ ПАРТИЙНЫХ МАСС, И СВЯЗЬ С МАССАМИ РАБОЧИХ И КРЕСТЬЯН, И, НАКОНЕЦ, ЭТО САМОЕ ГЛАВНОЕ, ПРАКТИЧЕСКАЯ РАБОТА С ДОБРОСОВЕСТНЫМ СТАРАТЕЛЬНЫМ ОТНОШЕНИЕМ К НЕЙ, С СОЗНАНИЕМ ДЕЙСТВИТЕЛЬНОЙ ОТВЕТСТВЕННОСТИ ЗА ЕЕ ВЫПОЛНЕНИЕ. КОАЛИЦИИ, ПАРИТЕТЫ, ПРОПОРЦИОНАЛЬНОЕ ПРЕДСТАВИТЕЛЬСТВО И Т.П. СПОСОБЫ МЕХАНИЧЕСКОГО РЕШЕНИЯ ЗАДАЧИ ЕДВА ЛИ ПОМОГУТ ДЕЛУ [...]

НАДО ПРЕКРАТИТЬ ПЕРЕПАЛКИ И НЕ РАЗВЯЗЫВАТЬ НОВУЮ ГРУППИРОВОЧНУЮ СТИХИЮ ПО ПОВОДУ ОТЗЫВА ХОДЖАНОВА, А ПРОЯВИТЬ БОЛЬШЕ ВДУМЧИВОГО, ДЕЛОВОГО И СПОКОЙНОГО ОТНОШЕНИЯ К РАБОТЕ ${ }^{84}$.

НО И НА V КРАЕВОЙ ПАРТКОНФЕРЕНЦИИ (ДЕКАБРЬ 1925 Г.) ГОЛОЩЕКИН ПРИЗНАЛ, ЧТО

В ЖИЗНЬ ПРОВОДИТСЯ НЕ ТО, ЧТО ПОСТАНОВЛЯЕТ ЦК ИЛИ КК, А ТО, ЧТО В ЛИЧНОМ ПИСЬМЕ ПИШЕТ КАКОЙ-НИБУДЬ «ВОЖДЬ». ... НАРЯДУ С КОМИТЕТОМ ИМЕЕМ ОРГАНИЗАЦИОННЫЙ ЦЕНТР - УЧРАСПРЕД В ДОМЕ КАКОГО-НИБУДЬ «ВОЖДЯ». ПРИЕЗЖАЕТ ТОВАРИЩ, НЕ ЗАХОДИТ В КОМИТЕТ, А ВНАЧАЛЕ ИДЕТ ТУДА И ТАМ ПОЛУЧАЕТ ДИРЕКТИВЫ. ${ }^{85}$

ИМЕННО « НАЦИОНАЛЬНЫЙ ПЕРЕПЛЕТ», КАК ОН ВЫРАЗИЛСЯ НА СОВЕЩАНИИ СЕКРЕТАРЕЙ ПАРТОРГАНИЗАЦИЙ ТЮРКО-ТАТАРСКОЙ ГРУППЫ В ЦК ПАРТИИ 2 ЯНВАРЯ 1926 Г., СОСТАВИЛ НАИБОЛЬШУЮ СЛОЖНОСТЬ.

ЧЕМ БЛИЖЕ ПОДХОДЯТ КОММУНИСТЫ К ВЛАСТИ В ПАРТИЙНОМ ИЛИ СОВЕТСКОМ ПОРЯДКЕ, ТЕМ ДЕЛАЮТСЯ БОЛЕЕ ОГОЛТЕЛЫМИ В НАЦ. ВОПРОСЕ. [...] ВОПРОС О НАЦ. САМОСОЗНАНИИ МЕЖДУ ПРОЧИМ ВЫРАЖАЕТСЯ В ТОМ, ЧТО ОНИ ХОТЯТ СОВСЕМ БЕЗ РУССКИХ И БЕЗ ЦК». ЕСТЬ РАЗГОВОРЫ О ТОМ, ЧТО НЕ МЫ ХОЗЯЕВА, А РУССКИЙ ЦЕКА, МОСКВА ХОЗЯИН. [...] МНОГИЕ МОСКОВСКИЕ СОВЕТСКИЕ РАБОТНИКИ СОВЕРШЕННО ЗАБЫЛИ О ТЕХ РЕЗОЛЮЦИЯХ, КОТОРЫЕ ВЫНОСИЛИСЬ И НА МЕЛОЧАХ ТАК ИНОГДА РАЗДРАЖАЮТ ЭТУ ПУБЛИКУ, ЧТО МЕЛКИЕ ОБИДЫ РАЗРАЖАЮТСЯ В ЦЕЛУЮ БУРЮ,

ТАК ХАРАКТЕРИЗОВАЛ ОН НАСТРОЕНИЯ КАЗАХСКОЙ ЭЛИТЫ. ПРЕОБРАЗОВАНИЯ ЭКОНОМИКИ И КУЛЬТУРЫ ПРЕДЛАГАЛ

ПРОВОДИТЬ ...ЧЕРЕЗ ТЕХ ЛИЦ, КОТОРЫЕ НАМ БЛИЖЕ. ЭТО ИМ СОЗДАСТ попУляРность. СБлизиться нУжно, но осторожно. ${ }^{86}$

ОТНОШЕНИЕ МОСКВЫ К ПРОБЛЕМАМ СТАНОВЛЕНИЯ ВЛАСТИ В АВТОНОМИЯХ РЕЗЮМИРОВАЛ ПРЕДСЕДАТЕЛЬСТВОВАВШИЙ В.М. МОЛОТОВ. О НАЗНАЧЕНЦАХ ОН ЗАЯВИЛ : 
К ПАРТИЙНОМУ РУКОВОДСТВУ НУЖНО ПРИВЛЕКАТЬ НЕ ЛЕВЫХ, А ЛУЧШИХ. [...] ЧТОБЫ ЛЮДИ ЗНАЛИ ЯЗЫК, РАБОТАЯ ТАМ, ИНАЧЕ НИЧЕГО НЕ ПОЛУЧИТСЯ. [...] НАМ НУЖНЫ ЕВРОПЕЙЦЫ КВАЛИФИЦИРОВАННЫЕ. КАК ОНИ БУДУТ РАБОТАТЬ НА МЕСТНОЙ РАБОТЕ (ГОЛОС : КАТОРГА БУДЕТ) - ДЛЯ МНОГИХ ЭТО НЕ БУДЕТ КАТОРГА [...] ЭТО БЕРЕТСЯ ИЗ ОПРЕДЕЛЕННЫХ УЗКИХ КАДРОВ ЛЮДЕЙ, КОТОРЫХ МЫ ЗАСТАВИМ УЧИТЬ УЗБЕКИСТАНСКИЙ ЯЗЫК, [...] В ВОЗРАСТНОМ ОТНОШЕНИИ ТЕПЕРЬ НОВЫЕ ЛЮДИ.

ПО ПОВОДУ НАЦИОНАЛОВ ПРЕДЛАГАЛАСЬ АПРОБИРОВАННАЯ БЮРОКРАТИЧЕСКАЯ РЕЦЕПТУРА :

МЫ ДОЛЖНЫ УСИЛИТЬ ЧИСТКУ МЕХАНИЧЕСКИ. ИНОЙ РАЗ КУЧКУ ВЫЧИСТИТЬ (С МЕСТА : НЕ ОСОБОЙ ЧИСТКОЙ, А В ПРАКТИЧЕСКОЙ РАБОТЕ). ДА, Я ПОЛАГАЮ, НЕ В ФОРМЕ ОБЫЧНОЙ ЧИСТКИ, А СНИМАТЬ СОСТАВ, НАПРИМЕР, В ОДНОЙ МЕСТНОСТИ БОЛЕЕ ЗНАЧИТЕЛЬНЫЙ, ЧЕМ В ДРУГОЙ, БЕЗУСЛОВНО, БУДЕМ МЕНЯТЬ, ДЛЯ ЭТОГО ПЕРИОДА ПРИГОДИЛСЯ ЭТОТ СОСТАВ, ДЛЯ ДРУГОГО БУДЕТ ПОДЧИЩЕННЫЙ, БУДЕМ ВЛИВАТЬ НОВЫЕ. ${ }^{87}$

ВМЕСТО ТАКТИКИ «РАЗДЕЛЯЙ И ВЛАСТВУЙ» СЛЕДОВАЛО ПЕРЕХОДИТЬ К ДОСТИЖЕНИЮ ПРАКТИЧЕСКИХ РЕЗУЛЬТАТОВ В УКРЕПЛЕНИИ ЕДИНСТВА СТРАНЫ И СИСТЕМЫ УПРАВЛЕНИЯ. 23 ЯНВАРЯ 1926 Г. В СВЯЗИ СО СЛОЖНОСТЬЮ И ТРУДНОСТЯМИ МЕЖНАЦИОНАЛЬНЫХ ОТНОШЕНИЙ ГОЛОЩЕКИН ОБЯЗАЛ СЕКРЕТАРЕЙ ГУБКОМОВ ПАРТИИ ЕЖЕМЕСЯЧНО СООБЩАТЬ О СОСТОЯНИИ ДЕЛА НА МЕСТАХ. 2 МАРТА КАЗКРАЙКОМ ВКП(Б) НАПРАВИЛ НА МЕСТА ПИСЬМО « О МЕЖНАЦИОНАЛЬНЫХ ОТНОШЕНИЯХ И ГРУППИРОВКАХ ВНУТРИ ПАРТИЙНЫХ ОРГАНИЗАЦИЙ», ПОСКОЛЬКУ ОБНАРУЖИЛИСЬ НОВЫЕ ПОДТВЕРЖДЕНИЯ ГРУППИРОВОЧНОЙ БОРЬБЫ, ОСОБЕННО ПРИ ПЕРЕВЫБОРАХ СОВЕТОВ. ТРУДНО БЫЛО, ПО ПРИЗНАНИЮ РУКОВОДЯЩЕГО ОРГАНА, «СКАЗАТЬ, КТО БОЛЬШЕ РАЗЛАГАЕТ» - БЕСПАРТИЙНЫЕ ПРЕДСТАВИТЕЛИ РОДОВ «НАШИ ПАРТРЯДЫ ИЛИ НАОБОРОТ». ЭТИ ЯВЛЕНИЯ НАБЛЮДАЛИСЬ ВО ВСЕХ РЕГИОНАЛЬНЫХ ОРГАНИЗАЦИЯХ ВКП (Б), А ОБИЛИЕ РЕЗОЛЮЦИЙ ТОЖЕ ПОВСЮДУ НЕ ДАВАЛО ДОЛЖНЫХ РЕЗУЛЬТАТОВ, ПОРОЖДАЯ ПЕССИМИЗМ СРЕДИ ПАРТИЙЦЕВ КАК ПО ПОВОДУ ВОЗМОЖНОСТИ РЕШИТЬ ПРОБЛЕМУ В СИЛУ ЕЕ ЗЛОСТНОЙ УКОРЕНЕННОСТИ, ТАК И В ОТНОШЕНИИ ДЕЙСТВЕННОСТИ ПРИНИМАВШИХСЯ РЕШЕНИЙ. В КАЧЕСТВЕ ПАНАЦЕИ ОТ ХРОНИЧЕСКОЙ БОЛЕЗНИ ПРЕДЛАГАЛОСЬ РАЗЛИЧАТЬ НИЗОВУЮ МАССУ КОММУНИСТОВ, РОДОВЫМИ СВЯЗЯМИ «СПАЯННУЮ» С БЕСПАРТИЙНЫМИ В АУЛЕ (ДЛЯ НИХ НАЗНАЧАЛИСЬ «ВОСПИТАНИЕ, ПРИМЕР, ЕЩЕ РАЗ ВОСПИТАНИЕ И ПРИМЕР»), И РУКОВОДСТВО. В ПОСЛЕДНЕМ ПРОЯВЛЯЛИСЬ НЕ ТОЛЬКО ПРИНЦИПИАЛЬНЫЕ РАСХОЖДЕНИЯ, НО И БОРЬБА ЗА ЛИЧНОЕ ВЛИЯНИЕ И ЗА ВЛАСТЬ, И БЕЗОТВЕТСТВЕННОСТЬ ИЗ-ЗА ОТРЫВА ОТ МАСС, ЧТО ПОРОЖДАЛО ДОНОСЫ, В Т.Ч. «С ГРУППОВОЙ ЦЕЛЬЮ», И УТАИВАНИЕ « ДЕЗОРГАНИЗУЮЩИХ ДЕЙСТВИЙ ГРУППОВЫХ РУКОВОДИТЕЛЕЙ». ДЛЯ ЭТОЙ НАИБОЛЕЕ ВРЕДНОЙ ЧАСТИ ПОЛАГАЛАСЬ УДАРНАЯ ДОЗА СПЕЦМЕРОПРИЯТИЙ : СОБРАНИЯ АКТИВА, « ОРГАНИЗАЦИЯ НИЗОВ ДЛЯ ВСКРЫТИЯ» ДЕЙСТВИЙ ГРУППИРОВЩИКОВ И ДАВЛЕНИЯ НА НИХ, НАКАЗАНИЕ ОСОБО ОТЛИЧИВШИХСЯ, ВПЛОТЬ ДО ИСКЛЮЧЕНИЯ ИЗ ПАРТИИ, ДЕЛОВОЙ ПОДБОР КАДРОВ И, КОНЕЧНО, ОТРЫВ ПАРТИЙНЫХ ВЕРХОВ ОТ ИДЕОЛОГИЧЕСКОГО ВЛИЯНИЯ ЧЛЕНОВ АЛАШ, КОИХ ВСЕ ЖЕ РАЗРЕШАЛОСЬ ИСПОЛЬЗОВАТЬ В СОВЕТСКИХ ОРГАНАХ ${ }^{88}$.

ЧТОБЫ, НАКОНЕЦ, РАЗОБРАТЬСЯ В СИТУАЦИИ И КАК-ТО ПОКОНЧИТЬ С УТОМИТЕЛЬНОЙ ДЛЯ ВСЕХ БОРЬБОЙ, КОНТРОЛЬНАЯ КОМИССИЯ ЕЩЕ С ОСЕНИ 1925 Г. ПОПРОБОВАЛА ОСНОВАТЕЛЬНО ИССЛЕДОВАТЬ ИСТИННЫЕ ПРИЧИНЫ БЕДЫ И НАЙТИ МЕТОДЫ ЕЕ УСТРАНЕНИЯ. ИСПОЛЬЗОВАЛИСЬ АРХИВНЫЕ МАТЕРИАЛЫ, СВЕДЕНИЯ ИЗ УСТНЫХ БЕСЕД И ПИСЬМЕННЫЕ. ОДНАКО ВЫШЛИ « НЕОБРАБОТАННЫЕ, В БОЛЬШИНСТВЕ СЛУЧАЕВ СЫРЫЕ 
МАТЕРИАЛЫ», А ПОТОМУ КОМИССИЯ ПОЛОЖИЛАСЬ НА АРХИВЫ И ОПЯТЬ ЖЕ - НА ПИСЬМЕННЫЕ СВИДЕТЕЛЬСТВА КРАЕВОГО И ГУБЕРНСКОГО АКТИВА, РАССЧИТЫВАЯ, ВИДИМО, НА ПОНИМАНИЕ ИНФОРМАТОРАМИ СВОЕЙ ОТВЕТСТВЕННОСТИ. В ДОКЛАДЕ ОСНОВНЫЕ ПРИЧИНЫ ВОЗНИКНОВЕНИЯ И РАЗВИТИЯ ГРУППИРОВОК ПРАВОМЕРНО СВЯЗЫВАЛИСЬ С ОСОБЕННОСТЯМИ СОЦИАЛЬНЫХ ПРОЦЕССОВ, КОГДА ПО МЕРЕ КОЛОНИЗАЦИИ КРАЯ УСИЛИЛИСЬ КУЛЬТУРНЫЙ ПРОГРЕСС, КРИСТАЛЛИЗАЦИЯ ПОЛИТИЧЕСКИХ ОРИЕНТИРОВ ИНТЕЛЛИГЕНЦИИ И НАСЕЛЕНИЯ В ЦЕЛОМ. БОРЬБА ЗА ВЛАСТЬ ПОВЫСИЛА РОЛЬ СОЦИАЛЬНО-КЛАССОВЫХ ПРИОРИТЕТОВ В ПОВЕДЕНИИ НЕМНОГОЧИСЛЕННЫХ, НО РАЗНОШЕРСТНЫХ ПО ПРОИСХОЖДЕНИЮ И ПОЛИТИЧЕСКОМУ ОПЫТУ НАЦИОНАЛОВ. ПРОТИВОРЕЧИЯ В ИХ СРЕДЕ БЫЛИ НЕИЗБЕЖНЫ, А « ЕВРОПЕЙЦЫ» ВЫНУЖДЕННО ИСПОЛЬЗОВАЛИ ВСЕХ, КАЗАВШИХСЯ СКОЛЬКО-ТО ГОДНЫМИ ДЛЯ ДЕЛА, ПЫТАЯСЬ НА ХОДУ РАЗОБРАТЬСЯ, «КТО ЕСТЬ КТО» И КАК-ТО ОПТИМИЗИРОВАТЬ УПРАВЛЕНИЕ. ВЫДЕЛЯВШИЕСЯ ГРУППЫ (ВНУТРИ НИХ ТОЖЕ МОГЛИ ВОЗНИКАТЬ КОНФЛИКТЫ И АЛЬЯНСЫ) ОБОЗНАЧАЛИСЬ ПО ЛИДЕРАМ, А ДЛЯ ИХ ОЦЕНКИ ИСПОЛЬЗОВАЛИСЬ СВЕДЕНИЯ КОНКУРЕНТОВ. СУБЪЕКТИВИЗМ В ИТОГЕ БЫЛ НЕИЗБЕЖЕН : ДОСТАТОЧНО ОГРАНИЧЕННОЕ ПЕРЕСЕКАЮЩЕЕСЯ ПРОСТРАНСТВО ПОСТУПКОВ, СМЫСЛОВ, АМБИЦИЙ, ПОДОЗРЕНИЙ И НЕДОМОЛВОК, ВЗАИМНЫХ ОБВИНЕНИЙ, ПРОТИВОРЕЧИВЫХ ОБЪЯСНЕНИЙ ОДНИХ И ТЕХ ЖЕ СОБЫТИЙ МОГЛО ПОСТАВИТЬ В ТУПИК ДАЖЕ САМЫХ ОПЫТНЫХ АНАЛИТИКОВ ЭТНОСОЦИАЛЬНОЙ ПСИХОЛОГИИ. ХОДЖАНОВ, К ПРИМЕРУ, ГРУППИРОВКИ СВЯЗЫВАЛ С ПЕСТРЫМ НАЦИОНАЛЬНЫМ СОСТАВОМ КРЕСТЬЯН, КОГДА ОТ УКЛОНОВ НЕ СВОБОДЕН И НЕ ГАРАНТИРОВАН НИ ОДИН АКТИВНЫЙ КОММУНИСТ РЕСПУБЛИКИ.

ТАК ИЛИ ИНАЧЕ, ПИСЬМЕННЫЕ ОБЪЯСНЕНИЯ ФИГУРАНТОВ ПЕСТРИЛИ ВЗАИМНЫМИ УПРЕКАМИ В СХОДНЫХ ГРЕХАХ : КАРЬЕРИЗМ, НЕВЕРНОЕ ТОЛКОВАНИЕ И ОСУЩЕСТВЛЕНИЕ НАЦИОНАЛЬНОЙ ПОЛИТИКИ, УКЛОН К « КОЛОНИЗАТОРСТВУ» ОДНИХ (МЕНДЕШЕВЦЕВ) И ДЕЙСТВИЯ ПОД ВЛИЯНИЕМ НАЦИОНАЛИСТОВ-АЛАШОРДИНЦЕВ ДРУГИХ (САДВОКАСОВЦЕВ). ВОЗНИКШИЕ В НЕДРАХ ТАССР ГРУППЫ РЫСКУЛОВА И ХОДЖАНОВА ДОБАВИЛИ ОСТРОТЫ И ПУТАНИЦЫ В БОРЬБУ ЗА РУКОВОДЯЩИЕ ПОСТЫ, ОСОБЕННО В СВЯЗИ С РАЗМЕЖЕВАНИЕМ СРЕДНЕЙ АЗИИ. В ИТОГЕ «В СТАРОМ КАЗАХСТАНЕ» ПОБЕДУ ОДЕРЖАЛА САДВОКАСОВСКАЯ ГРУППА, А В ПРИСОЕДИНЕННЫХ ОБЛАСТЯХ ЮГА ХОДЖАНОВСКАЯ, И К V КРАЕВОЙ ПАРТКОНФЕРЕНЦИИ ${ }^{89}$ «САДВОКАСОВСКАЯ ГРУППА ЯВЛЯЕТСЯ ПРЕОБЛАДАЮЩЕЙ СИЛОЙ». «ЕВРОПЕЙЦЫ» ПРИ ЭТОМ СТАНОВИЛИСЬ ЗАЛОЖНИКАМИ ЛЮБОЙ ИЗ ГРУПП - НЕВАЖНО, СТАРАЛИСЬ ОНИ БЫТЬ « РЕГУЛЯТОРАМИ», ПОДДЕРЖИВАЛИ ТУ ИЛИ ИНУЮ «ИДЕЙНУЮ ПЛАТФОРМУ» ИЛИ ОСТАВАЛИСЬ БЕЗРАЗЛИЧНЫМИ.

КОМИССИЯ ЗАКЛЮЧИЛА : ГРУППЫ ЛАВИРОВАЛИ, ПРИВЛЕКАЯ СТОРОННИКОВ ПАТРИАРХАЛЬНО-РОДОВОЙ ИЕРАРХИИ ДЛЯ ПРЕОБЛАДАНИЯ НАД КОНКУРЕНТАМИ. АЛАШОРДИНЦЫ ВНОВЬ ОКАЗЫВАЛИСЬ В ЦЕНТРЕ ОБВИНЕНИЙ ${ }^{90}$. ЭТО ОБЪЯСНЯЛОСЬ НЕ СТОЛЬКО ИХ КОВАРСТВОМ И ИЗОЩРЕННОЙ ХИТРОСТЬЮ, СКОЛЬКО ЭТНИЧЕСКОЙ ТРАДИЦИЕЙ И ПОЛИТИКО-ПРАВОВОЙ КУЛЬТУРОЙ КАЗАХОВ. ПРЕДЛОЖЕНИЯ АЛАШЕВЦЕВ О САМОБЫТНОМ ПУТИ К СОЦИАЛИЗМУ БЫЛИ ОПРАВДАННЫ, НО МОГЛИ УВЕСТИ БОЛЬШЕВИКОВ, КАК ИМ КАЗАЛОСЬ, НА ОКОЛИЦУ, ДАЛЕКУЮ ОТ УВЕРЕННОГО И ПОБЕДНОГО ПУТИ ПО БУДТО БЫ ЯСНОЙ МАРКСИСТСКОЙ МАГИСТРАЛИ. ПОЭТОМУ ОБВИНЕНИЯ В НАЦИОНАЛИЗМЕ И РАЗЖИГАНИИ МЕЖНАЦИОНАЛЬНОЙ РОЗНИ, АБСОЛЮТИЗАЦИИ ЗАДАЧ КОРЕНИЗАЦИИ, НЕДОВЕРИИ К РУКОВОДЯЩЕЙ РОЛИ РУССКОГО ПРОЛЕТАРИАТА И ВОЗМОЖНОСТИ СОВЕТИЗАЦИИ АУЛА И ПР. АДРЕСОВАЛИСЬ ИМЕННО АЛАШОРДИНЦАМ. 
МЕЖДУ ТЕМ ОБЪЕДИНЕННЫЙ ПЛЕНУМ КАЗКРАЙКОМА И КРАЙКК ВКП(Б) 29 НОЯБРЯ 1926 Г. ОБСУДИЛ ПОЛОЖЕНИЕ В БЮРО КРАЙКОМА ПАРТИИ В СВЯЗИ ВСЕ С ТОЙ ЖЕ ГРУППИРОВОЧНОЙ БОРЬБОЙ. ГЛАВНЫМИ ВИНОВНИКАМИ ОБЪЯВЛЯЛИСЬ ХОДЖАНОВ, УЖЕ НЕ РАБОТАВШИЙ В РЕСПУБЛИКЕ, САДВОКАСОВ И МУНБАЕВ. ОНИ ОСУЖДАЛИСЬ ЗА ПОПЫТКИ ПРОТИВОСТОЯТЬ РАДИКАЛЬНОМУ СЛОМУ ТРАДИЦИОННЫХ СОЦИАЛЬНОЭКОНОМИЧЕСКИХ ОТНОШЕНИЙ В АУЛЕ И ПРОВЕСТИ КОРЕНИЗАЦИЮ АППАРАТА ПРОПОРЦИОНАЛЬНО ЧИСЛЕННОСТИ КАЗАХСКОГО НАСЕЛЕНИЯ, А НЕ ПО « ФУНКЦИОНАЛЬНОСТИ». МУНБАЕВ И САДВОКАСОВ ЗАЯВИЛИ ОБ ОТКАЗЕ ОТ ГРУППОВОЙ БОРЬБЫ. ХОДЖАНОВ В ФЕВРАЛЕ 1927 Г. В СВЯЗИ С ЭТИМ РЕШЕНИЕМ НАПОМНИЛ КРАЙКОМУ О СВОЕЙ ОЦЕНКЕ ГРУППИРОВОК КАК КАРЬЕРНЫХ, ГДЕ ПОЛИТИЧЕСКИЕ И РОДОВЫЕ ФАКТОРЫ ИГРАЮТ ОБСЛУЖИВАЮЩУЮ РОЛЬ», И БЮРО КРАЙКОМА - КАК КОАЛИЦИИ ГРУПП, А НЕ РАБОЧЕГО ОРГАНА. ОБЪЯСНЯЯ УЧАСТИЕ В ГРУППИРОВКАХ АКТИВНОЙ РЕАКЦИЕЙ НА ПОЛИТИЧЕСКУЮ СРЕДУ, А НЕ ЛИЧНЫМ ТВОРЧЕСТВОМ, ОН НАПОМИНАЛ О РЫСКУЛОВЕ, КОТОРЫЙ «БОЛЬШЕ ВСЕХ ПОДВИЗАЛСЯ [...] В ЛИЧНЫХ ГРУППИРОВОЧНЫХ НАПАДКАХ НА МЕНЯ». АНАЛОГИЧНЫЕ ОБЪЯСНЕНИЯ В НЕПРИЧАСТНОСТИ К СОБЫТИЯМ ПОСЛЕ ЕГО ОТЗЫВА ИЗ КАССР ОН ВЫНУЖДЕН БЫЛ ПОВТОРИТЬ В ПИСЬМЕ В КАЗКРАЙКОМ ОТ 10 АВГУСТА 1927 Г., ПРИЗНАВ, МЕЖДУ ПРОЧИМ, ЧТО КАЗАХСТАН КАК СЛЕДУЕТ НЕ ЗНАЕТ, И ПРОЯВЛЯЛ СЕБЯ ВО ВРЕМЯ РАБОТЫ ТАМ «ГЛАВНЫМ ОБРАЗОМ, КАК ТУРКЕСТАНЕЦ» ${ }^{91}$. К ЭТОМУ ВРЕМЕНИ В СООТВЕТСТВИИ С ОСНОВНЫМИ ТЕНДЕНЦИЯМИ БОРЬБЫ ЗА ВЛАСТЬ В ЦЕНТРЕ И НА МЕСТАХ ГРУППИРОВКИ СТАЛИ ОЦЕНИВАТЬСЯ ПО ДВУМ КРИТЕРИЯМ « ПРАВЫЕ» И «ЛЕВЫЕ». И БОРЬБА С НИМИ С КОНЦА 1925 Г. РАЗВОРАЧИВАЛАСЬ ПО ВВЕДЕННЫМ В МОСКВЕ СТАНДАРТАМ: РАЗОБЛАЧЕНИЯ НА СОБРАНИЯХ И В ПЕЧАТИ, ПАРТИЙНЫЕ ВЗЫСКАНИЯ, «ВПЛОТЬ ДО ВЫСШИХ МЕР ПО ОТНОШЕНИЮ РУКОВОДИТЕЛЕЙ ИХ». ПОКАЗАТЕЛЬНЫМ СТАЛ ПРОЦЕСС 1926 Г. НАД Ж. АЙМАУТОВЫМ, КОТОРЫЙ САДВОКАСОВ ОЦЕНИЛ КАК ПОЛИТИЧЕСКИЙ СУД НАД АЛАШ-ОРДОЙ ${ }^{92}$. ПРЕЗИДИУМ КАЗКРАЙКОМА ВКП(Б) СНОВА ОБРАТИЛСЯ К ЗЛОСЧАСТНЫМ ГРУППИРОВКАМ 17 ОКТЯБРЯ 1927 Г. ПРИЧИНЫ ИХ ПОЯВЛЕНИЯ НАЗЫВАЛИСЬ ВСЕ ТЕ ЖЕ, А ОТКАЗ ОТ НИХ НА ІІІ ПЛЕНУМЕ КРАЙКОМА РАСЦЕНИВАЛСЯ КАК ЗАКОНОМЕРНОЕ СВИДЕТЕЛЬСТВО РОСТА КЛАССОВОГО СОЗНАНИЯ ТРУДОВЫХ МАСС И САМИХ КОММУНИСТОВ. МЕТОДЫ ДАЛЬНЕЙШЕГО ОЧИЩЕНИЯ ОТ ЗАСТАРЕЛОЙ БОЛЕЗНИ ТОЖЕ НЕ ОТЛИЧАЛИСЬ НОВИЗНОЙ НАПРАВИТЬ «ПО ПАРТИЙНОМУ ПУТИ» ЗАМЕЧЕННЫЕ РАЗНОГЛАСИЯ, «УГЛУБИТЬ, УСИЛИТЬ, ОБРАТИТЬ ВНИМАНИЕ» И ПР. ВПРОЧЕМ, РАСШИРЕНИЕ СОЦИАЛЬНОЙ БАЗЫ ЧЕРЕЗ ОБЩЕСТВЕННЫЕ СЕТИ И ОРГАНИЗАЦИЮ БЕДНОТЫ, ПОДГОТОВКА КАДРОВ « ИЗ НАРОДА» ПОСТЕПЕННО УКРЕПЛЯЛИ ИДЕОЛОГИЧЕСКИЕ И ОРГАНИЗАЦИОННЫЕ ПОЗИЦИИ ВЛАСТИ. НАКОНЕЦ, 3 МАЯ 1928 Г. ЦК ВКП(Б) ПО ДОКЛАДУ КАЗКРАЙКОМА « ИЗЖИВАНИЕ ГРУППИРОВОЧНОЙ БОРЬБЫ» ТЕСНО СВЯЗАЛ СО ВСЕМ КОМПЛЕКСОМ ФОРСИРОВАННОГО ВНЕДРЕНИЯ СОЦИАЛИЗМА В РЕСПУБЛИКЕ (ЛИКВИДАЦИЯ БАЙСТВА, ЗЕМЛЕУСТРОЙСТВО, КОРЕНИЗАЦИЯ СОВЕТСКОГО АППАРАТА, РАЗВИТИЕ ОБРАЗОВАНИЯ И Т.Д.). ГЛАВНЫЙ УПОР УЖЕ ДЕЛАЛСЯ НА ОРГАНИЗАЦИОННО-ХОЗЯЙСТВЕННЫЕ ЗАДАЧИ ${ }^{93}$. ВСЕГО С АПРЕЛЯ 1920 ПО МАЙ 1928 ГГ. ЦК ПАРТИИ ПРИНЯЛ 16 ПОСТАНОВЛЕНИЙ И ПИСЕМ О ПАРТОРГАНИЗАЦИЯХ КАССР, И 14 ИЗ НИХ ПО ОРГАНИЗАЦИОННЫМ И ЭТНОПОЛИТИЧЕСКИМ ПРОБЛЕМАМ ${ }^{94}$.

70 В РАМКАХ ОСТРОЙ БОРЬБЫ В РУКОВОДСТВЕ ВКП(Б) БЮРО КАЗКРАЙКОМА ПО ДАННЫМ КОНТРОЛЬНОЙ КОМИССИИ НЕ МОГЛО НЕ ОБНАРУЖИТЬ СОЮЗНИКОВ ТРОЦКОГО В ЛИЦЕ 
САДВОКАСОВА, СУЛТАНБЕКОВА И МУСТАМБАЕВА И ПОДТВЕРЖДЕНИЙ ИХ НАЦИОНАЛИСТИЧЕСКОЙ ЛИНИИ, СВЯЗИ С АЛАШ-ОРДОЙ И ПР. В ПОСТАНОВЛЕНИИ ОТ 16 МАЯ 1928 Г. ОНИ ОБВИНЯЛИСЬ В ОЧЕНЬ «СВОЕВРЕМЕННЫХ» ДЛЯ РАЗОБЛАЧЕНИЯ ВРАГОВ СОЦИАЛИЗМА «БЛОКАХ» - «СЛЕВА», “ СПРАВА», И НАОБОРОТ»" НАЧАЛИСЬ АРЕСТЫ И РЕПРЕССИИ, В Т.Ч. ПРОТИВ АЛАШОРДИНЦЕВ, А ЗАТЕМ И ВСЕХ ОСТАЛЬНЫХ. БЫЛИ ОТСТРАНЕНЫ И НАИБОЛЕЕ ОПЫТНЫЕ, ПРЕДАННЫЕ ИДЕЯМ БОЛЬШЕВИЗМА НАЦИОНАЛЫ, АКТИВНО УЧАСТВОВАВШИЕ В БОРЬБЕ ЗА СОВЕТСКУЮ ВЛАСТЬ.

71 СТАНОВЛЕНИЕ СОВЕТСКОЙ ГОСУДАРСТВЕННОСТИ, ЕЕ ТРАНСФОРМАЦИЯ И СТАБИЛИЗАЦИЯ В ХОДЕ ЭТНИЧЕСКОГО ОФОРМЛЕНИЯ И РЕСТРУКТУРИЗАЦИИ ПРАВЯЩЕГО КЛАССА КАЗАХСКОЙ АССР ОТРАЖАЮТ ДИНАМИКУ ЕГО ПОЛИТИЧЕСКОЙ КУЛЬТУРЫ И АМБИВАЛЕНТНЫЙ ХАРАКТЕР СОВЕТСКОЙ ЭТНОПОЛИТИКИ. КОНФЛИКТНОЕ ВЗАИМОДЕЙСТВИЕ РАЗВИВАЛОСЬ ПО РАЗНЫМ СЕТЯМ : ПОНАЧАЛУ МЕЖДУ «СТАРОЙ» ЭЛИТОЙ И БОЛЬШЕВИКАМИ, ПОСЛЕ ОТСТРАНЕНИЯ АЛАШЕВЦЕВ ОТ ПРЯМОГО УЧАСТИЯ ВО ВЛАСТИ - МЕЖДУ «ЕВРОПЕЙЦАМИ» И НАЦИОНАЛАМИ, ВНУТРИ ПОСЛЕДНИХ - МЕЖДУ ФОРМИРУЮЩИМСЯ ПОКОЛЕНИЕМ НОМЕНКЛАТУРЫ И ТЕМИ ЕЕ ПРЕДСТАВИТЕЛЯМИ, КОТОРЫЕ СОХРАНЯЛИ НЕФОРМАЛЬНЫЕ ИЕРАРХИЧЕСКИЕ СВЯЗИ С ТРАДИЦИОННОЙ ЭЛИТОЙ. СВОЮ РОЛЬ ИГРАЛИ И МЕЖЛИЧНОСТНЫЕ КОНФЛИКТЫ. К ТОМУ ЖЕ, НОВАЯ КАЗАХСКАЯ БЮРОКРАТИЯ НЕ ОТКАЗАЛАСЬ ОТ ВОЗМОЖНОСТИ СОВМЕСТИТЬ АДМИНИСТРАТИВНЫЙ РЕСУРС С КАПИТАЛОМ ПРЕЖНИХ СОЦИАЛЬНЫХ СЕТЕЙ (РОДОВЫХ, ЖУЗОВЫХ $)^{96}$. ДОПОЛНИТЕЛЬНУЮ ОСТРОТУ БОРЬБЕ НАЦИОНАЛОВ ПРИДАЛО РАЗМЕЖЕВАНИЕ, УСИЛИВ ИХ СТРЕМЛЕНИЕ К ПЕРЕГРУППИРОВКЕ РЕГИОНОВ И ПЕРСОН ВЛИЯНИЯ НА ФОНЕ КОНСТРУИРОВАНИЯ ЭТНИЧЕСКОЙ КОНСОЛИДАЦИИ СВЕРХУ. В КАССР РОДОВЫЕ МЕХАНИЗМЫ ВЛАСТИ ОТЧАСТИ ВСТРАИВАЛИСЬ В УПРАВЛЕНЧЕСКИЕ ИНСТИТУТЫ И ОТНОШЕНИЯ ${ }^{97}$, ФОРМИРОВАЛАСЬ НОВАЯ ВНУТРИЭТНИЧЕСКАЯ СИСТЕМА ЗАВИСИМОСТЕЙ, ОБУСЛОВЛЕННАЯ ДОМИНИРОВАНИЕМ БЮРОКРАТИЧЕСКИХ КРИТЕРИЕВ СОЦИАЛЬНОЙ ОРГАНИЗАЦИИ. ПРЕЖНИЕ ЦЕННОСТНЫЕ ОРИЕНТИРЫ КУЛЬТИВИРОВАЛИСЬ В СЕМЕЙНОЙ, БЫТОВОЙ СФЕРАХ И МЕЖЛИЧНОСТНЫХ ОТНОШЕНИЯХ, НО И ЗДЕСЬ НОВАЯ ИЕРАРХИЯ ОБЩЕСТВЕННЫХ ОТНОШЕНИЙ ОКАЗЫВАЛА ВЛИЯНИЕ: ПРОИСХОДИЛО ОПРЕДЕЛЕННОЕ РАССЛОЕНИЕ НА ГРУППЫ, КОНЪЮНКТУРНО ОБЪЕДИНЯВШИЕ ВЛИЯТЕЛЬНЫХ В СОВЕТСКОЙ СИСТЕМЕ И ОТТОРГАВШИЕ ОТ СЕБЯ «НЕУДАЧНИКОВ». ПОСЛЕДНИЕ, В СВОЮ ОЧЕРЕДЬ, КОНСОЛИДИРОВАЛИСЬ НА ОСНОВЕ ВЗАИМОПОМОЩИ И В БОЛЬШЕЙ СТЕПЕНИ СОХРАНЯЛИ ПРИВЕРЖЕННОСТЬ ТРАДИЦИЯМ. ${ }^{98}$ ИНЫЕ ЭТНОСОЦИАЛЬНЫЕ ГРУППЫ ОСТАВАЛИСЬ ВНЕ ЭТИХ ВНУТРИЭТНИЧЕСКИХ СВЯЗЕЙ, ЧТО ВНОСИЛО ОПРЕДЕЛЕННУЮ НАПРЯЖЕННОСТЬ В МЕЖНАЦИОНАЛЬНЫЕ ОТНОШЕНИЯ.

ГОСУДАРСТВО В ЛИЦЕ НАЗНАЧЕНЦЕВ И БОЛЬШЕВИСТСКОЙ НАЦИОНАЛЬНОЙ БЮРОКРАТИИ, ДЕЙСТВУЯ СОВМЕСТНО ИЛИ ПАРАЛЛЕЛЬНО, НЕ ОТМЕНИЛИ КУЛЬТУРНЫЕ ОСОБЕННОСТИ И СМЫСЛЫ, ВНОСИМЫЕ В ПРЕДЛАГАЕМЫЕ ОБСТОЯТЕЛЬСТВА СОЦИАЛИСТИЧЕСКОГО СТРОИТЕЛЬСТВА. ПОПЫТКИ «ЕВРОПЕЙЦЕВ» ИСКОРЕНИТЬ « ОТСТАЛЫЕ» ЦЕННОСТИ И НОРМЫ, НАРЯДУ С КОНКУРЕНЦИЕЙ ВНУТРИ КАЗАХСКОЙ ЧАСТИ ПАРТИЙНО-СОВЕТСКОЙ АДМИНИСТРАЦИИ С ЕЕ АРСЕНАЛОМ ИНСТРУМЕНТОВ БОРЬБЫ ЗА ВЛИЯНИЕ, ОБУСЛОВИЛИ ОСТРОТУ И ДЛИТЕЛЬНОСТЬ ГРУППИРОВОЧНОЙ БОРЬБЫ. ЦЕНТР БЫЛ ВЫНУЖДЕН ПРИСПОСАБЛИВАТЬСЯ К СИТУАЦИИ НА МЕСТЕ. ЭТНИЧНОСТЬ И КУЛЬТУРА ПОМЕШАЛИ» ВЫСТРОИТЬ МОНОЛИТНЫЙ СТОЛП ВЛАСТИ - ОНА, СКОРЕЕ, ПОХОДИЛА НА « ТАНЦУЮЩИЕ БЕРЕЗЫ» В БОРОВОМ. С КОНЦА 1920-Х ГГ. ПОВСЕМЕСТНОЕ УСИЛЕНИЕ ЦЕНТРАЛИЗАЦИИ, 
ШЛИФОВКА МЕТОДОВ ФОРМИРОВАНИЯ НОМЕНКЛАТУРЫ И РЕПРЕССИИ ПРИВЕЛИ К ОПРЕДЕЛЕННОЙ СТАБИЛИЗАЦИИ И ВРЕМЕННОЙ «ВНУТРЕННЕЙ ЭМИГРАЦИИ» НАЦИОНАЛОВ, УЖЕ НЕ ВОСПРИНИМАВШИХСЯ ОТДЕЛЬНО ОТ СИСТЕМЫ.

\section{NOTES}

1. СТАТЬЯ ПОДГОТОВЛЕНА В РАМКАХ ПРОЕКТА РГНФ №15-31-14001А(Ц).

2. АНАЛИЗ ФОРМИРОВАНИЯ КАЗАХСКОГО ЧИНОВНИЧЕСТВА ЗАПАДНОГО КАЗАХСТАНА В ХІХ ВЕКЕ ВО ВЗАИМОСВЯЗИ С ПОЛИТИКОЙ ЦЕНТРА И РЕГИОНОВ ПРОВЕЛА Г.С.СУЛТАНГАЛИЕВА, «КАЗАХСКОЕ ЧИНОВНИЧЕСТВО ОРЕНБУРГСКОГО ВЕДОМСТВА: ФОРМИРОВАНИЕ И НАПРАВЛЕНИЕ ДЕЯТЕЛЬНОСТИ (ХІХ)», Acta Slavica Iaponica, 27, с. 77-101.

3. О. ХЛЕВНЮК, « СИСТЕМА ЦЕНТР-РЕГИОНЫ В 1930-1950-Е ГОДЫ», Cahiers du Monde russe, 44 (2-3), 2003, С. 253-268; «ПЕРИФЕРИЙНОСТЬ «ЦЕНТРА» В СОВРЕМЕННЫХ НАЦИОНАЛЬНЫХ ИСТОРИЧЕСКИХ НАРРАТИВАХ», Forum AI, Ab Imperio, 1, 2012.

4. КРЫМ, КИРГИЗИЯ, БУРЯТ-МОНГОЛИЯ, ЮГО-ОСЕТИЯ, КАРАКАЛПАКИЯ, ДАГЕСТАН, ТАТАРИЯ. РГАСПИ (РОССИЙСКИЙ ГОСУДАРСТВЕННЫЙ АРХИВ СОЦИАЛЬНО-ПОЛИТИЧЕСКОЙ ИСТОРИИ), Ф. 17, ОП. 68, ОРГРАСПРЕДОТДЕЛ ЦК РКП(Б), Д. 191, Л. 18 ; ЦК РКП(Б)-ВКП(Б) И НАЦИОНАЛЬНЫЙ ВОПРОС, КНИГА 1, 1918-1933 ГГ., М. : РОССПЭН, 2005, с. 355-359.

5. СУБЭТНИЧЕСКИЕ СВЯЗИ КАК НЕФОРМАЛЬНЫЕ СЕТИ В ПОЛИТИЧЕСКОЙ ЖИЗНИ И СТЕПЕНЬ УЧАСТИЯ ГОСУДАРСТВА В КОНСТИТУИРОВАНИИ ГРУПП С РАЗНЫМИ ПОЛИТИЧЕСКИМИ И КУЛЬТУРНЫМИ ЦЕЛЯМИ СЧИТАЕТ ВАЖНЫМИ Э. ШАТЦ, «РОЛЬ ГОСУДАРСТВА И УСТОЙЧИВОСТЬ РОДОВЫХ СВЯЗЕЙ В КАЗАХСТАНЕ», КАЗАХСТАН И РОССИЯ : ОБЩЕСТВА И ГОСУДАРСТВА, М. : « ПРАВА ЧЕЛОВЕКА», 2004, с. 128-129. ЛОКАЛЬНАЯ ПОЛИТИЧЕСКАЯ ЭЛИТА ПРЕКРАСНО ЗНАЛА, КАК ПРОДВИГАТЬ И МАНИПУЛИРОВАТЬ НАЦИОНАЛИСТИЧЕСКИМИ ЧУВСТВАМИ В СВОЮ ПОЛЬЗУ, СЧИТАЕТ ДЖ. СМИТ, « НАЦИОНАЛЬНОЕ СТРОИТЕЛЬСТВО И НАЦИОНАЛЬНЫЙ КОНФЛИКТ В СССР В 1920-Х ГОДАХ», Аb imperio. ЭТНИЧНОСТЬ И НАЦИЯ, 3, 2001. НА РОЛЬ СОЦИАЛЬНОГО КАПИТАЛА И ПОЛОЖЕНИЯ КАК СЕТЕВОГО РЕСУРСА ВЛАСТИ ОБРАТИЛ ВНИМАНИЕ Г. ДЕРЛУГЬЯН, АДЕПТ БУРДЬЕ НА КАВКАЗЕ : ЭСКИЗЫ К БИОГРАФИИ В МИРОСИСТЕМНОЙ ПЕРСПЕКТИВЕ, М. : ИЗДАТ.ДОМ Т ТЕРРИТОРИЯ БУДУЩЕГО», 2010, с. 515.

6. НА РЯДЕ ПРИМЕРОВ ЭТО РАССМАТРИВАЮТ F. Hirsch, Empire of nations: Ethnographic knowledge and the making of the Soviet Union, Ithaca : Cornell univ.press, 2005 ; A. Frings, " Playing Moscow off against Kazan : Azerbaijan maneuvering to latinization in the Soviet Union», Ab imperio, 4, 2009, c. 249-266 ; А. ХАУГЕН АНАЛИЗИРУЕТ ЭВОЛЮЦИЮ СОВЕТСКОЙ НАЦИОНАЛЬНОЙ ПОЛИТИКИ И КОНФЛИКТЫ МЕЖ- И ВНУТРИЭТНИЧЕСКОГО СВОЙСТВА В РУКОВОДСТВЕ РЕСПУБЛИК ЦЕНТРАЛЬНОЙ АЗИИ В СВЯЗИ С ИХ НАЦИОНАЛЬНО-ТЕРРИТОРИАЛЬНЫМ РАЗМЕЖЕВАНИЕМ, A. Haugen, The Establishment of National Republics in Soviet Central Asia, N.Y., 2003.

7. ДВИЖЕНИЕ АЛАШ В НАЧАЛЕ ХХ В. КОНСОЛИДИРОВАЛО КАЗАХСКУЮ ИНТЕЛЛИГЕНЦИЮ И ОБЩЕСТВЕННЫХ ДЕЯТЕЛЕЙ ВОКРУГ ИДЕИ КУЛЬТУРНОГО И ПОЛИТИЧЕСКОГО ПРОГРЕССА, В ДЕКАБРЕ 1917 Г. ПРОВОЗГЛАСИЛО АВТОНОМИЮ И СОЗДАЛО ПРАВИТЕЛЬСТВО АЛАШ-ОРДА ВО ГЛАВЕ С А.Н. БУКЕЙХАНОВЫМ. КОСАЧ СЧИТАЕТ : ЛИДЕРЫ АЛАШ-ОРДЫ СТАВИЛИ В ЦЕНТР КОНСТРУИРОВАВШЕГОСЯ ИМИ СООБЩЕСТВА « ФРАКЦИИ РОДОПЛЕМЕННЫХ ОБРАЗОВАНИЙ», К КОИМ ПРИНАДЛЕЖАЛИ САМИ, ЧТО ИСКЛЮЧАЛО ДЕМОКРАТИЧЕСКИЕ СПОСОБЫ СОЗИДАНИЯ НАЦИИ. Г. КОСАЧ, « КАЗАХСКИЙ “ОБРАЗОВАННЫЙ КЛАСС” В РОССИЙСКОЙ ИМПЕРИИ», КАЗАХСТАН 
И РОССИЯ: ОБЩЕСТВА И ГОСУДАРСТВА, М.: «ПРАВА ЧЕЛОВЕКА», 2004, с.52. ОН И СУШКО МЕЖРОДОВУЮ И МЕЖЖУЗОВУЮ КОНКУРЕНЦИЮ (ЖУЗ - ИСТОРИЧЕСКИ СЛОЖИВШИЕСЯ РЕГИОНАЛЬНЫЕ ОБЪЕДИНЕНИЯ КАЗАХОВ : СТАРШИЙ - ЮГ, СРЕДНИЙ - ЦЕНТР, ВОСТОК И СЕВЕР, МЛАДШИЙ - ЗАПАД КАЗАХСТАНА) ИЛЛЮСТРИРУЮТ ПРИМЕРАМИ БОРЬБЫ АЛАШ И ПАРТИИ « УШ ЖУЗ». СУШКО ПЫТАЕТСЯ ДОКАЗАТЬ НАЛИЧИЕ МЕЖЖУЗОВЫХ ПРОТИВОРЕЧИЙ В АЛАШ ОБРАЗОВАНИЕМ ЗАПАДНОГО И ВОСТОЧНОГО ОТДЕЛЕНИЙ АЛАШ-ОРДЫ, ТЯГОТЕНИЕМ СЕМИРЕЧЬЯ (КАЗАХОВ СТАРШЕГО ЖУЗА) К ТУРКЕСТАНУ ВСЛЕДСТВИЕ ЖУЗОВОЙ ПОЛИТИЧЕСКОЙ КУЛЬТУРЫ КАЗАХОВ И ИХ НЕСПОСОБНОСТИ К КОНСОЛИДАЦИИ. ОН СЧИТАЕТ : ВКЛЮЧЕНИЕ АЛАШЕВЦЕВ В ОРГАНЫ СОВЕТСКОЙ ВЛАСТИ ПОРОДИЛО МЕЖРОДОВУЮ БОРЬБУ МЕЖДУ НИМИ И НАЦИОНАЛ-КОММУНИСТАМИ, А ТАКЖЕ МЕЖДУ « ВСЕМИ КИРГИЗСКИМИ НАЦИОНАЛИСТАМИ» И РУССКИМИ КОММУНИСТАМИ. А.В. СУШКО, «МЕЖРОДОВАЯ БОРЬБА КАЗАХСКОЙ (КИРГИЗСКОЙ) ИНТЕЛЛИГЕНЦИИ В ГОДЫ РЕВОЛЮЦИИ И ГРАЖДАНСКОЙ ВОЙНЫ В РОССИИ», ВЕСТНИК ТГУ, 11 (67), 2008, с. 329-332, 334. НО В РУКОВОДСТВЕ « УШ ЖУЗ» БЫЛИ ПРЕДСТАВИТЕЛИ СРЕДНЕГО ЖУЗА, КАК И В АЛАШ, НАРЯДУ С ПРЕДСТАВИТЕЛЯМИ ДРУГИХ ЖУЗОВ. ВОСТОЧНОГО ОТДЕЛЕНИЯ АЛАШ-ОРДЫ ВООБЩЕ НЕ БЫЛО, А ЗАПАДНОЕ СОЗДАНО В СЕНТЯБРЕ 1918 Г. ВМЕСТО Т.Н. УИЛЬСКОГО ОЛЯЯТА (ВИЛАЙЕТ, ОЛЯЯТ, ОЙЯЛАТ - АДМИНИСТРАТИВНО-ТЕРРИТОРИАЛЬНАЯ ЕДИНИЦА, СОЗДАНА В МАЕ 1918 Г. НА ТЕРРИТОРИИ УРАЛЬСКОЙ ОБЛАСТИ С ЦЕНТРОМ В ЖАМБЕЙТЫ) В ПРОТИВОВЕС АМБИЦИЯМ ПРОВОЗГЛАСИВШЕГО ЕГО ВЫХОДЦА ИЗ МЛАДШЕГО ЖУЗА, ЧЛЕНА АЛАШ-ОРДЫ Ж. ДОСМУХАМЕДОВА И В ИНТЕРЕСАХ ОРГАНИЗАЦИОННО-ПОЛИТИЧЕСКОГО УКРЕПЛЕНИЯ АВТОНОМИИ.

8. В.К. ГРИГОРЬЕВ, Н.Р. ДЖАГФАРОВ И В.П. ОСИПОВ, ИДЕЙНО-ПОЛИТИЧЕСКАЯ РАБОТА ПАРТИЙНЫХ ОРГАНИЗАЦИЙ КАЗАХСТАНА (1917-1925 ГГ.), АЛМА-АТА : КАЗАХСТАН, 1989, с. 89 ; Н.Р. ДЖАГФАРОВ, В.П. ОСИПОВ, «НАЦИОНАЛ-УКЛОНИЗМ: МИФЫ И РЕАЛЬНОСТЬ», О ПРОШЛОМ - ДЛЯ БУДУЩЕГО, (НЕКОТОРЫЕ АКТУАЛЬНЫЕ ПРОБЛЕМЫ ИСТОРИИ КОМПАРТИИ КАЗАХСТАНА В СВЕТЕ ГЛАСНОСТИ), АЛМА-АТА : КАЗАХСТАН, 1990, с. 153-186. ЗАСЛУЖИВАЮТ ВНИМАНИЯ ИХ УКАЗАНИЯ НА РАЗЛИЧИЯ В ОБРАЗОВАТЕЛЬНОМ УРОВНЕ И ПОЛИТИЧЕСКОМ ОПЫТЕ РАЗНЫХ ПОКОЛЕНИЙ НАЦИОНАЛОВ, СМЕНЯВШИХСЯ ВО ВЛАСТИ; ПОПЫТКИ ТЕХ И ДРУГИХ С РАЗНЫМИ ЦЕЛЯМИ ИСПОЛЬЗОВАТЬ ВО ВНУТРИЭТНИЧЕСКОЙ КОНКУРЕНЦИИ «ЕВРОПЕЙЦЕВ»; СТРЕМЛЕНИЕ «НАЦИОНАЛ-УКЛОНИСТОВ» КОНСОЛИДИРОВАТЬ КАЗАХСКУЮ ЧАСТЬ ПАРТБЮРОКРАТИИ И СОВЕТСКИХ АКТИВИСТОВ ; РОЛЬ МЕЖЛИЧНОСТНЫХ ОТНОШЕНИЙ В БОРЬБЕ ГРУППИРОВОК И ЕЕ ВЛИЯНИЕ НА ВСЕ СФЕРЫ НАЦИОНАЛЬНО-ГОСУДАРСТВЕННОГО СТРОИТЕЛЬСТВА.

9. Н. МАСАНОВ, «КАЗАХСКАЯ ПОЛИТИЧЕСКАЯ И ИНТЕЛЛЕКТУАЛЬНАЯ ЭЛИТА. КЛАНОВАЯ ПРИНАДЛЕЖНОСТЬ И ВНУТРИЭТНИЧЕСКОЕ СОПЕРНИЧЕСТВО», ВЕСТНИК ЕВРАЗИИ, 1, 1999, с. 46-61.

10. ВОПРОСЫ ИСТОРИИ КОМПАРТИИ КАЗАХСТАНА, ВЫП. 6, АЛМА-АТА : КАЗАХСТАН, 1969, с. 113. В 1921 Г. ОТВЕТСЕКРЕТАРЬ СЕМИПАЛАТИНСКОГО ГУБКОМА ПАРТИИ ПИСАЛ В ЦК РКП(Б), ЧТО В ГУБЕРНИИ 80 \% КОММУНИСТОВ НЕГРАМОТНЫ, ПАРТЯЧЕЙКИ РАЗБРОСАНЫ НА 500-800 ВЕРСТ, ЛИТЕРАТУРА И МАТЕРИАЛЫ ЦК ДОХОДЯТ В НИЧТОЖНЫХ КОЛИЧЕСТВАХ, ГАЗЕТА ВЫХОДИТ 2-3 РАЗА В НЕДЕЛЮ РАЗМЕРОМ В 0,5 ПИСЧЕГО ЛИСТА, НЕТ ДАЖЕ БУМАГИ, ЧЕРНИЛЬНИЦ И РУЧЕК. ЦЕНТР ДОКУМЕНТАЦИИ НОВЕЙШЕЙ ИСТОРИИ ВОСТОЧНО-КАЗАХСТАНСКОЙ ОБЛАСТИ, Г.СЕМЕЙ (цдни вко), Ф. 1, оп. 1, д. 18, л. 27.

11. И.В. СТАЛИН, СОЧ., Т. 4, с. 360-361.

12. В.А. ТУЛЕПБАЕВ, ГЛАВ. РЕД., И ДР., ВЕХИ КОНСОЛИДАЦИИ. ИЗ ОПЫТА ПАРТИЙНЫХ ОРГАНИЗАЦИЙ КАЗАХСТАНА В РЕШЕНИИ НАЦИОНАЛЬНОГО ВОПРОСА В 1917-1927 ГГ. (К 70-ЛЕТИЮ КОМПАРТИИ КАЗАХСТАНА), СБ. ДОКУМЕНТОВ, АЛМА-АТА : КАЗАХСТАН, 1990, с. 194-212 ; КОММУНИСТИЧЕСКАЯ ПАРТИЯ КАЗАХСТАНА: ОРГАНИЗАЦИОННО-ПОЛИТИЧЕСКОЕ РАЗВИТИЕ: СПРАВОЧНИК, АЛМА-АТА : КАЗАХСТАН, 1990, С. 278-288.

13. КОММУНИСТИЧЕСКАЯ ПАРТИЯ КАЗАХСТАНА : ОРГАНИЗАЦИОННО-ПОЛИТИЧЕСКОЕ РАЗВИТИЕ, С. 34-37, 278-283. В МАЕ 1924 Г. В СОСТАВЕ КИРОБКОМА БЫЛО 10 КАЗАХОВ И 9 РУССКИХ (2 СЕКРЕТАРЯ - 
РУССКИЙ И КАЗАХ), ИЗ НИХ 12 С МЕСТ, В Т.Ч. СЕКРЕТАРИ ВСЕХ ГУБКОМОВ. 31 \% ЧЛЕНОВ ОБКОМА СОСТАВЛЯЛИ РАБОЧИЕ, КАЗАХИ - 53. РГАСПИ, Ф. 17, ОП. 31, ИНФОРМАЦИОННЫЙ ОТДЕЛ, Д. 24, Л. 1.

14. ТУЛЕПБАЕВ, ГЛАВ. РЕД., И ДР., ВЕХИ КОНСОЛИДАЦИИ, С. 194-212; КОММУНИСТИЧЕСКАЯ ПАРТИЯ КАЗАХСТАНА : ОРГАНИЗАЦИОННО-ПОЛИТИЧЕСКОЕ РАЗВИТИЕ, С. 278-288.

15. Й. БАБЕРОВСКИ СЧИТАЕТ : ОНИ, КАК И М.СУЛТАНГАЛИЕВ ИЛИ Ф. ХОДЖАЕВ, ПЫТАЛИСЬ ПРИМИРИТЬ НОВОЕ И КУЛЬТУРНЫЕ ТРАДИЦИИ, СОЦИАЛИЗМ И ИСЛАМ. Й. БАБЕРОВСКИ, ВРАГ ЕСТЬ ВЕЗДЕ : СТАЛИНИЗМ НА КАВКАЗЕ, М. : РОССПЭН, 2010, 269-270.

16. О ЖУЗОВОЙ И РОДОВОЙ ПРИНАДЛЕЖНОСТИ КАЗАХСКОЙ ЭЛИТЫ СМ. : МАСАНОВ, « КАЗАХСКАЯ ПОЛИТИЧЕСКАЯ И ИНТЕЛЛЕКТУАЛЬНАЯ ЭЛИТА...» ; Т. Uyama, « The Geography of Civilizations : A Spatial Analysis of the Kazakh Intelligentsia's Activities, from the Mid-Nineteen ${ }^{\text {th }}$ to the Early Twentieth Century», in Kimitaka Matsuzato, ed., Regions : A Prism to View the Slavic-Eurasian World, Sapporo : Slavic Research Center, 2000, c. 98.

17. « ОЧЕНЬ НЕРВНЫЙ, ЭНЕРГИЧНЫЙ», - ПИСАЛИ О НЕМ СОТРУДНИКИ ГПУ В КИРОБЛКК РКП(Б) В СЕНТЯБРЕ 1922 Г. М.К. КОЙГЕЛЬДИЕВ, ГЛ. РЕД., ДВИЖЕНИЕ АЛАШ, СБ. ДОКУМЕНТОВ И МАТЕРИАЛОВ, Т. 3, КН. 1, АЛМАТЫ : «ЕЛ-ШЕЖіРЕ», 2007, С. 114. КАК « ЧЕЛОВЕКА КРАЙНЕ ГОРЯЧЕГО И УВЛЕКАЮЩЕГОСЯ» ЕГО ХАРАКТЕРИЗОВАЛ ЕЩЕ В 1905 Г. И УЕЗДНЫЙ НАЧАЛЬНИК. НАУЧНЫЙ АРХИВ ИРИ РАН, Ф. В.А. ПЯСКОВСКОГО, ПАПКА 41, Л. 129.

18. Д.А. АМАНЖОЛОВА, РОССИЯ И ЦЕНТРАЛЬНАЯ АЗИЯ, СБ. ДОКУМЕНТОВ, КАРАГАНДЫ, 2005, С. 236.

19. КАЗАХСТАНСКАЯ ПРАВДА, 1991, 8 ИЮНЯ, 10 СЕНТЯБРЯ.

20. КРАСНЫЙ ТЕРРОР: ПОЛИТИЧЕСКАЯ ИСТОРИЯ КАЗАХСТАНА (СБ. ДОКУМЕНТАЛЬНЫХ МАТЕРИАЛОВ ПОЛИТИЧЕСКИХ РЕПРЕССИЙ 20-50-Х ГОДОВ ХХ ВЕКА), АЛМАТЫ : ТОО « ТИПОГРАФИЯ ОПЕРАТИВНОЙ ПЕЧАТИ», 2008, с. 92.

21. ДВИЖЕНИЕ АЛАШ, С. 63, 59-61.

22. АМАНЖОЛОВА, РОССИЯ И ЦЕНТРАЛЬНАЯ АЗИЯ, С. 321 ; Е. ХАСЕНОВ, « К 70-ЛЕТИЮ КОНЧИНЫ СМАГУЛА САДУАКАСОВА», www.arba.ru, 27.01.2004 ; ДВИЖЕНИЕ АЛАШ, с. 97-98.

23. ДВИЖЕНИЕ АЛАШ, С. 109-110, 129.

24. ДВИЖЕНИЕ АЛАШ, С. 100.

25. РГАСПИ, Ф. 17, ОП. 31, Д. 24, Л. 12.

26. РГАСПИ, Ф.17, ОП. 31 , Д. 31, 22ОБ. НО ЕСЛИ ВНОВЬ ВХОДИВШИЕ В СССР АЗИАТСКИЕ РЕСПУБЛИКИ ПРЕВРАЩАТЬ В АВТОНОМИИ БЫЛО НЕЦЕЛЕСООБРАЗНО ПО МЕЖДУНАРОДНЫМ СООБРАЖЕНИЯМ, ТО ПОВЫШАТЬ СТАТУС КАССР, ОБРЕМЕНЯЯ СЕБЯ ДОПОЛНИТЕЛЬНЫМИ ПРОБЛЕМАМИ С И БЕЗ ТОГО АМБИЦИОЗНЫМИ И К ТОМУ ЖЕ НЕКОНСОЛИДИРОВАННЫМИ КАЗАХСКИМИ КАДРАМИ, ДОСТАВИВШИМИ УЖЕ НЕМАЛО ХЛОПОТ, МОСКВА В ЭТОТ ПЕРИОД ПОСЧИТАЛА ШАГОМ НЕПРОДУКТИВНЫМ. СМ. : ДОКЛАД СЕКРЕТАРЯ ЦК РКП(Б) Я.Э. РУДЗУТАКА НА ПЛЕНУМЕ ЦК РКП(Б) О НАЦИОНАЛЬНО-ТЕРРИТОРИАЛЬНОМ РАЗМЕЖЕВАНИИ СРЕДНЕАЗИАТСКИХ РЕСПУБЛИК 26 ОКТЯБРЯ 1924 Г., ЦК РКП(Б)-ВКП(Б) И НАЦИОНАЛЬНЫЙ ВОПРОС, С. 242-247.

27. ДВИЖЕНИЕ АЛАШ, С. 177.

28. РГАСПИ, Ф. 17, ОП. 31, Д. 24, Л. 2-4. ПРИМЕР ВСТРАИВАНИЯ ТРАДИЦИОННЫХ ИЕРАРХИЧЕСКИХ СЕТЕЙ В СОВЕТСКУЮ СИСТЕМУ В АЗЕРБАЙДЖАНЕ ПРИВОДИТ Й. БАБЕРОВСКИ, ВРАГ ЕСТЬ ВЕЗДЕ : СТАЛИНИЗМ НА КАВКАЗЕ, С. 271.

29. ОДНАКО РОДОВАЯ И ЖУЗОВАЯ ПРИНАДЛЕЖНОСТЬ НЕ ВСЕГДА ИГРАЛА ВЕДУЩУЮ РОЛЬ. ПО РАЗНЫЕ СТОРОНЫ «БАРРИКАД» ОКАЗАЛИСЬ АРГЫНЫ, ПРЕДСТАВЛЯВШИЕ ОДНО ИЗ САМЫХ МНОГОЧИСЛЕННЫХ ПЛЕМЕН СРЕДНЕГО ЖУЗА А.БУКЕЙХАНОВ, Ж. АКПАЕВ, А.БАЙТУРСЫНОВ, Х. ГАББАСОВ, А. ЕРМЕКОВ И Н. НУРМАКОВ, С. СЕЙФУЛИН, О. ИСАЕВ, КИПЧАКИ М. ЧОКАЕВ И А. ДЖАНГИЛЬДИН, НАЙМАНЫ К. ТОГУСОВ И М. ТЫНЫШПАЕВ. К МЛАДШЕМУ ЖУЗУ ОТНОСИЛИСЬ Х. И Ж. ДОСМУХАМЕДОВЫ И М. МУРЗАГАЛИЕВ. ПОЛИТИЧЕСКИЕ ПРОТИВНИКИ И ВЫХОДЦЫ ИЗ РАЗНЫХ ЖУЗОВ МОГЛИ ВЫСТУПАТЬ СОЛИДАРНО : В ОКТЯБРЕ 1922 Г. РЫСКУЛОВ И С. ХОДЖАНОВ 
ТЕЛЕГРАФИРОВАЛИ В ЦК РКП(Б) ПРОСЬБУ ОСВОБОДИТЬ ИЗ-ПОД АРЕСТА БУКЕЙХАНОВА, В ИТОГЕ ВЫСЛАННОГО В МОСКВУ, АМАНЖОЛОВА, РОССИЯ И ЦЕНТРАЛЬНАЯ АЗИЯ, С. 366. КАК БАЖА (СВОЯК) В 1930-Е ГГ. РЫСКУЛОВ ПОМОГАЛ И Ж. ДОСМУХАМЕДОВУ.

30. ПО МНЕНИЮ Д. ЛИВЕНА, «ВОЛЯ И СПОСОБНОСТЬ СОВЕТСКОЙ ВЛАСТИ К ПРОНИКНОВЕНИЮ ВГЛУБЬ ОБЩЕСТВА И К ЕГО ПРЕОБРАЗОВАНИЮ БЫЛИ ДЕЙСТВИТЕЛЬНО ОЧЕНЬ ВЕЛИКИ». СОГЛАШАЯСЬ С ВЫСОКОЙ ОЦЕНКОЙ ВОЛИ, УПОРСТВА И ЦЕЛЕУСТРЕМЛЕННОСТИ БОЛЬШЕВИКОВ, ВРЯД ЛИ ТАК ЖЕ МОЖНО ОЦЕНИТЬ СПОСОБНОСТЬ НОВОЙ ВЛАСТИ ДЕЙСТВИТЕЛЬНО ПРОНИКНУТЬ ВГЛУБЬ ЭТНОКУЛЬТУРНЫХ ОБЩНОСТЕЙ И УТВЕРДИТЬСЯ В ЗАПРОГРАММИРОВАННОМ ВИДЕ. Д. ЛИВЕН, « ИМПЕРИЯ, ИСТОРИЯ И СОВРЕМЕННЫЙ МИРОВОЙ ПОРЯДОК - 2», Ab imperio, 1, 2005, URL : $\quad$ http://abimperio.net/cgi-bin/aishow.pl? state $=$ showa\&idart $=1213 \&$ page $=2 \&$ idlang $=2 \&$ Code $=$ Xv5oB3aVpMLZlHcsIeraNfxС $\quad$ (ДАТА ОБРАЩЕНИЯ : 1.01.2014).

31. “"МНЕНИЕ БЕЗ ПРИКРАС”, ПИСЬМО ЧЛЕНА КИРВРК Т.И.СЕДЕЛЬНИКОВА В.И. ЛЕНИНУ, 1920 Г.», ИСТОРИЧЕСКИЙ АРХИВ, 4, 1994, с. 79-81.

32. ДЕХКАНЕ - СРЕДНЕАЗИАТСКИЕ КРЕСТЬЯНЕ. ГА РФ (ГОСУДАРСТВЕННЫЙ АРХИВ РОССИЙСКОЙ ФЕДЕРАЦИИ), Ф. 1235, ВЦИК, ОП. 99, ОРГАНИЗАЦИОННЫЙ ОТДЕЛ, Д. 106, Л. 69-75, 67 ; РГАСПИ, Ф. 17, ОП. 67, ПЕРЕПИСКА ОРГРАСПРЕДОТДЕЛА С МЕСТНЫМИ ПАРТИЙНЫМИ ОРГАНАМИ, Д. 82, л. 136, 138.

33. РГАСПИ, Ф. 17 , ОП. 31 , Д. 24 , Л. 11ОБ.; ОП. 68 , Д. 188 , Л. $19,10-11$. О РОЛИ БАРЫМТЫ СМ. В. МАРТИН, « БАРЫМТА : ОБЫЧАЙ В ГЛАЗАХ КОЧЕВНИКОВ, ПРЕСТУПЛЕНИЕ В ГЛАЗАХ ИМПЕРИИ», В РОССИЙСКАЯ ИМПЕРИЯ В СОВРЕМЕННОЙ ЗАРУБЕЖНОЙ ЛИТЕРАТУРЕ : АНТОЛОГИЯ, М., 2005, с. 266-287.

34. БАРЫМТА - НОРМА ОБЫЧНОГО ПРАВА, ДОПУСКАВШАЯ ВОЗВРАЩЕНИЕ СИЛОЙ ИМУЩЕСТВА. Б. КАРАТАЕВ ПИСАЛ : « КОРЫСТЬ СТАЛА ДОМИНИРУЮЩИМ СТИМУЛОМ ДЕЯТЕЛЬНОСТИ ВСЕХ “БАС-АДАМОВ”[БУКВАЛЬНО - ГЛАВНЫЙ ЧЕЛОВЕК - Д.А.]. ...БЕЗ ПОДКУПОВ И ВЗЯТОК У НИХ НИЧТО НЕ ДЕЛАЕТСЯ И НЕ ТВОРИТСЯ. НИКАКОЙ ОБЩЕСТВЕННОЙ ДЕЯТЕЛЬНОСТИ И НИКАКИХ ОБЩЕСТВЕННЫХ НАДОБНОСТЕЙ ИЛИ ПОЛЬЗЫ ДЛЯ НИХ НЕ СУЩЕСТВУЕТ. ...УГНЕТЕННОЕ ПОЛОЖЕНИЕ КИРГИЗОВ ПРИ ЦАРИЗМЕ ВЫРАБОТАЛО В НИХ ПСИХИКУ ХИТРЫХ РАБОВ. ОНИ ВЫНУЖДЕНЫ ПРИЗНАВАТЬ ВЛАСТЬ-СИЛУ. ОНИ ГОВОРЯТ : КТО НАС НЕ РЕЖЕТ, КТО НАС ЗАЩИЩАЕТ - С ТЕМ МЫ. НО ВЫБИРАЮТ, КТО СИЛЬНЕЕ». ЦГА РК (ЦЕНТРАЛЬНЫЙ ГОСУДАРСТВЕННЫЙ АРХИВ РК), Ф. 1227, Б.Б. КАРАТАЕВ, ОП. 1, Д. 7. Л. 10-11, 30. ВЫРАЖАЮ БЛАГОДАРНОСТЬ О. КОНЫРАТБАЕВУ ЗА ПРЕДОСТАВЛЕНИЕ ДОКУМЕНТА.

35. С.С. ПЕСТКОВСКИЙ, « КИРГИЗЫ И СОВЕТСКАЯ ВЛАСТЬ», ЖИЗНЬ НАЦИОНАЛЬНОСТЕЙ, 27 АПРЕЛЯ 1920, №12 (69) ; « В КИРГИЗИИ», ЖИЗНЬ НАЦИОНАЛЬНОСТЕЙ, 9 ИЮНЯ 1920, №17 (74); РГАСПИ, Ф. 17, ОП. 60, ОТДЕЛ АГИТАЦИИ И ПРОПАГАНДЫ ЦК ВКП(Б), Д. 237, Л. 11-25, 87.

36. ТУЛЕПБАЕВ, ГЛАВ. РЕД., И ДР., ВЕХИ КОНСОЛИДАЦИИ, С. 82-95, 164-165 ; РГАСПИ, Ф. 17, оП. 84, БЮРО СЕКРЕТАРИАТА ЦК РКП(Б), Д. 1056, Л. 11. МАРТИН ПИШЕТ : ИМЕННО ЭТОТ СЛОЙ ОПРЕДЕЛЯЛ УСПЕХ РАСПРОСТРАНЕНИЯ КАЗАХСКОГО ЯЗЫКА В ОФИЦИАЛЬНОЙ СФЕРЕ. Т. МАРТИН, ИМПЕРИЯ « ПОЛОЖИТЕЛЬНОЙ ДЕЯТЕЛЬНОСТИ». НАЦИИ И НАЦИОНАЛИЗМ В СССР, 1923-1939, М. : РОССПЭН, 2011, с. 191-198. РОСТ КВАЛИФИЦИРОВАННЫХ СПЕЦИАЛИСТОВ-КАЗАХОВ ПРОИСХОДИЛ ПО МЕРЕ РАЗВИТИЯ СИСТЕМЫ ПРОФЕССИОНАЛЬНОГО ОБРАЗОВАНИЯ.

37. ТУЛЕПБАЕВ, ГЛАВ. РЕД., И ДР., ВЕХИ КОНСОЛИДАЦИИ, С. 165-166. В НАРКОМАТАХ НА 1 ЯНВАРЯ 1925 Г. КАЗАХИ СОСТАВЛЯЛИ $8,3 \%$, ПРИЧЕМ НАИБОЛЬШЕЕ КОЛИЧЕСТВО ИХ БЫЛО В НАРКОМПРОСЕ, НАРКОМСОБЕСЕ, НК РКИ, НАРКОМЮСТЕ, ГОСБАНКЕ (ОТ 28 ДО 15,5 \%). ТАМ ЖЕ, 91. МАРТИН ПРИВОДИТ ДАННЫЕ О ПРЕДСТАВИТЕЛЬСТВЕ ТИТУЛЬНЫХ НАЦИОНАЛЬНОСТЕЙ В ВЫБОРНЫХ СОВЕТСКИХ ОРГАНАХ, В Т.Ч. В КАССР, В 1927 Г. : МАРТИН, ИМПЕРИЯ « ПОЛОЖИТЕЛЬНОЙ ДЕЯТЕЛЬНОСТИ». НАЦИИ И НАЦИОНАЛИЗМ В СССР, 1923-1939, С. 199. ОТСУТСТВУЮЩИЕ В ЕГО ТАБЛИЦЕ 16 ДАННЫЕ ПО КАССР (УЕЗДЫ И ЦИК) МОЖНО УТОЧНИТЬ ТАМ ЖЕ, С. 165-166 (СООТВЕТСТВЕННО В 
УЕЗДАХ 49,6\%, ЦИК - 50 \%), ГДЕ ПРИВОДЯТСЯ СВЕДЕНИЯ И ПО ГОРСОВЕТАМ, АУЛСОВЕТАМ, ГОРИСПОЛКОМАМ.

38. СРЕДИ ПРОЧИХ В ЭТОМ И ДВУХ СЛЕДУЮЩИХ СТОЛБЦАХ, ОЧЕВИДНО, УЧИТЫВАЛИСЬ РУССКИЕ И ДРУГИЕ « ЕВРОПЕЙЦЫ».

39. ТУЛЕПБАЕВ, ГЛАВ. РЕД., И ДР., ВЕХИ КОНСОЛИДАЦИИ, С. 166. УДЕЛЬНЫЙ ВЕС КАЗАХОВ В ВЫБОРНЫХ ОРГАНАХ ВЛАСТИ, ПАРТОРГАНИЗАЦИЯХ И ПРОФОРГАНАХ СМ. ТАМ ЖЕ, С. 165,130-131, 168.

40. БЕЛЬСЕНДЫ - АКТИВИСТ. У.ИСАЕВ В ПИСЬМЕ И.СТАЛИНУ В 1932 Г. НАЗЫВАЕТ ИХ АКТИВИСТАМИ НАИЗНАНКУ, НОВЫМ ПАРАЗИТИЧЕСКИМ СЛОЕМ В АУЛЕ. СМ.: АНТОЛОГИЯ СОЦИАЛЬНО-ПОЛИТИЧЕСКОЙ МЫСЛИ КАЗАХСТАНА С ДРЕВНЕЙШИХ ВРЕМЕН ДО НАШИХ ДНЕЙ (В ДВУХ ТОМАХ), АЛМАТЫ : ИНСТИТУТ РАЗВИТИЯ КАЗАХСТАНА, 2002, с. 481-482.

41. АМАНЖОЛОВА, РОССИЯ И ЦЕНТРАЛЬНАЯ АЗИЯ, С. 353-357.

42. ПРЕДСЕДАТЕЛЬ РАЙИСПОЛКОМА НА УКРАИНЕ ПОЛУЧАЛ ОТ 45 ДО 75 РУБ. В МЕС. В ЗАВИСИМОСТИ ОТ МЕСТНЫХ БЮДЖЕТОВ; В БАШКИРИИ - 40 РУБ., В АКТЮБИНСКОЙ ГУБ. ПРЕДСЕДАТЕЛЬ ВОЛИСПОЛКОМА ПОЛУЧАЛ 12 РУБ. ПРЕДСЕЛЬСОВЕТА В БЕЛОРУССИИ ПОЛУЧАЛ 15,6 РУБ., В ФЕРГАНСКОЙ ОБЛАСТИ 12,5, В АКТЮБИНСКОЙ ГУБЕРНИИ 5 РУБ., ПРИЧЕМ ЖАЛОВАНИЕ ВЫДАВАЛОСЬ С БОЛЬШИМ ОПОЗДАНИЕМ (В АКТЮБИНСКОЙ ГУБЕРНИИ ДО 3 МЕСЯЦЕВ). ЗИМОЙ 1924/25 Г. ПУД ПШЕНИЦЫ СТОИЛ 10 КОП., АРШИН СИТЦА - ДО 50 КОП., ЛЕТОМ 1925 Г. ПУД ПШЕНИЦЫ ПРОДАВАЛСЯ УЖЕ ЗА 1,5 РУБ. И ВЫШЕ, НА ПРОМТОВАРЫ ЦЕНЫ СНИЗИЛИСЬ - ЭФФЕКТ « НОЖНИЦ ЦЕН» И ЗДЕСЬ ИМЕЛ МЕСТО. РГАСПИ, Ф. 17, ОП. 68, Д. 184, Л. 30-52 ; Д. 188, Л. 69 ; « V ВСЕКАЗАХСКИЙ (ВСЕКИРГИЗСКИЙ) СЪЕЗД СОВЕТОВ», ВЛАСТЬ СОВЕТОВ, 14 ИЮНЯ 1925, 23-24, c. 25-26.

43. РГАСПИ, Ф. 17 , ОП. 69 , ОРГРАСПРЕД ЦК ВКП(Б), Д. 593, Л. 16-19 ; Д. 668, Л. 61-63 ; НАРОДНОЕ ХОЗЯЙСТВО КАЗАХСТАНА, 3-4, 1930, с. 17,19; 5-6,1930, с. 41.

44. ЭТНИЧЕСКИЙ РАКУРС СТАТИСТИКИ ОБЪЯСНЯЛСЯ « НЕДОВЫЯВЛЕННОСТЬЮ ПРЕСТУПЛЕНИЙ СРЕДИ КАЗАХСКОГО И УЗБЕКСКОГО СОСТАВА ПАРТОРГАНИЗАЦИИ. БОЛЬШИНСТВО КАЗАХОВ И УЗБЕКОВ В СИЛУ СВОЕЙ КУЛЬТУРНОЙ И ПОЛИТИЧЕСКОЙ ОТСТАЛОСТИ, А ОТЧАСТИ ПО ЧИСТО БЫТОВЫМ УСЛОВИЯМ БОРЬБЫ С БОЛЕЗНЕННЫМИ ЯВЛЕНИЯМИ ПОЧТИ НИКАКОЙ НЕ ВЕДУТ, ИНОГДА КОММУНИСТ-КОЧЕВНИК ...НЕ ЗНАЕТ, КУДА ОБРАТИТЬСЯ С ЖАЛОБОЙ, А ЕСЛИ И ЗНАЕТ, ТО ЗАМАЛЧИВАЕТ ПРЕСТУПНЫЕ ЯВЛЕНИЯ ПО БЫТОВЫМ РОДСТВЕННО-ГРУППИРОВОЧНЫМ СООБРАЖЕНИЯМ». ТУЛЕПБАЕВ, ГЛАВ. РЕД., И ДР., ВЕХИ КОНСОЛИДАЦИИ, С. 116-117.

45. ДВИЖЕНИЕ АЛАШ, С. 115.

46. ПРЕДСТАВИТЕЛЬСТВО ГПУ ПО КАССР ПРИСТАЛЬНО СЛЕДИЛО ЗА « СОСТОЯНИЕМ И ДЕЯТЕЛЬНОСТЬЮ КИРНАЦГРУППИРОВОК», ОБРАЩАЯ ВНИМАНИЕ ЦЕНТРА НА СЕТЕВЫЕ СВЯЗИ АЛАШОРДИНЦЕВ В УЧРЕЖДЕНИЯХ ГУБЕРНИЙ И УЕЗДОВ, В Т.Ч. НА ПРОТИВОПОСТАВЛЕНИЕ СУБЭТНИЧЕСКОЙ СОЛИДАРНОСТИ КАЗАХОВ КЛАССОВОМУ ПОДХОДУ И ОБЩЕНАЦИОНАЛЬНОЙ РУССКОМУ « КОЛОНИЗАТОРСТВУ». АМАНЖОЛОВА, РОССИЯ И ЦЕНТРАЛЬНАЯ АЗИЯ, с. 368-387.

47. ПРИЗНАНИЕ Л.М. КАГАНОВИЧА В ЦК РКП(Б) 1922 Г., ПОЖАЛУЙ, МОГЛИ ПОВТОРИТЬ МНОГИЕ : « Я ХОТЬ И ПОНИМАЮ НАЦИОНАЛЬНУЮ ПОЛИТИКУ ПАРТИИ, НО РАБОТАТЬ В ЭТОЙ ОБЛАСТИ НЕ МОГУ». АМАНЖОЛОВА, РОССИЯ И ЦЕНТРАЛЬНАЯ АЗИЯ, С. 342.

48. М.П. ТОМСКИЙ ПИСАЛ ЛЕНИНУ В 1921 Г. ИЗ ТАССР : «НИ С ОДНОЙ ГРУППОЙ ССОРЫ НЕИЗВЕСТНО, КТО ПРИГОДИТСЯ В БУДУЩЕМ. НИ ОДНОЙ, БЕЗ КРАЙНЕЙ НЕОБХОДИМОСТИ, ПОДДЕРЖКИ ПРОТИВ ДРУГОЙ. НИ НА КОПЕЙКУ ВЕРЫ !». РГАСПИ, Ф.558, КОЛЛЕКЦИЯ НАРКОМНАЦА, ПАПКА 2, Д. 37,ТУРКЕСТАН, Л. 7.

49. ПЕСТКОВСКИЙ ВЫДЕЛИЛ БАЙТУРСЫНОВА И ТУНГАНЧИНА, БОЛЕЕ ЛОЯЛЬНЫХ СОВЕТСКОЙ ВЛАСТИ ДЖАНГИЛЬДИНА И КАРАТАЕВА, А ТАКЖЕ ЕЕ ИСКРЕННЕГО СТОРОННИКА МЕНДЕШЕВА ЧЕСТНОГО, НО ПОКА МАЛО РАЗБИРАЮЩЕГОСЯ В СИТУАЦИИ, АМАНЖОЛОВА, РОССИЯ И ЦЕНТРАЛЬНАЯ АЗИЯ, 1905-1925 ГГ., С. 80-181. 
50. ЭТО НЕ ВСЕГДА ОЗНАЧАЛО ОБЪЕКТИВНОСТЬ ИХ АНАЛИЗА; К ТОМУ ЖЕ ПРИ РЕАЛИЗАЦИИ ДИРЕКТИВ ЦЕНТРА УЧИТЫВАЛАСЬ КОНКРЕТНАЯ РАССТАНОВКА СИЛ.

51. АМАНЖОЛОВА, РОССИЯ И ЦЕНТРАЛЬНАЯ АЗИЯ, С. 331-333. РАДУС-ЗЕНЬКОВИЧ ОБЪЕКТИВНО ВЫСОКО ОЦЕНИВАЛ БУКЕЙХАНОВА КАК ЗНАТОКА РЕГИОНА, КАЗАХСКОЙ КУЛЬТУРЫ И ИСТОРИИ. КОРОСТЕЛЕВ ЖЕ ЕГО ВЛИЯНИЕ УСМАТРИВАЛ НЕ В АВТОРИТЕТЕ ЛИЧНОСТИ ДЛЯ ПЕРСОНИФИЦИРОВАННОЙ СОЦИАЛЬНОЙ КОММУНИКАЦИИ КОЧЕВНИКОВ, А ИДЕЙНО-КЛАССОВОМ ПРОТИВОСТОЯНИИ.

52. ЮДОВСКИЙ РЕШЕНИЕМ ОРГБЮРО ЦК В ФЕВРАЛЕ 1922 Г. БЫЛ НАПРАВЛЕН В КАССР УПОЛНОМОЧЕННЫМ ЦК РКП(Б). РГАСПИ, Ф. 17, ОП. 112, ОРГАНИЗАЦИОННОЕ БЮРО И СЕКРЕТАРИАТ цК РКП(Б), Д. 284, Л. 21.

53. КОРОСТЕЛЕВ В ТОМ ЖЕ ДУХЕ СООБЩАЛ СТАЛИНУ : ЮДОВСКИЙ НЕ ЖЕЛАЕТ ВНИКАТЬ В СУТЬ ДЕЛА, БЕСТАКТЕН, ПРОВОЦИРУЕТ СКЛОКИ И ПР. В ИЮЛЕ ЕГО ПРИШЛОСЬ ОТЗЫВАТЬ, АМАНЖОЛОВА, РОССИЯ И ЦЕНТРАЛЬНАЯ АЗИЯ, С. 350-355.

54. АМАНЖОЛОВА, РОССИЯ И ЦЕНТРАЛЬНАЯ АЗИЯ, С. 356-357. ГПУ С 1923 Г. ПЕРЛЮСТРИРОВАЛО ПИСЬМА САДВОКАСОВА И ЛИШЬ ПОСЛЕ ПРОТЕСТА НАНЕЙШВИЛИ ПРЕКРАТИЛО, НЕ НАЙДЯ НИЧЕГО КРАМОЛЬНОГО В ЕГО ИНТИМНОЙ ПЕРЕПИСКЕ С БУДУЩЕЙ ЖЕНОЙ - ДОЧЕРЬЮ БУКЕЙХАНОВА. РГАСПИ, Ф. 17, ОП. 31, Д. 24, Л. 28.

55. КАК ЗАМЕСТИТЕЛЬ НАРКОМНАЦА В ФЕВРАЛЕ 1922 Г. ОН ВЫСТУПИЛ НА РАСШИРЕННОМ ПЛЕНУМЕ КИРОБКОМА РКП(Б) И ЧЕРЕЗ НЕДЕЛЮ НАПИСАЛ СТАЛИНУ О СВОИХ ДИСКУССИЯХ С РУКОВОДСТВОМ КАССР, РАСКРИТИКОВАЛ РУССКИХ РАБОТНИКОВ, ЗАЩИЩАЯ «АВТОРИТЕТНЫХ СРЕДИ КИРГИЗСКИХ ТРУДОВЫХ МАСС» САДВОКАСОВА, МУРЗАГАЛИЕВА, АУЭЗОВА И ДР., КОТОРЫЕ «СТОЯТ НАКАНУНЕ ПЕРСОНАЛЬНОГО УХОДА ОТ РАБОТЫ», И ДАЖЕ ПРЕДЛОЖИЛ УПРАЗДНИТЬ КИРРЕСПУБЛИКУ». КОРОСТЕЛЕВ, В СВОЮ ОЧЕРЕДЬ, 3 МАРТА ВСЛЕД ЗА МЕНДЕШЕВЫМ НАПИСАЛ СТАЛИНУ В Т.Ч. О ПОПЫТКЕ РЫСКУЛОВА «ОТ БЕЗДЕЛЬЯ» ЗАНЯТЬСЯ В ОРЕНБУРГЕ « ВЫСОКОЙ ПОЛИТИКОЙ», СГРУППИРОВАВ МОЛОДЫЕ И НЕУСТОЙЧИВЫЕ КАЗАХСКИЕ КАДРЫ, АМАНЖОЛОВА, РОССИЯ И ЦЕНТРАЛЬНАЯ АЗИЯ, С. 344-350, 355. ВПРОЧЕМ, ЕГО РОЛЬ ВО ВНУТРИРЕСПУБЛИКАНСКИХ ДЕЛАХ БЫЛА ТОГДА МИНИМАЛЬНОЙ.

56. 28-ЛЕТНИЕ СЕЙФУЛЛИН И ХОДЖАНОВ, 26-ЛЕТНИЙ А. АСЫЛБЕКОВ, 25-ЛЕТНИЙ АУЭЗОВ, 23-ЛЕТНИЙ У. ДЖАНДОСОВ И 22-ЛЕТНИЙ САДВОКАСОВ СДЕЛАЛИ СТРЕМИТЕЛЬНУЮ КАРЬЕРУ. ОТМЕТИМ ИХ ТЕСНУЮ ИДЕЙНО-ПСИХОЛОГИЧЕСКУЮ СВЯЗЬ С ПРЕДСТАВИТЕЛЯМИ СТАРШИХ ПОКОЛЕНИЙ, ПАТЕРНАЛИСТСКУЮ ВОСПИТАТЕЛЬНУЮ ПРАКТИКУ СТАРШИХ И ИХ УМЕНИЕ ИСПОЛЬЗОВАТЬ ОСОБЕННОСТИ МОЛОДЕЖИ ЧЕРЕЗ СИСТЕМУ ФОРМИРОВАНИЯ ПРИОРИТЕТОВ СОЦИАЛЬНОГО СЛУЖЕНИЯ И ДОЛГА, КОЛЛЕКТИВИЗМА И СОЛИДАРНОСТИ НАД ЭГОИСТИЧЕСКИМИ И ЧАСТНЫМИ ИНТЕРЕСАМИ И ЦЕЛЯМИ (КОТОРЫЕ, КОНЕЧНО ЖЕ, СОХРАНЯЛИ ЗНАЧЕНИЕ). МОЛОДЫЕ ВЫДВИЖЕНЦЫ ПОСТЕПЕННО СТАНОВИЛИСЬ ВСЕ БОЛЕЕ САМОСТОЯТЕЛЬНЫМИ, ВКЛЮЧАЯСЬ В РАЗЛИЧНЫЕ КОМБИНАЦИИ ПОД ДАВЛЕНИЕМ СИТУАЦИИ, СОБСТВЕННЫХ АМБИЦИЙ И ПРЕДСТАВЛЕНИЙ О ДО́ЛЖНОМ.

57. В САМОМ ДЕЛЕ: ДАЖЕ НА НЕОФИЦИАЛЬНОЙ ВСТРЕЧЕ ПРЕДСТАВИТЕЛЕЙ ТУРКЕСТАНА, ТАТАРСКОЙ, БАШКИРСКОЙ И КАЗАХСКОЙ АССР В МОСКВЕ В ДЕКАБРЕ 1922 Г. ВО ВРЕМЯ РАБОТЫ Х ВСЕРОССИЙСКОГО СЪЕЗДА СОВЕТОВ, ПОДДЕРЖАВШЕГО ОБРАЗОВАНИЕ СССР, ОН «ВЕЛ СЕБЯ СДЕРЖАННО», ВЫРАЗИВ ГОТОВНОСТЬ ПОДЧИНИТЬСЯ РЕШЕНИЮ ЦК ВКП(Б). ГЛАВА СНК КАССР С. СЕЙФУЛЛИН, В ГОСТИНИЧНОМ НОМЕРЕ КОТОРОГО СОСТОЯЛОСЬ ОБСУЖДЕНИЕ, ВООБЩЕ ПРЕДПОЧЕЛ ОТМОЛЧАТЬСЯ. АСЫЛБЕКОВ И МУРЗАГАЛИЕВ ГОРЯЧО ВЫСТУПАЛИ ЗА ТО, ЧТОБЫ «ОТВОЕВАТЬ СЕБЕ МЕСТО В СОЮЗЕ» НА РАВНЫХ С УКРАИНОЙ И БЕЛОРУССИЕЙ ПРАВАХ, АМАНЖОЛОВА, РОССИЯ И ЦЕНТРАЛЬНАЯ АЗИЯ, С. 368-371.

58. ДОКУМЕНТ ГОТОВИЛИ ЮДОВСКИЙ, АЙТИЕВ И НАХИДЖАНОВ. РГАСПИ, Ф. 17, ОП. 112, Д. 333, л. 5, 95, Д.313. Л. 3-4, Д. 328, Л. 4; циРКУляРНОЕ ПИСьМО цК РКП(Б) КОММУНИСТАМ КИРРЕСПУБЛИКИ, ТУЛЕПБАЕВ, ГЛАВ. РЕД., И ДР., ВЕХИ КОНСОЛИДАЦИИ, С. 64-66. В БОЛЕЕ РАННЕМ 
ИЗДАНИИ ОНО ДАТИРУЕТСЯ 15 ИЮНЯ 1922 Г., КПСС И СОВЕТСКОЕ ПРАВИТЕЛЬСТВО О КАЗАХСТАНЕ. 1917 -1977 ГГ. СБ. ДОКУМЕНТОВ И МАТЕРИАЛОВ, АЛМА-АТА : КАЗАХСТАН, 1978, с. 60-62.

59. ДОПОЛНИТЕЛЬНЫЕ НАПРАВЛЕНИЯ СДЕЛАЛО ОРГБЮРО В 1923 Г., КПСС И СОВЕТСКОЕ ПРАВИТЕЛЬСТВО О КАЗАХСТАНЕ, С. 62-63, 66.

60. ЦК РКП(Б)-ВКП(Б) И НАЦИОНАЛЬНЫЙ ВОПРОС, с. 78.

61. ДВИЖЕНИЕ АЛАШ, с. 127-139, 171-173.

62. РГАСПИ, Ф. 17, ОП. 31 , Д. 24, Л. 2-4 С ОБ. В ПРЕДСТАВЛЕННОМ ИМ ДЕЛЕНИИ « ВОСТОЧНАЯ» ГРУППИРОВКА ВКЛЮЧАЛА В СЕБЯ И ПРЕДСТАВИТЕЛЕЙ УРАЛЬСКОЙ ГУБЕРНИИ.

63. ЦК РКП(Б)-ВКП(Б) И НАЦИОНАЛЬНЫЙ ВОПРОС, с. 146-147. СМ. : « ПИСЬМО А.Т. ДЖАНГИЛЬДИНА И.В. СТАЛИНУ ОТ 24 АПРЕЛЯ 1925 Г.», АМАНЖОЛОВА, РОССИЯ И ЦЕНТРАЛЬНАЯ АЗИЯ, С. 415-420. В СОВЕРШЕННО СЕКРЕТНОМ ПИСЬМЕ В ЦК И СТАЛИНУ НАНЕЙШВИЛИ ПИСАЛ В 1925 Г.: «О ДЖАНГЕЛЬДИНЕ МОЖНО СКАЗАТЬ, ЧТО НА ГРОШ АМУНИЦИИ, НА РУБЛЬ АМБИЦИИ. АБСОЛЮТНО НЕРАБОТОСПОСОБНЫЙ, НЕУМНЫЙ, НО НИКОМУ ПОКОЮ НЕ ДАЕТ, ПОЧЕМУ ОН НЕ В БЮРО ОБКОМА, ПОЧЕМУ ОН НЕ ПРЕДКИРЦИКА - ЗДЕСЬ, НА БЕДУ, СЧИТАЕТСЯ САМЫМ СТАРЫМ ПАРТИЙЦЕМ И НА ЭТОМ ОСНОВАНИИ ИМЕЕТ ЧРЕЗВЫЧАЙНЫЕ ПРЕТЕНЗИИ». РГАСПИ, Ф. 17, ОП. 31, Д. 24, Л. 210 .

64. РГАСПИ, Ф. 17, ОП. 31 Д. 24, Л. 11-13 С ОБ., 24 С ОБ.

65. ПРИЕМ ХОДЖАНОВА В ПАРТИЮ В 1920 Г. БЫЛ ВО МНОГОМ ПРОДИКТОВАН ЕГО ЛИЧНЫМИ ДОСТОИНСТВАМИ, СТОЛЬ ВАЖНЫМИ В БОРЬБЕ МЕЖДУ «РАБОТНИКАМИ ИЗ КОРЕННОГО НАСЕЛЕНИЯ» И «ЕВРОПЕЙСКОЙ» ГРУППОЙ : « ВЫСОКОЕ ОБЩЕЕ РАЗВИТИЕ СРЕДИ КИРГИЗСКИХ РАБОТНИКОВ, [...] ЭНЕРГИЧНОСТЬ И УМЕНЬЕ ОРИЕНТИРОВАТЬСЯ В ЛЮБОЙ ОБСТАНОВКЕ», ПОДКРЕПЛЕННЫЕ СЛОВЕСНЫМИ УВЕРЕНИЯМИ В «ЖЕЛАНИИ ИСКРЕННЕ И ЧЕСТНО РАБОТАТЬ РАДИ ИНТЕРЕСОВ ПРОЛЕТАРИАТА КИРГИЗСКОГО НАСЕЛЕНИЯ И СОВЕТСКОЙ ВЛАСТИ», ДВИЖЕНИЕ АЛАШ, с. 181.

66. С. ҚОЖАНОВ, ҚҰЖАТТАР МЕН МАТЕРИАЛДАР ЖИНАҒЫ, АЛМАТЫ: ЖАЛЫН БАСПАСЫ, 2013, c. 233-243. О ЕГО ПОЗИЦИИ В ПЕРИОД РАЗМЕЖЕВАНИЯ СМ. ТАКЖЕ Haugen, The Establishment of National Republics in Soviet Central Asia, c. 132-135, 143.

67. ДВИЖЕНИЕ АЛАШ, с. 251. ОЦЕНКА НАНЕЙШВИЛИ : «ОН СРЕДИ КИРГИЗ, ПОЖАЛУЙ, ОДИН ИЗ САМЫХ СПОСОБНЫХ, НО ЗАТО САМЫЙ БЕЗЗАСТЕНЧИВЫЙ, САМЫЙ ЦИНИЧНЫЙ, ОН НЕ ПОБРЕЗГАЕТ НИКАКИМИ СРЕДСТВАМИ ДЛЯ СВОИХ ЦЕЛЕЙ. ИЗ ВСЕХ КИРРАБОТНИКОВ У НЕГО ЯРЧЕ ВСЕГО ВЫРАЖЕН НАЦИОНАЛИСТИЧЕСКИЙ УКЛОН. У ВСЕХ КИРРАБОТНИКОВ ЕСТЬ МЕСТНИЧЕСТВО, НО РЕЗЧЕ ВСЕГО ВЫРАЖЕНО ЭТО У ТОВ. ХОДЖАНОВА...», РГАСПИ, Ф. 17, ОП. 31, Д. 24, Л. 210 Б.-22.

68. ДВИЖЕНИЕ АЛАШ, с. 108-118, 125-126, 127-167, 172-173, 187-194, 205-208, 217-239, 244-254, 260-273, 279-282 ; АМАНЖОЛОВА, РОССИЯ И ЦЕНТРАЛЬНАЯ АЗИЯ, с. 368-387, 415-420.

69. ДВИЖЕНИЕ АЛАШ, с. 109-110, 129.

70. КПСС И СОВЕТСКОЕ ПРАВИТЕЛЬСТВО О КАЗАХСТАНЕ, С. 72-74.

71. ДВИЖЕНИЕ АЛАШ, С. 216.

72. ДВИЖЕНИЕ АЛАШ, с. 141, 134.

73. ДВИЖЕНИЕ АЛАШ, С. 143.

74. Ж.У. КЫДЫРАЛИНА, КАЗАХСКАЯ ИНТЕЛЛИГЕНЦИЯ И НАЦИОНАЛЬНЫЙ ВОПРОС (ХХ В.), АСТАНА : АКАД.ГОС.УПР. ПРИ ПРЕЗИДЕНТЕ РК, 2008, с. 113.

75. Т.К. КәКішЕВ, БАС РЕД., Sahara s¥ӊқаry (Memleket zhəne қоғат қаjratkerI, zhaңa zamanғy әdebiet keshbasshysy S. Sejfullinge arnalady) [СТЕПНОЙ СОКОЛ (ПОСВЯЩАЕТСЯ ЛИДЕРУ ЛИТЕРАТУРЫ НОВОГО ВРЕМЕНИ, ГОСУДАРСТВЕННОМУ И ОБЩЕСТВЕННОМУ ДЕЯТЕЛЮ С. СЕЙФУЛЛИНУ)], АЛМАТЫ : ҚР БҒМ ОҒК, 2004, с. 92-98.

76. АМАНЖОЛОВА, РОССИЯ И ЦЕНТРАЛЬНАЯ АЗИЯ, с. 415-420.

77. КРАСНОРЕЧИВАЯ РИТОРИКА БЫЛА ТРАДИЦИОННЫМ СРЕДСТВОМ ТОЛКОВАНИЯ ВЛАСТНЫХ ПРИТЯЗАНИЙ И КОНФЛИКТНЫХ СИТУАЦИЙ В КОЧЕВОМ ОБЩЕСТВЕ, ЧТО ОТЧАСТИ ОБЪЯСНЯЕТ КАК 
ЭЗОПОВ ЯЗЫК АЛАШЕВЦЕВ В ПЕЧАТИ, ТАК И АКТИВНЫЕ ПИСЬМЕННЫЕ ОБРАЩЕНИЯ ВСЕХ СКОЛЬКО-ТО ЗНАЧИМЫХ НАЦИОНАЛОВ В ЦЕНТР.

78. ГРИГОРЬЕВ, ДЖАГФАРОВ, ОСИПОВ, ИДЕЙНО-ПОЛИТИЧЕСКАЯ РАБОТА ПАРТИЙНЫХ ОРГАНИЗАЦИЙ КАЗАХСТАНА (1917-1925 ГГ.), с. 101-102.

79. ДВИЖЕНИЕ АЛАШ, С. 194-195.

80. РГАСПИ, Ф. 17 , ОП. 31 , Д. 24 , Л. 31 . С. ХОДЖАНОВ, ДОСТАВИВШИЙ СВОЕЙ ИЗВОРОТЛИВОСТЬЮ НАЗНАЧЕНЦАМ БОЛЬШЕ ВСЕГО ХЛОПОТ, НЕ УВИДЕЛ РАЗЛИЧИЙ В ТАКТИКЕ ЕЖОВА И НАНЕЙШВИЛИ. ДВИЖЕНИЕ АЛАШ, С. 251.

81. КАЗАХИ-БИЛИНГВЫ ИМЕЛИ БО́ЛЬШИЙ ПОТЕНЦИАЛ МОБИЛЬНОСТИ И АДАПТИВНОСТИ: РУССКОЯЗЫЧНЫЕ РАБОТНИКИ РЕДКО СЧИТАЛИ НУЖНЫМ ИЗУЧАТЬ ЯЗЫК, ДАЖЕ КОГДА ВЛАСТЬ СТИМУЛИРОВАЛА ИХ К ЭТОМУ.

82. РГАСПИ, Ф. 17, ОП. 84, Д. 586, Л. 39-48 ; АМАНЖОЛОВА, РОССИЯ И ЦЕНТРАЛЬНАЯ АЗИЯ, с. 368-387. СВЯЗАННЫЕ С НАЦИОНАЛЬНЫМ РАЗМЕЖЕВАНИЕМ АСПЕКТЫ ВЗАИМООТНОШЕНИЙ НАЦИОНАЛОВ МЕЖДУ СОБОЙ, С «ЕВРОПЕЙЦАМИ» И ЦЕНТРОМ НУЖДАЮТСЯ В ОТДЕЛЬНОМ РАССМОТРЕНИИ. КАЗАХСТАНСКИЕ ПРИМЕРЫ В СВЯЗИ С РАЗМЕЖЕВАНИЕМ ПРИВОДИТ ХАУГЕН, The Establishment of National Republics in Soviet Central Asia.

83. В СПРАВКЕ ИНСТИТУТА ИСТОРИИ ПАРТИИ ПРИ ЦК КП КАЗАХСТАНА - КАЗФИЛИАЛА ИМЛ ПРИ ЦК КПСС ОТ 18 МАЯ 1961 Г. УКАЗАНО: ХОДЖАНОВ ОТОЗВАН В МОСКВУ В НОЯБРЕ 1925 Г. Е.М. ГРИБАНОВА, А.Е. ЖУСЫПОВА, А.С. ЗУЛКАШЕВА И ДР., ДВИЖЕНИЕ АЛАШ. ИЗ ИСТОРИИ ИЗУЧЕНИЯ ВОПРОСА. СБ. ДОКУМЕНТОВ И МАТЕРИАЛОВ. 1918-2007 ГГ., АЛМАТЫ : ЕЛ-ШЕЖіРЕ, 2008, с. 34.

84. ГРИБАНОВА, ЖУСЫПОВА, ЗУЛКАШЕВА И ДР., ДВИЖЕНИЕ АЛАШ. ИЗ ИСТОРИИ ИЗУЧЕНИЯ ВОПРОСА. 1918-2007 ГГ., С. 196-200. К ЭТОМУ ВРЕМЕНИ ИМЕВШИЙ 7-ЛЕТНИЙ СТАЖ ПАРТИЕЦ ПРЕРВАЛ УЧЕБУ В СЕЛЬХОЗАКАДЕМИИ ИМ. ТИМИРЯЗЕВА И ВЕРНУЛСЯ В КАЗАХСТАН, ГДЕ ОСТРО НЕ ХВАТАЛО НАДЕЖНЫХ РАБОТНИКОВ. ПРИМЕРЫ ПОЛИТИЧЕСКОГО ПРАГМАТИЗМА У.ДЖАНДОСОВА И АНАЛИЗА ИМ СПЕЦИФИКИ ЭТНОСОЦИАЛЬНЫХ ВЗАИМООТНОШЕНИЙ СМ.: А.У.ДЖАНДОСОВ, «ДИХОТОМИЯ «КЛАССОВОГО» И «НАЦИОНАЛЬНОГО» В РЕФОРМАТОРСКОЙ ДЕЯТЕЛЬНОСТИ У.К. ДЖАНДОСОВА : ИСТОРИОГРАФИЧЕСКИЕ И ТЕОРЕТИЧЕСКИЕ АСПЕКТЫ (1925-1927 ГГ.)», У.К. ДЖАНДОСОВ И ОСОБЕННОСТИ СОЦИОКУЛЬТУРНОГО РАЗВИТИЯ КАЗАХСТАНА В 1918-1938 ГГ. МАТЕРИАЛЫ НАУЧНОЙ КОНФЕРЕНЦИИ АЛМАТЫ, 21 МАЯ 2009 Г., АЛМАТЫ, 2010, с. 56-132.

85. РГАСПИ, Ф. 17, ОП. 68, Д. 1919, Л. 19 ; ОП. 84, Д. 1056, Л. 9-10.

86. Д. АМАНЖОЛОВА, «КАК ВЕСТИ РУКОВОДСТВО, НА ЧТО ОРИЕНТИРОВАТЬСЯ?» СТЕНОГРАММА СОВЕЩАНИЯ СЕКРЕТАРЕЙ ПАРТОРГАНИЗАЦИЙ В ЦК ВКП(Б) ПО ВОПРОСУ О «БОЛЬШЕВИЗАЦИИ НАЦИОНАЛЬНЫХ КАДРОВ». 1926 Г., ИСТОРИЧЕСКИЙ АРХИВ, 5, 2015, С.106, 107, 115.

87. АМАНЖОЛОВА, « КАК ВЕСТИ РУКОВОДСТВО, НА ЧТО ОРИЕНТИРОВАТЬСЯ ?», С.118-119.

88. ТУЛЕПБАЕВ, ГЛАВ. РЕД., И ДР., ВЕХИ КОНСОЛИДАЦИИ, С. 100-101; ГРИБАНОВА, ЖУСЫПОВА, ЗУЛКАШЕВА И ДР., ДВИЖЕНИЕ АЛАШ. ИЗ ИСТОРИИ ИЗУЧЕНИЯ ВОПРОСА. 1918-2007 ГГ.,С. 205-208.

89. 1-7 ДЕКАБРЯ 1925 Г., КЗЫЛ-ОРДА.

90. ГРИБАНОВА, ЖУСЫПОВА, ЗУЛКАШЕВА И ДР., ДВИЖЕНИЕ АЛАШ. ИЗ ИСТОРИИ ИЗУЧЕНИЯ ВОПРОСА. 1918-2007 ГГ.,с. 219-228, 231-234, 261.

91. ГРИБАНОВА, ЖУСЫПОВА, ЗУЛКАШЕВА И ДР., ДВИЖЕНИЕ АЛАШ. ИЗ ИСТОРИИ ИЗУЧЕНИЯ ВОПРОСА. 1918-2007 ГГ., с. 217-219, 245-253. ИСТОРИЯ ИМЕЛА ПРОДОЛЖЕНИЕ : КАЗКРАЙКОМ ЧЕРЕЗ МЕСЯЦ ОБЪЯСНЯЛСЯ ПЕРЕД СТАЛИНЫМ : ОБВИНЕНИЯ В ЕГО АДРЕС ОТНОСЯТСЯ К СОБЫТИЯМ 1926 Г., А САМ ХОДЖАНОВ ДОЛЖЕН БЫЛ, КАК ТОГДА ТРЕБОВАЛОСЬ, СДЕЛАТЬ ОТКРЫТОЕ И ЧЕСТНОЕ ЗАЯВЛЕНИЕ» С ПРИЗНАНИЕМ ОШИБОК И ОТКАЗОМ ОТ ГРУППИРОВОК. Ibid., с. 256-257. АВГУСТОВСКОЕ ПИСЬМО ХОДЖАНОВА И РЕШЕНИЕ КАЗКРАЙКОМА ВКП(Б) СМ. : Ibid., c. 260-266.

92. ГРИБАНОВА, ЖУСЫПОВА, ЗУЛКАШЕВА И ДР., ДВИЖЕНИЕ АЛАШ. ИЗ ИСТОРИИ ИЗУЧЕНИЯ ВОПРОСА. 1918-2007 ГГ., с. 242. 
93. ГРИБАНОВА, ЖУСЫПОВА, ЗУЛКАШЕВА И ДР., ДВИЖЕНИЕ АЛАШ. ИЗ ИСТОРИИ ИЗУЧЕНИЯ ВОПРОСА. 1918-2007 ГГ., с. 267-269 ; КПСС И СОВЕТСКОЕ ПРАВИТЕЛЬСТВО О КАЗАХСТАНЕ, С. 90-94 ; С. САДВОКАСОВ, « О НАЦИОНАЛЬНОСТЯХ И НАЦИОНАЛАХ», БОЛЬШЕВИК, 1928, 1, 56-64.

94. ПОДСЧИТАНО ПО: КОММУНИСТИЧЕСКАЯ ПАРТИЯ КАЗАХСТАНА: ОРГАНИЗАЦИОННО-ПОЛИТИЧЕСКОЕ РАЗВИТИЕ, С. 226-228.

95. ГРИБАНОВА, ЖУСЫПОВА, ЗУЛКАШЕВА И ДР., ДВИЖЕНИЕ АЛАШ. ИЗ ИСТОРИИ ИЗУЧЕНИЯ ВОПРОСА. 1918-2007 ГГ., с. 279-280. СМ. ТАКЖЕ: СПРАВКИ ИНСТИТУТА ИСТОРИИ ПАРТИИ ПРИ ЦК КП КАЗАХСТАНА - КАЗФИЛИАЛА ИМЛ ПРИ ЦК КПСС « О ХОДЖАНОВЕ СУЛТАНБЕКЕ», « О САДВОКАСОВЕ СМАГУЛЕ» ОТ 18 МАЯ 1961 Г., КОЙГЕЛЬДИЕВ, ДВИЖЕНИЕ АЛАШ, С. 34-40.

96. ВМЕСТО ПРЕЖНИХ «ЖАКСЫЛАР» (ГЛАВЫ РОДОВ, БИИ, БАТЫРЫ) ПРАВИЛИ НОВЫЕ СОВЕТСКИЕ ЧИНОВНИКИ. СОЦИАЛЬНЫЕ ДИСТАНЦИИ ПРИОБРЕТАЛИ НОВОЕ КАЧЕСТВО. ПРИМЕР ТУРКМЕНИСТАНА СМ. : A.L. Edgar, « Tribal Nation: The Making of Soviet Turkmenistan», URL: http://press.princeton.edu/chapters/i7858.html (ДАТА ОБРАЩЕНИЯ : 17.06.2014).

97. БАБЕРОВСКИ СЧИТАЕТ, ЧТО БОЛЬШЕВИСТСКИЙ ДИСКУРС НЕ МОГ ПРОНИКНУТЬ В СУЩЕСТВО ПОВСЕДНЕВНЫХ ОТНОШЕНИЙ И НА КАВКАЗЕ СОХРАНИЛИСЬ ПАРАЛЛЕЛЬНЫЕ СЕТЕВЫЕ СТРУКТУРЫ ВЛАСТИ, А ЦЕНТР ПРИЗНАЛ КОНСЕРВАЦИЮ ТРАДИЦИОННЫХ ВЛАСТНЫХ ОТНОШЕНИЙ В КАЧЕСТВЕ УСЛОВИЙ СТАБИЛЬНОСТИ И НЕДОСТИЖИМОСТЬ ЕДИНООБРАЗИЯ. БАБЕРОВСКИ, ВРАГ ЕСТЬ ВЕЗДЕ : СТАЛИНИЗМ НА КАВКАЗЕ, с. 11, 791-794.

98. С.Н. АБАШИН НА ПРИМЕРЕ УЗБЕКСКОГО КИШЛАКА ДЕТАЛЬНО ПОКАЗАЛ, КАК НА ЛОКАЛЬНОМ УРОВНЕ ПЕРЕПЛЕТАЛИСЬ И ФУНКЦИОНАЛЬНО СОВМЕЩАЛИСЬ КОНКРЕТНЫЕ ЛЮДИ И ИНСТИТУТЫ, УСТАНАВЛИВАЛИСЬ РАЗНЫЕ СТЕПЕНИ КОНТРОЛЯ И УРОВНИ ЛОЯЛЬНОСТИ, КОТОРЫЕ ИСПОЛЬЗОВАЛИСЬ В БОРЬБЕ ЗА ВЛАСТЬ И ЕЕ ОСУЩЕСТВЛЕНИИ, КАК РОДСТВО ЗАВИСЕЛО ОТ ЭКОНОМИЧЕСКИХ И ПОЛИТИЧЕСКИХ ОТНОШЕНИЙ. ОН ПОДТВЕРЖДАЕТ, ЧТО СОВЕТСКАЯ СИСТЕМА ПРЕДСТАВЛЯЛА СЛОЖНЫЙ И ДИНАМИЧНЫЙ БАЛАНС РАЗНЫХ ИНТЕРЕСОВ И СИЛ, ИНСТИТУТОВ И СИМВОЛОВ, ПРИЧЕМ НЕ ТОЛЬКО ЛЮДИ И СООБЩЕСТВА ИСПОЛЬЗОВАЛИ СОВЕТСКИЕ ИНСТИТУТЫ И СИМВОЛЫ ДЛЯ СВОИХ ЧАСТНЫХ ЦЕЛЕЙ, НО И ВЛАСТЬ ИСПОЛЬЗОВАЛА ЛОКАЛЬНЫЕ ГРУППЫ ДЛЯ УКРЕПЛЕНИЯ СВОЕГО ВЛИЯНИЯ. С.Н. АБАШИН, СОВЕТСКИЙ КИШЛАК. МЕЖДУ КОЛОНИАЛИЗМОМ И МОДЕРНИЗАЦИЕЙ, М. : НОВОЕ ЛИТЕРАТУРНОЕ ОБОЗРЕНИЕ, 2015.

\section{RÉSUMÉS}

L'article analyse la corrélation entre facteurs ethniques et organisation politique dans la formation de la direction de la RSSA kazakhe dans les années 1920. Il s'intéresse notamment à la façon dont les particularités de la république - prédominance de la culture nomade sur des territoires immenses, complexité des relations intra-ethniques et morcellement politique de l'intelligentsia kazakhe, rôle de celle-ci dans la vie politique de l'ensemble de la région centrasiatique, notamment en matière de bornage, etc. - et les problèmes de la bolchevisation des cadres nationaux et de l'indigénisation des organes de pouvoir et de gestion ont influé sur le caractère et la stabilité du système politique dans la république. Il montre aussi en quoi la spécificité des relations mutuelles entre ceux que l'on nomme les "Européens », la "vieille » intelligentsia kazakhe et les nationaux promus, a trouvé son expression dans ladite lutte de faction entre les différents groupes de l'ethnobureaucratie. L'article conclut sur le développement dynamique et multivectoriel du système soviétique - équilibre complexe de 
pratiques culturelles et politiques, de hiérarchies, de symboles et de modèles comportementaux dans un espace ethnosocial original.

The article analyzes the correlation between organizational policy and ethnic factors in the formation of the leadership of the Kazakh ASSR in the 1920s. This Republic was characterized by a predominant nomadic culture over a vast territory, complex intra-ethnic relationships, and the Kazakh intelligentsia's political fragmentation and role in the political life of Central Asia - in issues related to boundaries, among others. The article focuses on how these features and problems related to the bolshevization of national cadres and the growing percentage of natives among government officials and in the administration impacted the nature and stability of the Republic's political system. The author shows how the specificity of the relationships between the so-called "Europeans," the "old" Kazakh intelligentsia and promoted nationals found expression in the so-called factional infighting between various groups of the ethnic bureaucracy. The article closes with an observation on the dynamic and multidimensional development of the Soviet system - as a complex balance of political and cultural practices, hierarchies, symbols and role models - within an original ethno-social context.

\section{AUTEUR}

DINA A. AMONŽOLOVA

инститУт Российской истории РАн, amanzholova19@mail.ru 